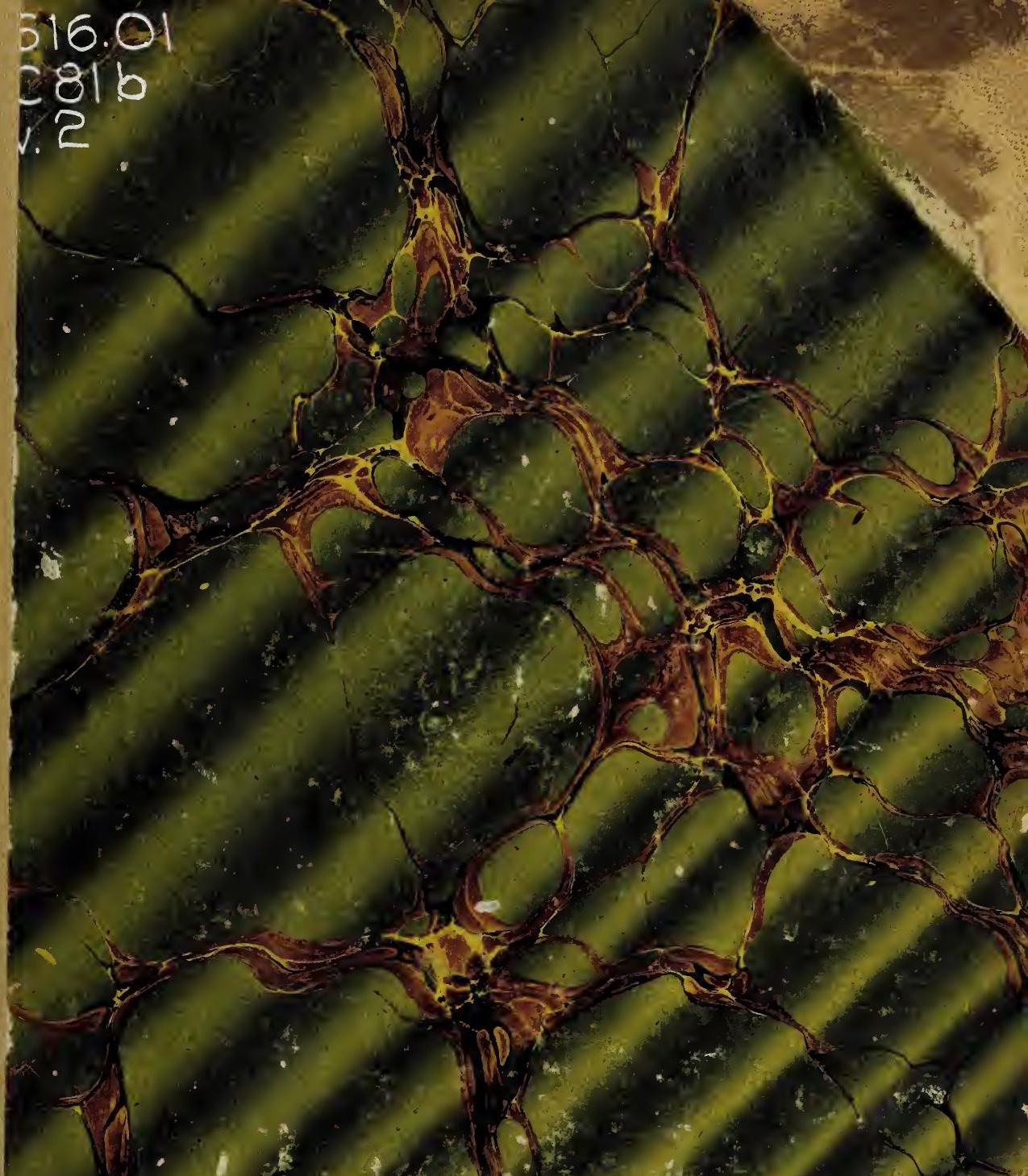

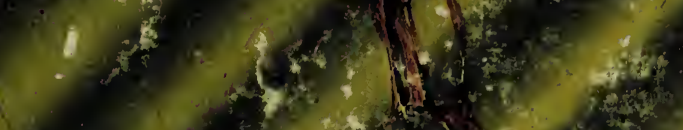

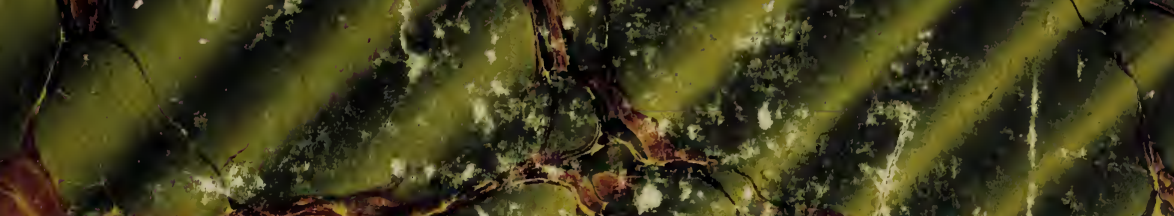
P.

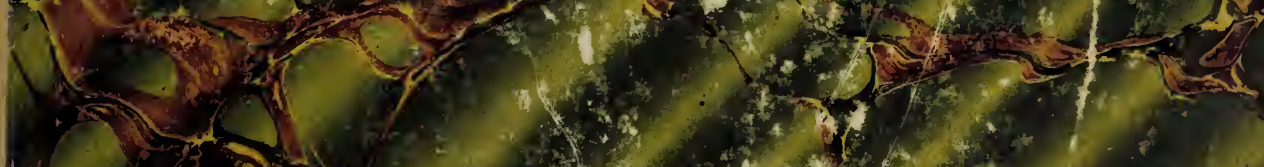
$\int x^{2}+4,4,4,42$

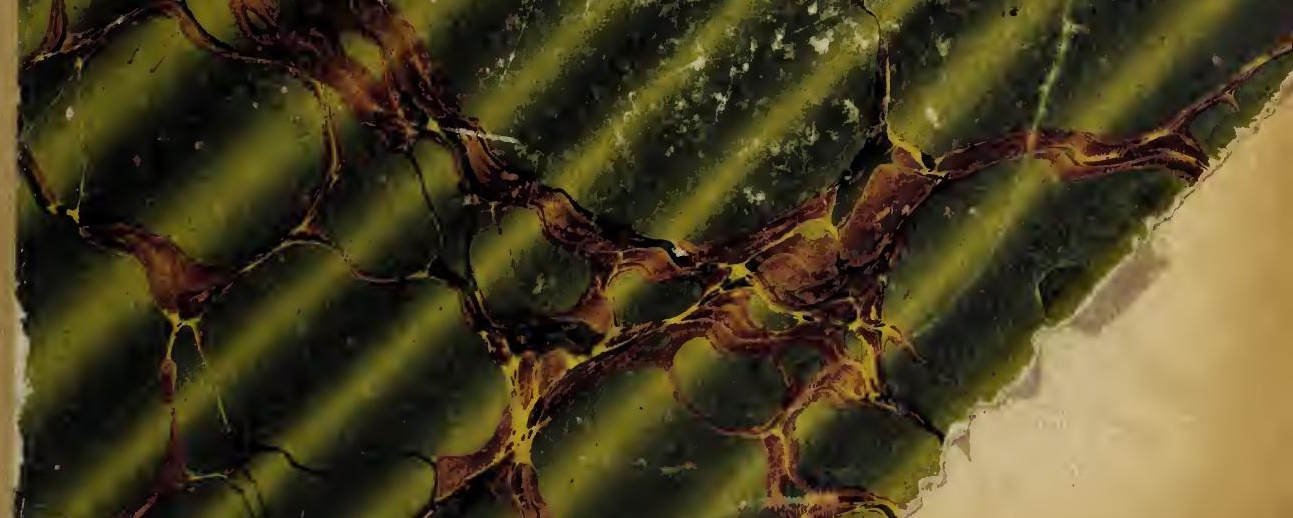




\section{Tí, Cat.}

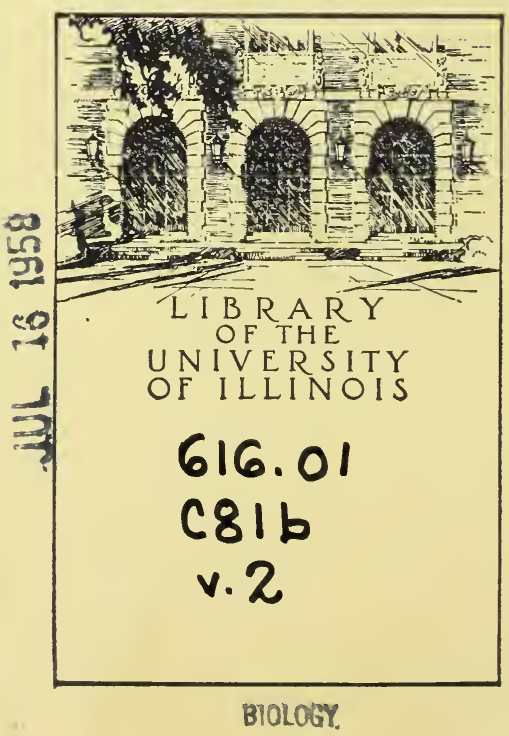


sonose 





\section{LES \\ B A C T ÉR I E S \\ ET LELR ROLE}

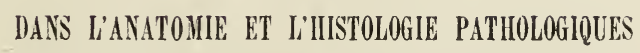

DES MALADIES INFECTIEUSES 

DANS LANATOMIE ET LIIISTOLOGHE PTHOLOGIQULE

\section{DES MLADIES INFECTIEUSES}

PAR

\section{A.-V. GORNIL}

l'rofesseur d'anatomie pathologinue? ¿i la Faculté de médecins de P'aris.

\author{
V. BABES \\ Ierregi it linirusitio de \\ Budapest.
}

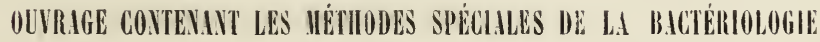

156 figures en noir et ell couleirs INTERCALÉES DAXS LE TEXTE

et accompagne dun atlas de XXVII planches en chromolithographie.

A I'LAS

\section{PAR IS}

ANCIENNE LIBRAIRIE GERMER BAILLIERE ET C

FÉLIX ALG.IN, EDITEUR

108, BOULEVARD SAINT-GERAIIN, 108

$188 \%$

Tous droits reserves 
Digitized by the Internet Archive in 2017 with funding from

University of Illinois Urbana-Champaign Alternates

https://archive.org/details/lesbacteriesetle02corn 
. 


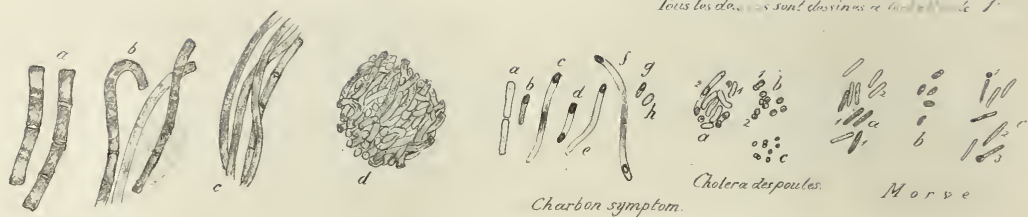

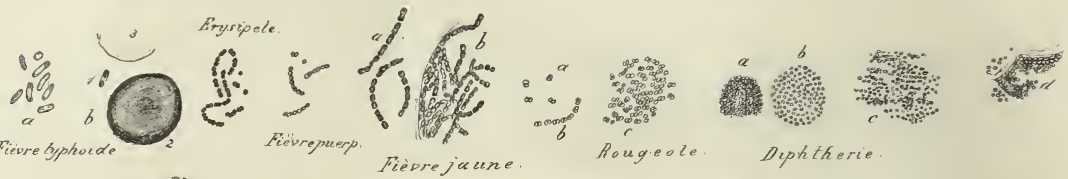

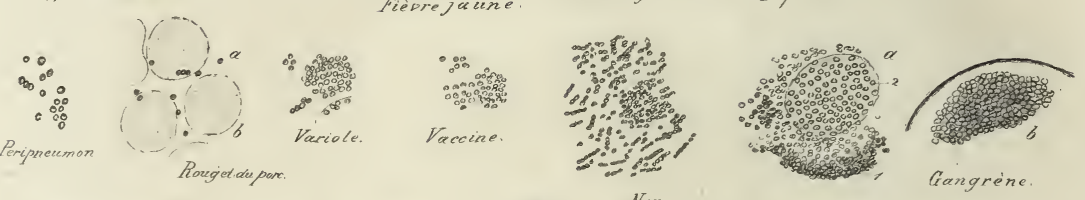
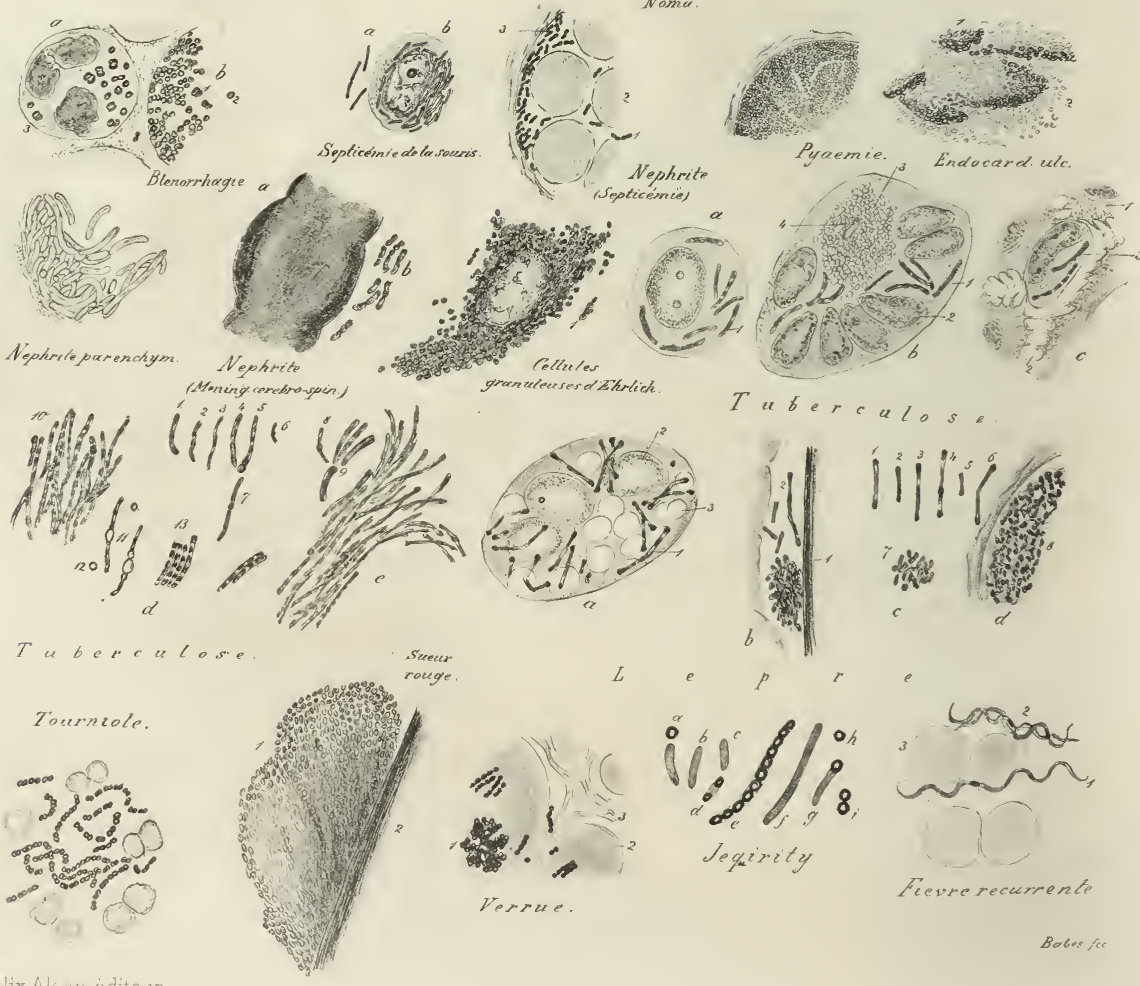

BACTERIES PATHOGENES 

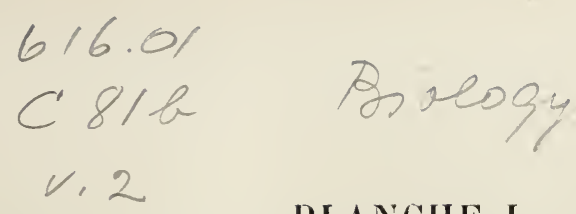

PLANGHE I

DIVERSES ESPÈCES DE BACTÉRIES REPRÉSENTÉES AU MÊME GROSSISSEMENT DE MLLLE DIAMĖTRES, AFIN QU'ON PUISSE LES COMPARER ENTRE ELLES.

Ia description de cette planche débute à gauche de la première rangée supérieure de bactéries el se continue jusqu'à la fin de la rangée inférieure (1).

\section{PREMIÈRE RANGÉE.}

Charbon. - $a$, bâtonnets tels qu'on les trouve dans le sang et dans les tissus de l'homme mort du charbon; $b$, filament's composés de bâtonnets provenant d'une ulcération de l'estomac dans la mycose gastro-intestinale ; c, bâtonnets et filaments plus minces observés dans le charbon du lapin; d, agglomération de bàtonnets minces du charbon dans un ulcère de l'estomac chez l'homme.

Charbon symptomatique. - Forme des bacilles de l'œdème du tissu fibromusculaire. $a$, deux bàtonnets lisses unis l'un avec l'autre; $b$, petit bàtonnet possédant une spore terminale un peu plus épaisse que le bâtonnet (bacille en battant de cloche); c, long bâtonnet possédant une spore terminale et, dans son milieu, une partie plus colorée ; $d$, bâtonnet offrant deux spores terminales; $f$, très long bàtonnet avec des spores; $g$, bàtonnet très court muni d'une spóre; $h$, bâtonnet court sans spore.

Choléra des poules. - $a$, groupe de bàtonnets trouvés dans les vaisseaux du muscle pectoral altéré. Quelques-uns de ces bàtonnets sont munis de spores; $b$, microcoques du choléra des poules tels qu'on les observe dans le liquide de l'œdème et dans les cultures. On y trouve souvent des formes en 8 ou en biscuit; $c$, microcoques plus petits provenant d'une culture ancienne ou atténuée.

Morvc. - $a$, bâtonnets provenant de cultures, les uns foncés 1 , les autres peu colorés, 2; $b$, bâtonnets courts dessinés d'après les cultures de Bouchard, Capitan et Charrin; $e$, bàtonnets provenant d'un cas de morve humaine observée par Babès en 1881. Les bàtonnets en battant de clo che, 1, 3, correspondent à des formes trouvées dans les cultures.

\section{DEUXIÈME RANGÉE.}

Fiévre typhoide. - $a$, groupe de bâlonnets observés dans le tissu réticulé des plaques de Peyer; $b, \boldsymbol{t}$, bàtonnel à spore provenant du sang; 2 , globule blanc altéré, fortement coloré, existant aussi dans le sang.

Erysipèle. - Microcoques isolés, diplocoques et chaînettes telles qu'ils existent dans l'exsudat et dans les vaisseaux lymphatiques du derme (Streptococcus).

Fiévre puerpérale. - Microbes en chaînettes (Streplococcus) provenant de l'exsudat opaque d'une péritonile puerpérale foudroyante.

Fiévre jaune. - $a$, chaînettes ressemblant à des bâtonnets; $b$, filaments accumulés remplissant les vaisseaux du rein.

Rougeole. - $a$, diplocoques souvent aplatis; $b$, chaînettes de diplococci;

(1) Nous conseillons l'emploi de la loupe pour bien voir les détails, les lettres et les chiffres des dessins de cette planche.

COINIL ET BABES. - Atlas. 
$c$, petit amas de bactéries situées dans le tissu interlobulaire du poumon.

Diphthéric. - $a, b$, zooglœes telles qu'on les rencontre très communément dans les pseudo-membranes; $c$, infiltration du tissu conjonctif de la muqueuse altérée; $d$, zooglœe située dans un vaisseau lymphatique à la surface d'une plaie diphthéritique.

(Nous n'avons pas dessiné ici les bacilles de la diphthérie, qui n'étaient pas connus au moment où cette planche a été gravée, en septembre 1883.)

\section{TROISIÈME RANGÉE.}

Péripneumonie bovine. - Grains ronds situés dans les vaisseaux lymphatiques du tissu conjonctif interlobulaire enflammé.

Rouget du porc. - Microbes isolés ou deux par deux, dans les vaisseaux, à côté de globules rouges.

Variole. - Microbes isolés, accouplés par deux ou par quatre ou en petites zooglœes dans les lacunes du corps muqueux de Malpighi, dans une pustule de variole.

Vaccine. - Microbes ressemblant beaucoup aux précédents.

Noma. - Micro-organismes habituellement disposés en chaînettes serrées provenant du liquide de l'œdème périphérique à la gangrène buccale (d'après une observation recueillie à Budapest).

Gangrène. - $a$, microbes ronds isolés ou en zòoglœe provenant d'une plaque de Peyer dans la fièvre typhoïde; 1 , partie profonde en contact avec le tissu vivant; 2, zooglœe bien limitée; $b$, zooglœe enfermée dans une capsule qui entoure un séquestre déterminé par un corps étranger.

\section{QUATRIÈME RANGÉE.}

Blennorrhagie. - Sécrétion puriforme d'un écoulement aigu examiné après dessiccation. $a$, cellules de pus renfermant de grands microbes, parfois des diplococci très serrés et aplatis, à centre brillant; $b$, bactéries plus petites siluées dans une vacuole.

Septicémie de la souris produite par l'injection du sang putréfié (Koch). Les bacilles sont libres dans le sang ou renfermés dans des leucocytes $b$.

Néphrite septique. - Cette figure se rapporte à un cas d'infection septicémique complexe observée chez l'homme et dans laquelle la disposition des bactéries ressemble à celle de la septicémie des souris de Koch. 1 , diplococci allongés et en grand nombre dans un vaisseau dont on voit la paroi 3 , et les globules rouges 2.

Pyémie. - Vaisseau du cœur rempli d'une zooglœe plus pâle à son centre qu'à ses bords.

Endocardite ulcéreuse. - La valvule ulcérée est infiltrée de microbes sous forme de nuage ou de zooglœes dont la périphérie présente des microcoques plus colorés que le centre.

\section{CINQUIÈME RANGÉE.}

Néphrite parenchymateuse observée ḋ la suite d'un rhumatisme. - Une grande partie des vaisseaux du rein était remplie de bâtonnets pâles et bomogènes.

Néphrite observée dans une méningite cérébro-spinale. - Les vaisseaux du 
rein étaient remplis par une masse presque homogène de bactéries $a$, si bien qu'il était presque impossible de distinguer les individus qui la composaient. Ces bactéries sont vues isolément en $b$; ce sont des diplocoques très serrés disposés en bâtonnets.

Cellule granuleuse d'Ehrlich. (Mastzellen.) - Les grains qui se trouvent dans le protoplasma de ces cellules ressemblent aux bactéries, mais ils sont moins réguliers comme disposition et comme grandeur.

Tuberculose. - a, bacilles situés dans une cellule endothéliale tuméfiée.

$b$, bacilles placés dans une cellule géante, et spécialement entre les noyaux, à la périphérie de la cellule; le centre de cette cellule montre des grains égaux entre eux, 3, et une petite masse hyaline, 4.

$c$, bacilles situés dans une cellule migratrice, dans les interstices qui séparent les cellules épithéliales du revêtement épithélial de la muqueuse buccale; 1 , cellule épithéliale; 2, interstice; 3 , bacille.

\section{SIXIÈME RANGÉE.}

Tuberculose. - De 1 à 7 on voit les divers aspects que présentent les bacilles dans les sécrétions; en 8 et 9 , groupes digités de bacilles comme on les observe quelquefois dans les cellules géantes; 10 , touffe de bacilles dans l'urine; 11 , bacilles renfermant des vacuoles dans un cas de tuberculose inoculée, et accompagnés de grains ronds 12;13, groupe de bacilles sporulés dans des crachats conservés pendant plusieurs mois; $e$, touffe de bacilles dans les cultures.

Lèpre. - $a$, grande cellule lépreuse présentant plusieurs noyaux, 2, des vacuoles, 3 , et des bacilles 1 .

$b$, bacilles de la lèpre libres dans la gaîne interne d'un poil ; 3 , amas de bacilles serrés les uns contre les autres; de 1 à 6 on a figuré les différentes formes de bacilles de l̉a lèpre dans les tissus; 7 , amas anciens de bacilles un peu atrophiés; $d$, amas de bactéries de la lèpre dans un vaisseau.

\section{SEPTIÈME ET DERNIÈRE RANGÉE.}

Tourniole. - Les chainettes de streptococci sont placées autour de débris de noyaux. Ces chaînettes existaient dans le liquide recueilli par piquure au début de la lésion.

Sueur rouge. - Sur un poil, 2, on voit une masse de bactéries un peu allongées, en zooglœes, qui sont surtout bien distinctes à leur périphérie 1 .

Verrue. - Dans le tissu conjonclif et les vaisseaux des papilles cutanées, on trouve des masses zooglœiques 1 , ou des chaìnettes serrées, réunies en paquets.

Jéquirity. - Les microbes représentés de $a$ à $d$ sont pris dans le liquide de l'œù̀me artificiel produit par l'injection de l'infusion; de $e \dot{a} i$, on a représenté les bacilles et spores de l'infusion elle-même.

Fièvre récurrente. - Les spirilles 1,2 , sont placés entre les globules rouges. $\mathrm{Au}$ milieu de la longueur des spirilles, on trouve souvent des grains allongés, fortement colorés qui sont séparés de la substance voisine par une partie plus claire. 


\section{PLANCHE II}

CIIARBON. - MYCOSE INTESTINALE.

Fıg. 1. - Coupe transversale de la partie superficielle d'un ulcère charbonneux (grossissement de $3 a ̈ 0$ diamètres). $b$, bacilles libres; les bactéries forment un feutrage dans lequel on peut distinguer des masses rondes colorées $g$.

Fig. 2. - La muqueuse de l'estomac dans le charbon expérimental du lapin. $b$, bacilles; $g l$, glandes.

Fig. 3. - Masses agglomérées de bacilles du charbon sous la forme de zooglœe (z) à la surface des plaques charbonneuses de l'intestin.

Fig. 4. - Sang desséché d'un individu atteint du charbon. $g$, globules rouges; $b$, bacilles.

Fig. 5. - Filaments du charbon développés au bord de la lamelle dans une préparation fraîche du sang.

Fig. 6. - Spores cultivés provenant du sang du même individu.

Fig. 7, 8 et 9. - Diverses formes des bacilles du foin. Grossissement de 400 diamètres.

FIG. 10. - Coupe transversale de la muqueuse de l'estomac de l'homme au commencement de l'affection. La surface est dépouillée de son épithélium et couverte d'un mucus contenant des bacilles. Les glandes $g l$ sont dilatées, et on y peut suivre la pénétration des bacilles $(b)$. Parfois les glandes sont tout à fait remplies de bacilles $\left(b^{\prime}\right)$. Il y a aussi des bacilles dans la partie superficielle de la muqueuse entre les glandes. La muqueuse est mince, pâle, ses cellules sont homogènes. Au-dessous de cette partie affectée, les vaisseaux lymphatiques sont dilatés, et le tissu est devenu embryonnaire.

Fig. 11. - Mycose intestinale liée à la présence de microbes ronds. Partie profonde de la muqueuse (grossissement de 500 diamètres). gl, coupes transversales des cryptes de Lieberkühn; $z$, masses bactériennes. 

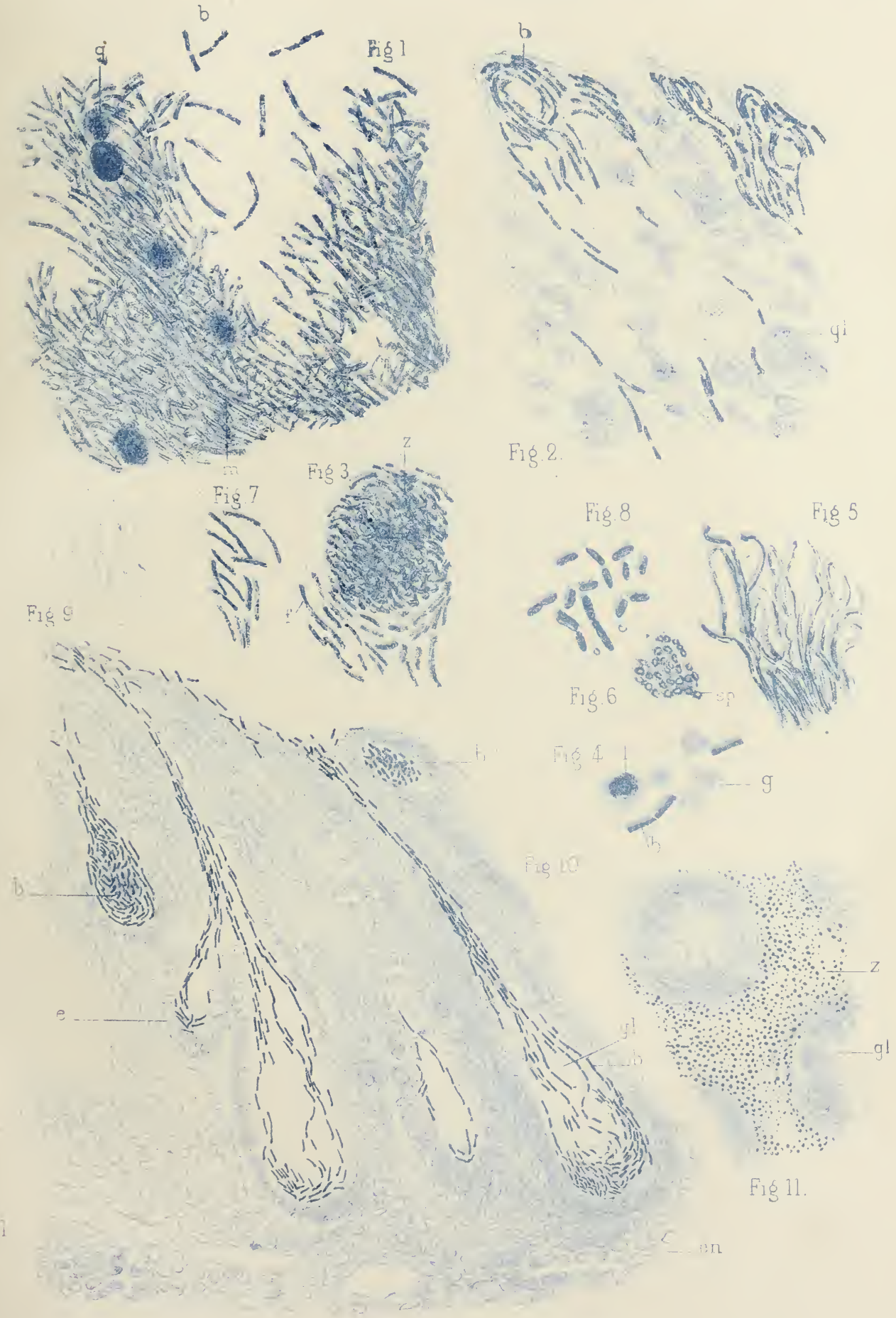

• 
Figl

栱

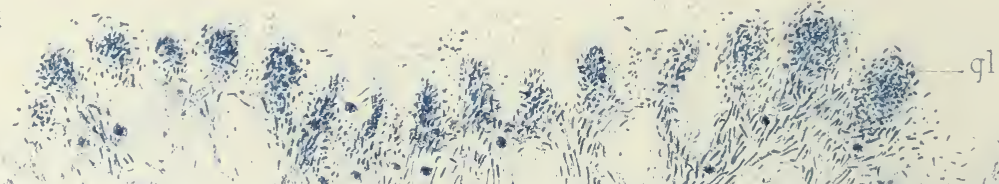
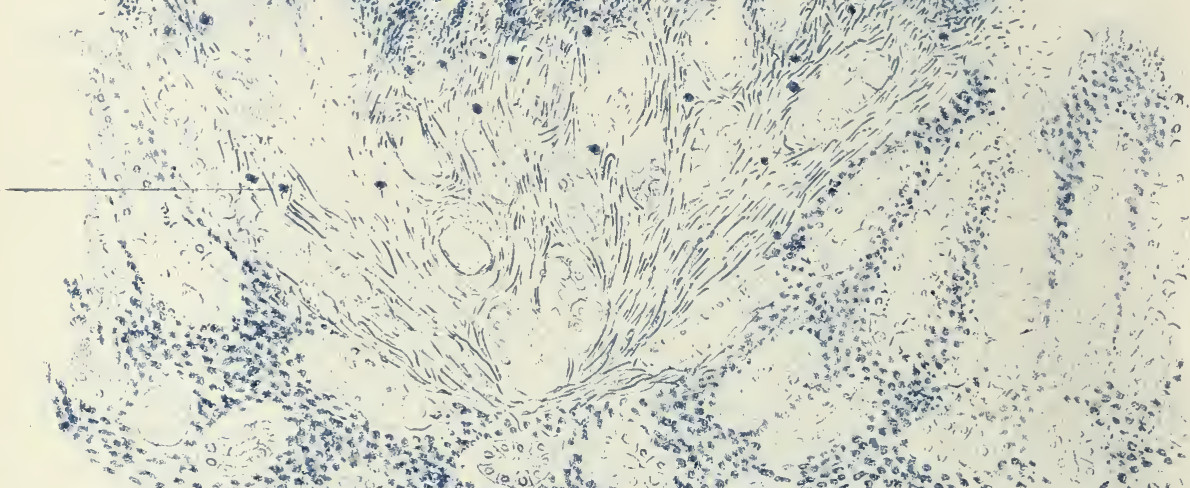

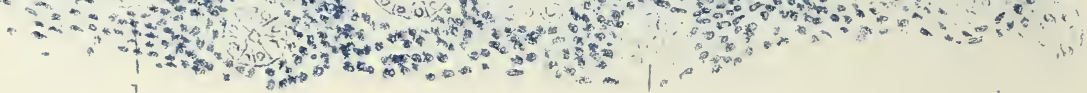

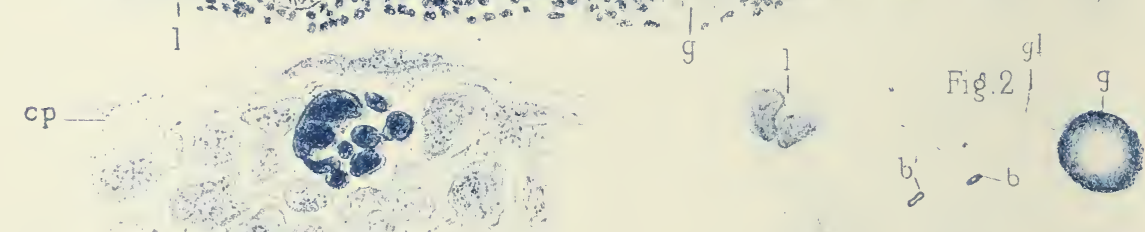

Figs 30

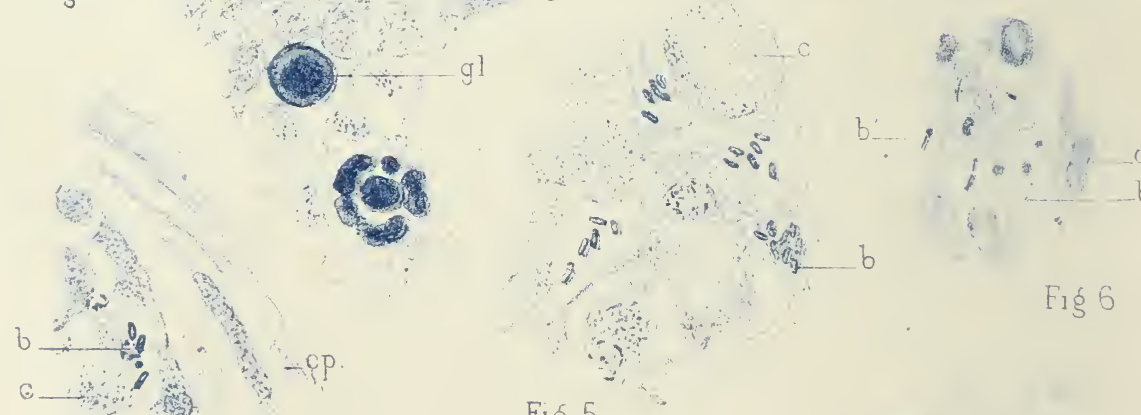

Fig. 4

Fig. 5 .

$\frac{1}{2+2}$

$x^{2}$

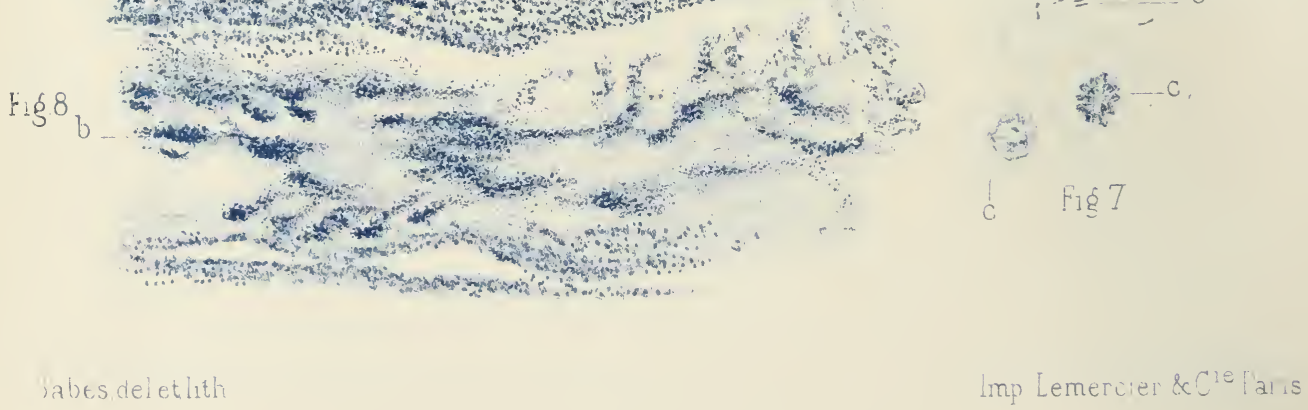

tis

imp Lemercier \& C Clatis 


\title{
PLANGHE III
}

\author{
CHarbon. - FIÈvRe typHOIde. - MORVE. - endocardite.
}

Fıg. 1. - Petil ulcère observé dans le charbon de l'estomac. Coupe colorée successivement par le violet de méthyl 5 B et par le picro-carminate, puis montée dans le baume de Canada. A la surface de la muqueuse, on voit des bacilles libres dans le mucus purulent superficiel. $g l$, masses agglomérées de bacilles formant des zooglœes; $f$, filaments bactéridiens remplaçant le tissu conjonctif entre les glandes. La coupe de ces dernières montre les cavités dépouillées d'épithélium dans l'étendue de la muqueuse altérée; $d$, tissu embryonnaire autour du tissu altéré par la présence des bacilles; $g$, glandes de l'estomac autour de la partie altérée. Grossissement de 200 diamètres.

Fig. 2. - Le sang dans un cas de fièvre typhoïde; préparation desséchée et colorée comme dans la figure 1 (grossissement de 600 diamètres environ). Entre les globules rouges, on voit un globule blanc à deux noyaux $l$, un globe ou disque bien coloré à sa périphérie, $g$, et des bacilles isolés $b$ ou deux à deux $b^{\prime}$.

FIg. 3. - Coupe de la partie périphérique d'un ganglion mésentérique dans la fièvre typhoïde (grossissement de 500 diamètres environ). A la partie supérieure du dessin, on voit la capsule dont les cellules fixes sont tuméfiées. Les cellules lymphatiques de la partie périphérique du ganglion, $c$, sont aussi tuméfiées et grenues. Entre les cellules, il y a des masses hyalines $g l$, formant des globes ou bien des amas constitués par débris de globes hyailins.

FIG. 4. - Coupe d'un autre ganglion hypertrophique dans la mème maladie (grossissement de 600 diamètres). $c p$, capsule ganglionnaire présentant des cellules fixes tuméfiées; $c$, cellules gonflées de la substance corticale; $b$, bacilles situés entre les cellules.

Fig. 5. - Coupe transversale d'une plaque de Peyer, de consistance médullaire, dans la fièvre typhoüde (grossissement de 800 mètres environ). $-c$, cellules hypertrophiées et granuleuses; $b$, bacilles siégeant surtout entre les cellules.

Fig. 6. - Une parcelle d'un abcès de la moelle des os desséchée, dans la morve de l'homme (grossissement de 800 diamètres). $c$, cellules de la moelle; $b$, bacilles ; $b^{\prime}$, bacilles avec des spores terminaux.

Fig. 7. - Coupe de la rate du cheval dans la morve. c, cellules de la pulpe ; $c^{\prime}$, les mêmes, en multiplication; $c^{\prime \prime}$, petit amas avec des cellules pâles sans noyaux; $b$, bacilles.

Fig. 8. - Coupe transversale de la valvule bicuspide dans l'endocardite ulcéreuse (grossissement de 600 diamètres environ). Au bord de l'ulcère on voit du sang coagulé $(p)$. La couche superficielle enflammée est remplie de cellules migratrices; la couche moyenne de la valvule est formée par un tissu pàle, sans structure, rempli de microbes disséminés ou formant des amas colorés, striés et mal limités. 


\title{
PLANCHE IV
}

\author{
CHOLÉRA DES POULES.
}

Fig. 1. - Préparatıon du tissu conjonctif infiltré de cellules migratrices et de micro-organismes, obtenue par l'extension et la demi-dessiccation. $f$, faisceau du tissu conjonctif. $a$, micro-organısmes; les granulations sont disposées deux à deux ou en séries entre les fibres du tissu conjonctif. $b$, cellules. - Grossissement de 600 diamètres.

Fig. 2. - Section à travers le muscle enflammé et infiltré par des microorganismes, vingt heures après l'injection sous-cutanée. $a, a^{\prime}, b$, faisceaux musculaires primitifs dissociés et divisés en petils disques transversaux. $c, d$, larges bandes occupées par des cellules lymphatiques el des micro-organismes qui sont situés au milieu d'un réliculum de fibrine. $m$, faisceau musculaire primitif isolé par dilacération. - Grossissement de 40 diamètres.

Fig. 3. - Section à travers le muscle enflammé et infiltré de micro-organismes, vingt heures après l'injection sous-cutanée. $a$, faisceau musculaire primitif remplacé en partie par des cellules lymphatiques $c$ et des microbes. $b$, faisceau musculaire primitif fragmenté. Dans le faisceau $a$, on voit, en $d$, une portion de la substance musculaire striée, tandis que tout le reste du faisceau est occupé par des cellules lymphatiques $c$, et par des micro-organismes. Dans le faisceau $b$, il existe des blocs de tissu musculaire strié qui sont séparés les uns des autres par des lacunes $m, n$. Dans ces lacunes, on voit souvent des microbes et quelquefois des cellules lymphatiques. 0 , cellules rondes provenant des cellules du sarcolemme proliférées. - Grossissement de 500 diamètres.

Fig. 4. - Section transversale du mème muscle. $b, b$, coupe transversale des faisceaux musculaires primitifs. $a$, $a$, coupe transversale de faisceaux primitifs dans lesquels le sarcolemme, $m$, est seul conservé. Les gaînes sarcolemmiques $a$, $a$, sont remplies de microbes. $v$, vaisseau. Grossissement de 500 diamètres.

Fig. 5. - Exsudat fibrineux infiltré dans le tissu conjonctif du muscle. $a$, cellules lymphatiques contenant des microbes. $c$, microbes isolés; $b$, fibrilles de fibrine. - Grossissement de 400 diamètres.

Fig. 6. - Section à travers une portion d'un séquestre et du tissu musculaire qui l'entoure huit jours après l'inoculation. $a, a, a$, tissu conjonctif enflammé formant de larges bandes autour des faisceaux secondaires des muscles $f$ et $b$. Ces derniers sont fragmentés, pàles et vitreux; $c, g$, gouttelettes de graisse interposées entre les parties mortifiées et les parties vivantes. $v$, veine très dilatée contenant du sang et des coagulations $h$. $a$, tissu musculaire enflammé, mais vivant, qui entoure la partie mortifiée. - Grossissement de 400 diamètres.

FIg. 10. - Cellule géante à noyaux multiples située à la surface interne de la membrane de séquestre. $a$, protoplasma granuleux et $b, b$, noyaux multiples de cette cellule; $e$, tissu conjonctif de la membrane forme un réticulum dont les mailles emprisonnent des cellules lymphatiques $f$. Grossissement de 400 diamètres. 
Fig 3

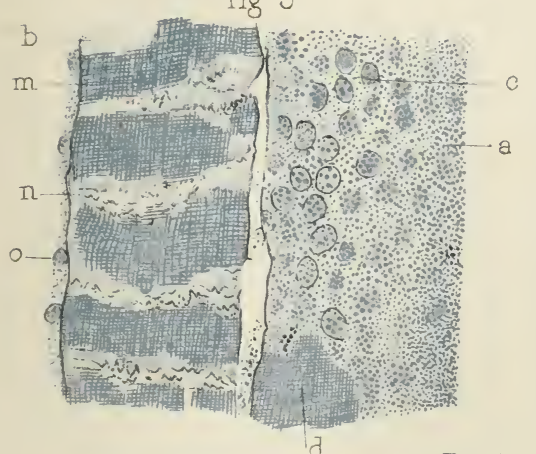

Fig 1

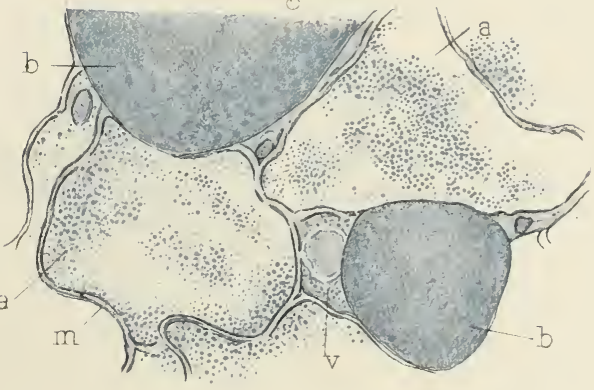

Fig 5

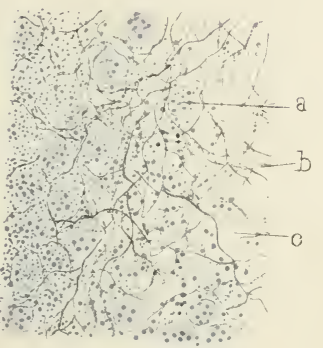

f

b

Q.

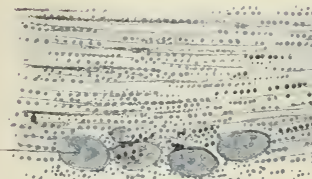
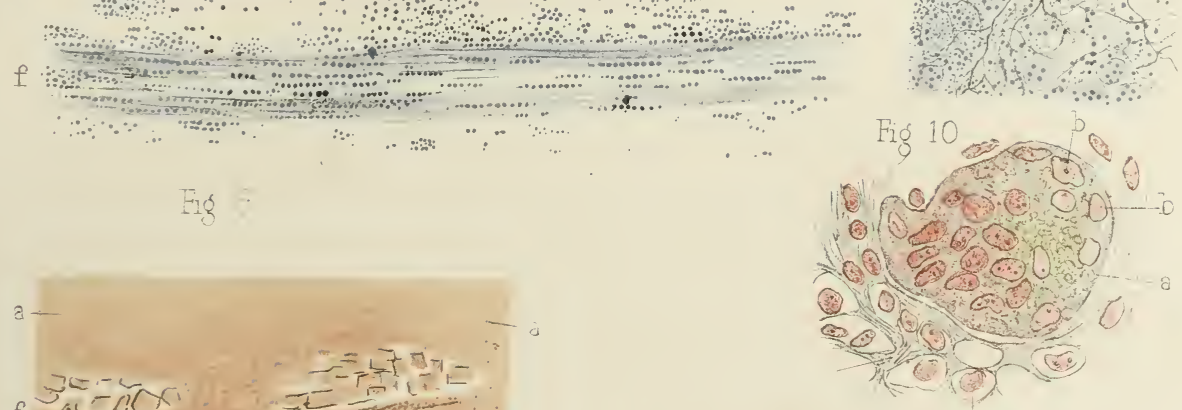

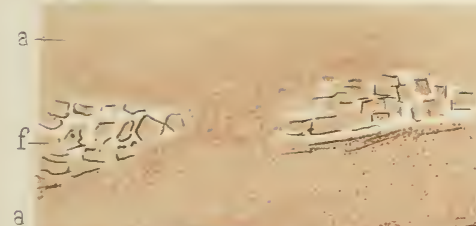

a

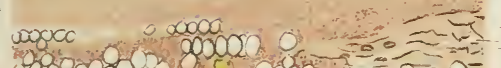

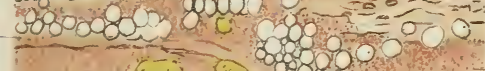
$\mathrm{v}+\mathrm{F} \quad 000000$

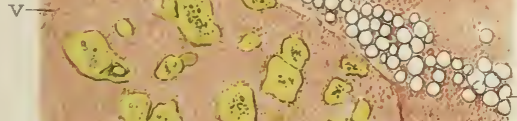

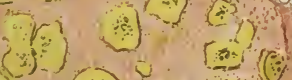

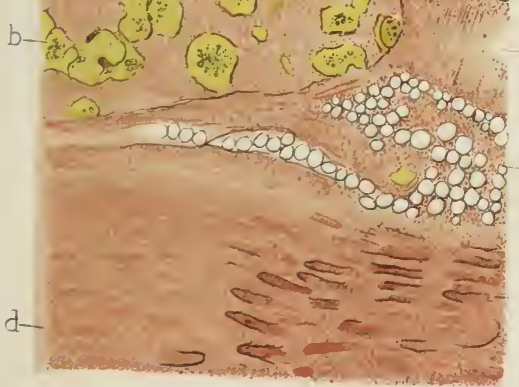

琴

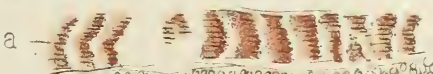
.

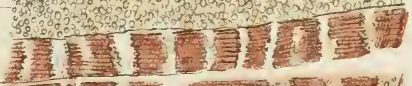

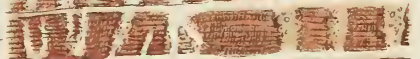

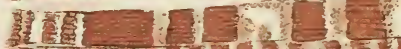

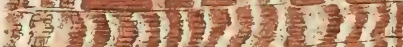

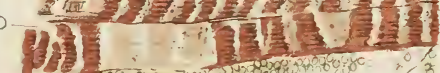
30860309

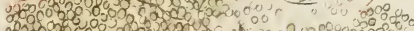
s.

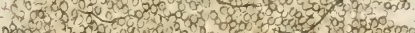
os

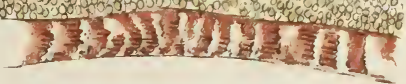



Fig 11
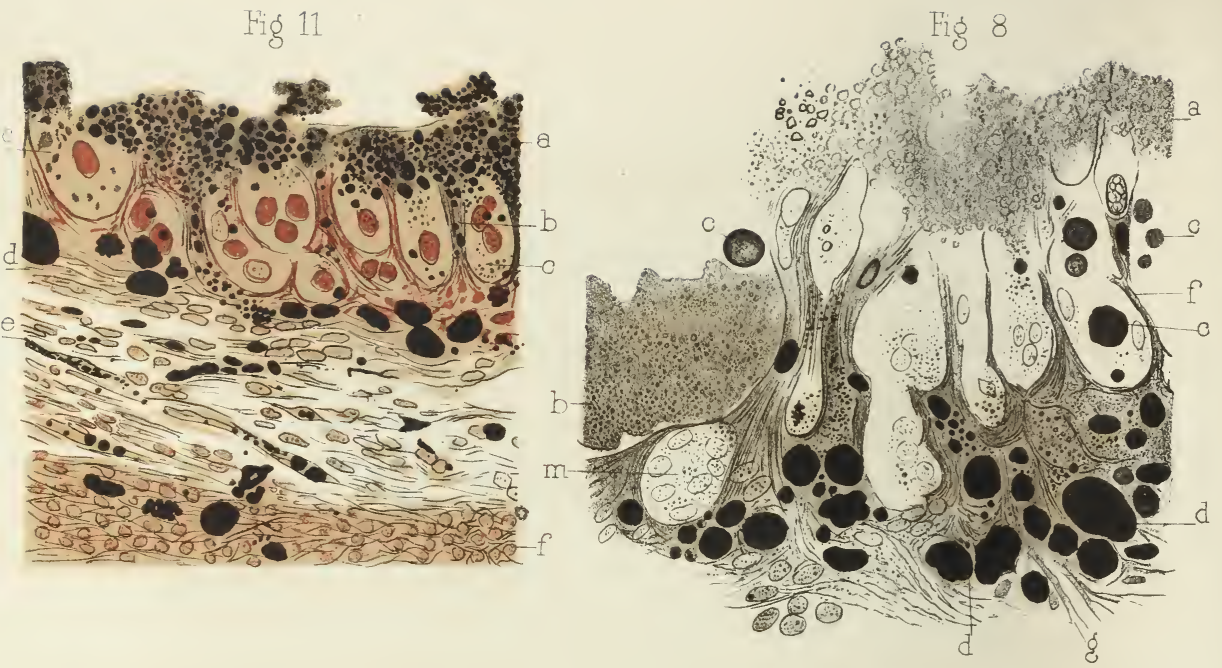

Fig 2

Fig 13
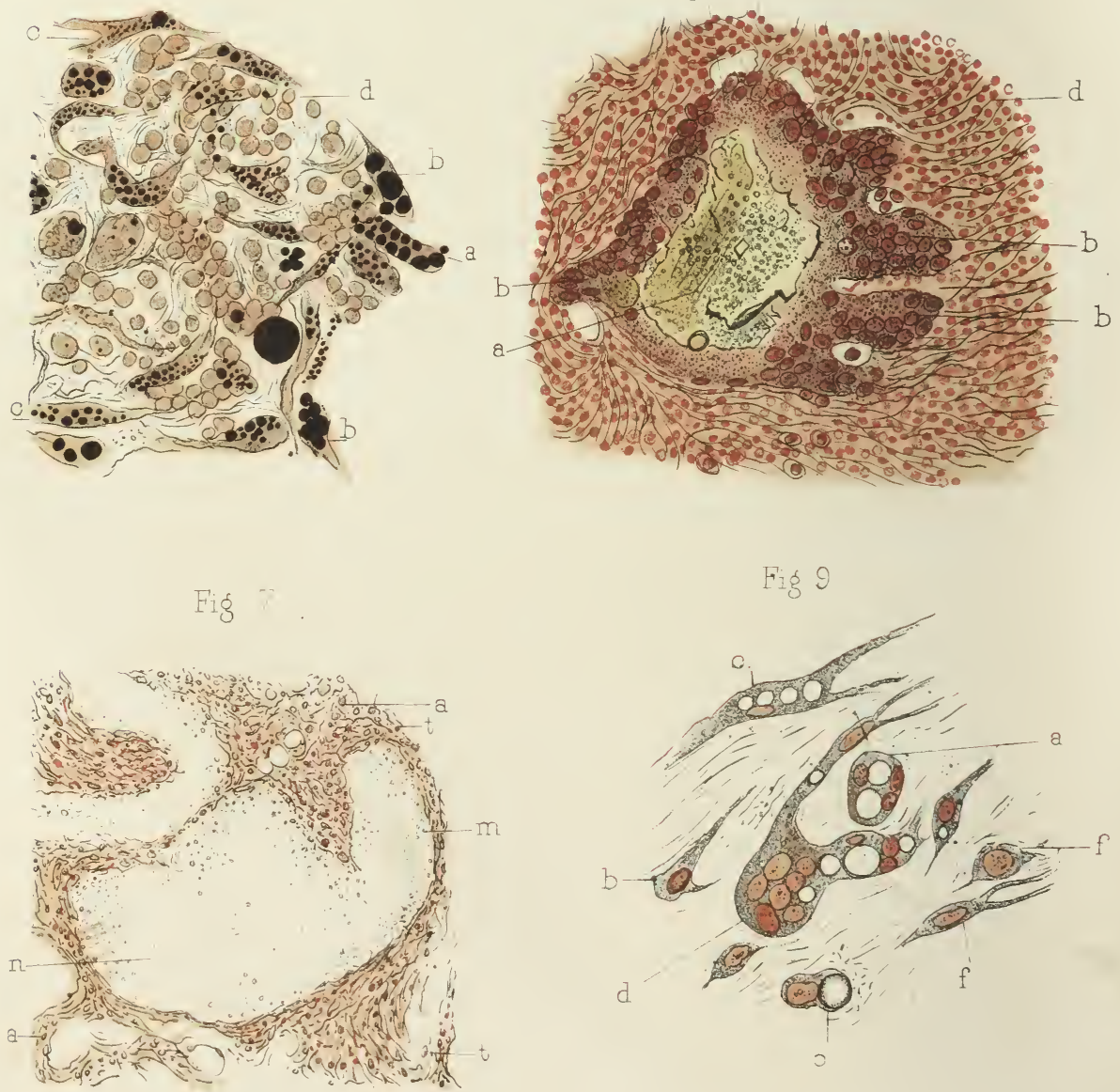

Nicolet lith 


\title{
PLANCHE V
}

\author{
CHOLÉRA DES POULES.
}

Fı́. 7. - Section à travers un séquestre datant d'un mois; $m$, fragment de muscle compris dans le séquestre; on voit très bien dans ce fragment la striation longitudinale et la striation transversale en $n$. Les stries transversales sont beaucoup plus fines et plus rapprochées les unes des autres qu'à l'état normal. Le tissu conjonctif $t$, qui sépare ces fragments musculaires, montre des cellules lymphatiques atrophié es, déformées, se colorant mal par le carmin, $a$, $a$. - Grossissement de 3500 diamètres.

FIg. 8. - Section à travers la membrane interne du kyste trois mois après l’inoculation. $a$, granulations et débris provenant du séquestre. A ces fragments, se trouvent mêlés de la graisse $c$ et des microbes, comme cela se voit bien en $b$. La surface interne de la membrane présente, entre les fibrilles du tissu conjonctif, des masses protoplasmiques granuleuses possédant dans leur intérieur des noyaux ovoïdes plus ou moins nombreux. Dans ces cellules, on trouve des gouttelettes de graisse $c ; f$, fibrilles du tissu conjonctif de la surface de la membrane; $g$, fibrilles de mème nature, de la profondeur de cette membrane. Ce tissu est rempli de grosses granulations graisseuses $d$. En $m$, il existe une grande cellule contenant sept noyaux. Préparation obtenue après le durcissement dans l'acide osmique. - Grossissement de 400 diamètres.

Fig. 9. - Cellules de la membrane moyenne de la poche présentant plusieur's noyaux et des gouttelettes de graisse, $a$, cellule possédant trois noyaux et deux gouttelettes de graisse; $b, f$, cellules ramifiées ne possédant qu'un noyau; $c$, cellule à un seul noyau présentant une gouttelette de graisse; 0 , cellule ramifiée présentant plusieurs granulations graisseuses; $d$, cellule géante à noyaux et à prolongements multiples porsédant aussi des gouttelettes adipeuses. - Grossissement de 400 diamètres.

Fig. 11. - Coupe de la membrane de la poche séquestre du choléra des poules après durcissement dans l'acide osmique, deux mois après l'inoculation. $a$, granulations graisseuses situées à la surface interne de la membrane; $b$, fibrilles, et $c$, cavités circonscrites par les fibrilles à la surface de la membrane. Dans ces cavités, on trouve des noyaux ovoïdes au milieu d'une masse protoplasmique qui contient aussi des granulalions graisseuses; $d$, gouttelettes de graisse situées dans la membrane; $e$, cellules rameuses ou aplaties du tissu conjonctif dont quelques-unes contiennent des granulations graisseuses fines; $f$, couche externe de la membrane composée par du tissu conjonctif embryonnaire. - Grossissement de 400 diamètres.

Fig. 12. - Section de la membrane de la poche du séquestre après durcissement dans l'acide osmique. Au milieu des fibrilles fines du tissu conjonctif, on voit des cellules aplaties ou rameuses contenant une grande quantité de gouttelettes de graisse assez volumineuses, comme en $b, b$, ou plus petites, comme en $a$ et en $c ; d$, cellules lymphatiques. - Grossissement de 400 diamètres.

Fig. 13. - Section transversale d'une petite dépression de la poche du séquestre. $a$, fragment du séquestre situé au centre d'une masse protoplasmique grenue $b, b, b$, qui l'entoure de toutes parts. Dans ce protoplasma granuleux, on voit une quantité considérable de noyaux ovoïdes volumineux, en sorte que le séquestre est environné par une immense cellule géante; $d$, tissu embryonnaire. - Grossissement de 250 diamètres. 


\section{PLANCHE VI}

tuberculose et Diphthérie des Gallinacées.

Fıg. 1. - Coupe d'un gros tubercule caséeux et calcaire située à la surface du péritoine intestinal et dessiné à un très faible grossissement (20 diamètres). Toutes les parties qui offrent une couleur bleue, $b$, sont des amas de bactéries de la tuberculose. Elles siègent dans des fentes dont quelquesunes représentent probablement des vaisseaux $v$, et elles sont entourées de parties calcifiées qui ont une couleur acajou. La préparation a été colorée par le violet d'Ehrlich, puis décolorée par l'acide nitrique et colorée ensuite par la safranine.

Fig. 2. - Tuberculose chronique d'un ganglion lymphatique de la poule. $a$, paroi caséeuse d'un abcès caséeux; $v$, vaisseau contenant des masses de bactéries; $c$, grandes cellules contenant des masses de bactéries. Grossissement de 150 diamètres.

Fig. 3. - Foie tuberculeux d'une poule. $v$, veine centrale autour de laquelle il s'est développé un amas tuberculeux; $c$, dégénérescence calcaire autour de la veine; $v$, vaisseau dont la paroi est épaissie et caséeuse et qui est rempli de bactéries de la tuberculose ; $f$, tissu du foie avec de petits vaisseaux remplis de sang. Grossissement de 100 diamètres.

Fig. 4. - Un petit tuberçule du foie du faisan. $c g$, cellules géantes contenant des bacilles de la tuberculose; $r$, réseau hyalin provenant en grande partie du tissu tuberculeux; $f$, cellules du foie peu altérées.

Virg. 5. - Coupe du foie tuberculeux dessiné à un grossissement de 6 diamètres. $a$, gros tubercule semi-transparent; $b, b$, petits tubercules développés autour des vaisseaux; $f$, tissu dı foie.

Fig. 6. - Trois cellules des tubercules du foie précédent. Ces cellules sont assez volumineuses, mais elles ne présentent qu'un noyau, ce qui les distingue des cellules géantes. Elles sont complètement remplies de touffes de bactéries débordantes. Grossissement de 600 diamètres.

Fig. 6. - Coupe de l'intestin d'une perdrix au niveau d'une plaque diphthéritique. $m$, fausse membrane épaisse qui recouvre l'intestin; $p$, villosités intestinales auxquelles adhère partiellement la fausse membrane comme cela se voit en $b ; e$, tunique musculaire. La muqueuse tout entière est mortifiée; entre les villosités, on voit des fentes qui sont remplies, ainsi que les glandes en tubes, de masses de bacilles colorés en bleu Grossissement de 20 diamètres. 


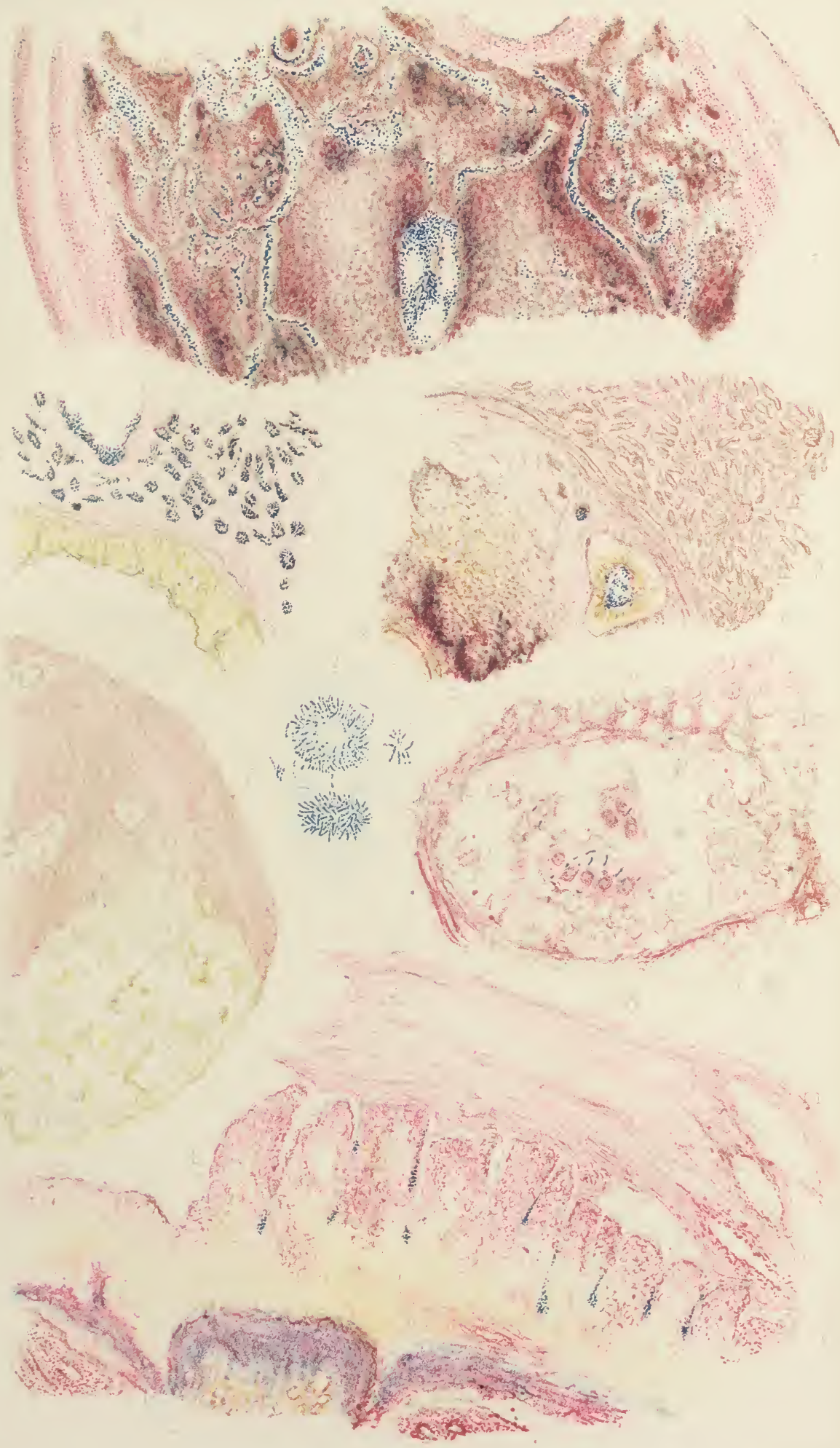



Lets

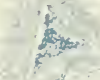

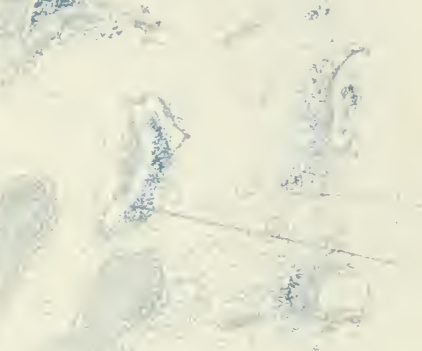

Honemis

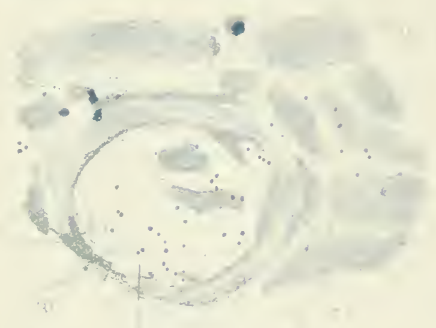

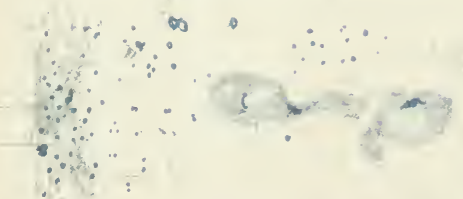

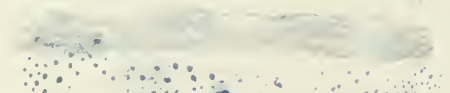

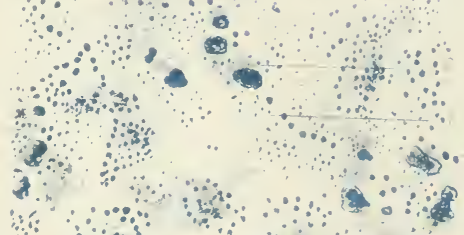

$\therefore$ a $\because \cdots$

ec $\therefore$ c o o

$\therefore \quad \therefore \quad \therefore$

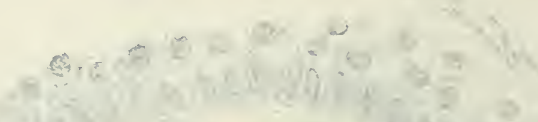

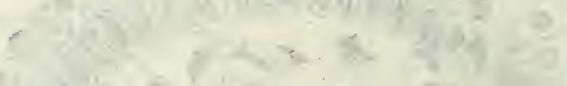

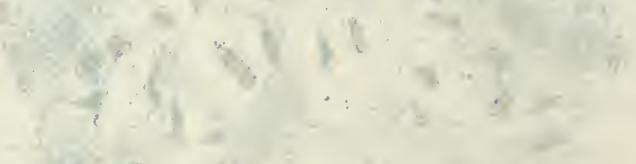

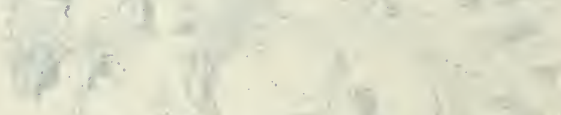

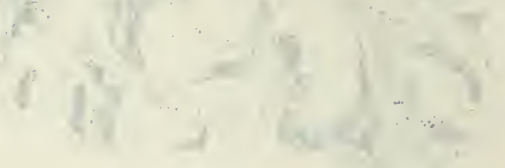
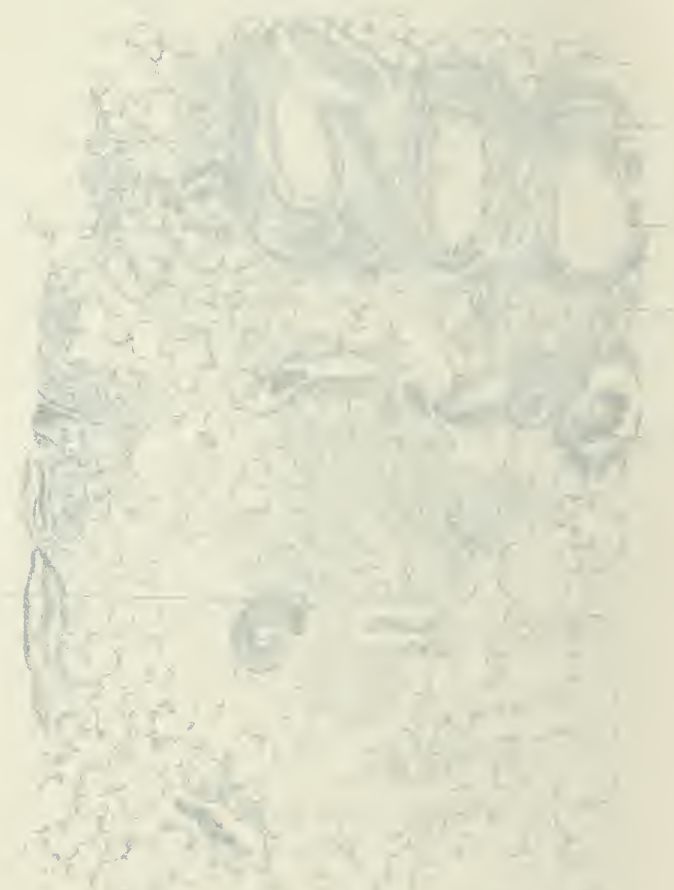

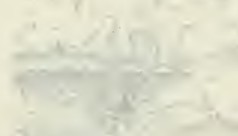

y. 


\section{PLANGHE VII}

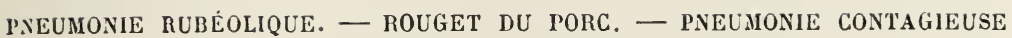
DE L'ESPĖCE BOVINE.

Fig. 1. - Elle représente la partie périphérique d'un îlot d'hépatisation grise consécutive à la rougeole chez un enfant; la préparation a été traitée par le violet de méthyle et ensuite par l'acide acétique faible et ronservée dans le baume du Canada. Grossissement de 60 diamètres environ.

$p$. plèvre viscérale couverte d'un exsudat fibrineux contenant des bactéries $b$.

ti, tissu interlobulaire contenant des follicules lymphatiques hypertrophiés ; $f$, petites artères, contenant des masses bactériennes qui, d'après la méthode indiquée, sont restées fortement colorées, $v b$.

$l$, vaisseaux lymphatiques dilatés contenant souvent des bactéries.

$c b$, grandes masses de bactéries dans le tissu conjonctif interlobulaire qui est infiltré par de la fibrine caogulée.

$a$, alvéoles entourés de leucocytes; $a^{\prime}$, alvéole contenant des masses bactériennes.

Fig. 2. - Section de la peau dans le rouget du porc; $m$, corps muqueux; $c$, couche cornée; $p$, tissu conjonctif d'une papille dans laquelle on voit des cellules de tissu conjonctif, des vaisseaux $v$, limités par leurs cellules endothéliales et contenant des microbes ronds. Les microbes sont presque tous contenus dans les vaisseaux capillaires. Grossissement de 400 diamètres.

Fig. 3. - Coupe du derme au-dessous des papilles dans le rouget du porc; $v$, section d'un vaisseau dans lequel on voit un grand nombre de microbes; $t, t, t$, fibres de tissu conjonctif limitant des vaisseaux capillaires contenant eux-mèmes des microbes $b$. Grossissement de 800 diamètres.

Fig. 4. - Éléments contenus dans un vaisseau lymphatique du poumon dans la péripneumonie du gros bétail ; $c$, noyaux des cellules lymphatiques; $n$, un autre noyau ; $c^{\prime}, c^{\prime \prime}$, granulations provenant de la destruction des noyaux; $n$, idem; $b$, granulations d'un diamètre uniforme (microbes?).

Fig. 5. - Section longitudinale d'un vaisseau lymphatique du poumon dans la péripneumonie bovine; $l$, paroi; $m, m$, cellules endothéliales de la paroi du vaisseau lymphatique; $n$, noyau de cellule lymphatique; $a$, amas de granulations provenant de débris de noyaux de cellules lymphatiques; $b$, granulations colorées, rondes et égales entre elles (microbes?).

Fig. 6. - Coupe du poumon dans la péripneumonie bovine; $b$, bronche; $c$, cartilage de la bronche; $v$, $v$, vaisseaux entourés de leurs lymphatiques $l, l, l$. Les vaisseaux lymphatiques sont remplis par un exsudat contenant de la fibrine el des globules blanes; $l^{\prime}$, bronche remplie de cellules; $v^{\prime}$, petite artériole entourée de son vaisseau lymphatique $l^{\prime \prime}$; $i$, coupe du tissu conjonctif périlobulaire dans lequel on voit, au bord de cette travée, des vaisseaux lymphatiques, $l^{\prime \prime \prime} ; l^{\prime \prime \prime}$. Grossissement de 20 diamètres. 


\section{PLANCHE VIII}

PHLEGMON .

Fıg. 1. - Préparation de pus desséché sur une lamelle et coloré par la fuchsine. $a$, chaînette composée de diplococci et de micrococci dont la partie terminale est formée à droite par de très petits microbes. $b$, chaînette plus longue, dont beaucoup de micro-organismes sont aplatis et lenticulaires. $c$, chaînette formée par des microbes plus volumineux; en $d$, la chaînette se continue avec de très petits microbes $e$, amas de diplococci; $f, f$, cellules dont le protoplasma contient des microbes: en $n$, le protoplasma est bien évident et rempli aussi de micro-organismes. Les noyaux de ces cellules sont arborescenls. Les noyaux $m$ et $p$ présentent des divisions séparées par des étranglements. Grossissement, obj. 12 à immersion de Vérick, oc. 2.

Fig. 2. - Coupe du tissu cellulo-adipeux. $a$, capillaire avec ses cellules endothéliales et un contenu fibrineux dans lequel on voit des microbes réunis en une chaînette de trois. $b$, microbes en chaînette le long des cloisons qui séparent les cellules adipeuses; $c$, cellules lymphatiques contenant beaucoup de microbes et situées au pourtour d'une cellule adipeuse; $m$, cellule tuméfiée. Même grossissement.

Fig. 3. - Coupe du tissu conjonctif sous-cutané. Les faisceaux $m$ sont pâlis et minces; on voit en $a$ une cellule fixe qui n'est pas altérée. Les espaces interfasciculaires contiennent des cellules lymphatiques à noyaux arborescents $b$, et de nombreux microbes accolés deux par deux ou en chaînettes. Même grossissement.

Fig. 4. - Section du tissu conjonctif de la partie moyenne du derme. $a$, faisceaux du tissu conjonctif limitant un espace interfasciculaire très dilaté. Les éléments contenus dans cet espace sont des cellules fixes très volumineuses, globuleuses $c, c, c$, renfermant des diplococci ou des chaînettes et en même temps des fragments de noyaux. Ces derniers sont bien colorés comme en $n$, ou presque incolores comme en $n^{\prime} ; d$, cellules migratrices contenant plus ou moins de microbes. En $d^{\prime}$ on voit des cellules dont les noyaux sont pâlis. $f^{\prime}$, fibrine. Même grossissement.

F1G. 5. - Coupe du tissu conjonctif infiltré de pus; les faisceaux de fibres sont mortifiés et pâles, les cellules lymphatiques sont aussi mortifiées. Il existe partout une grande quantité de microcoques.

Fı.6. - Un faisceau de fibres entouré de chaînettes de microbes ronds et de débris de cellules et de noyaux pris dans la partie mortifiée du phlegmon. 


$$
{ }_{m \rightarrow \infty}^{0} g \text { …… (3) }
$$$$
\text { n }
$$
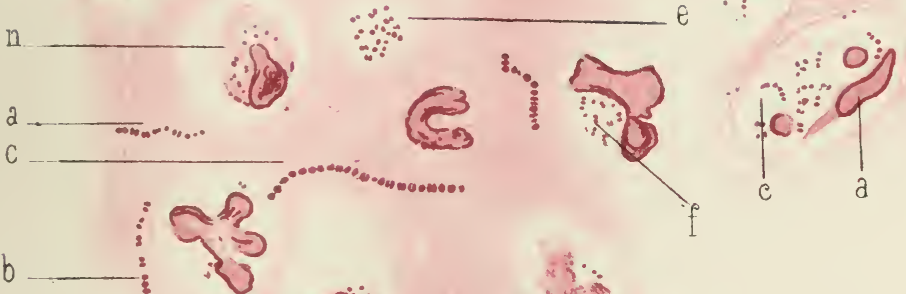

b
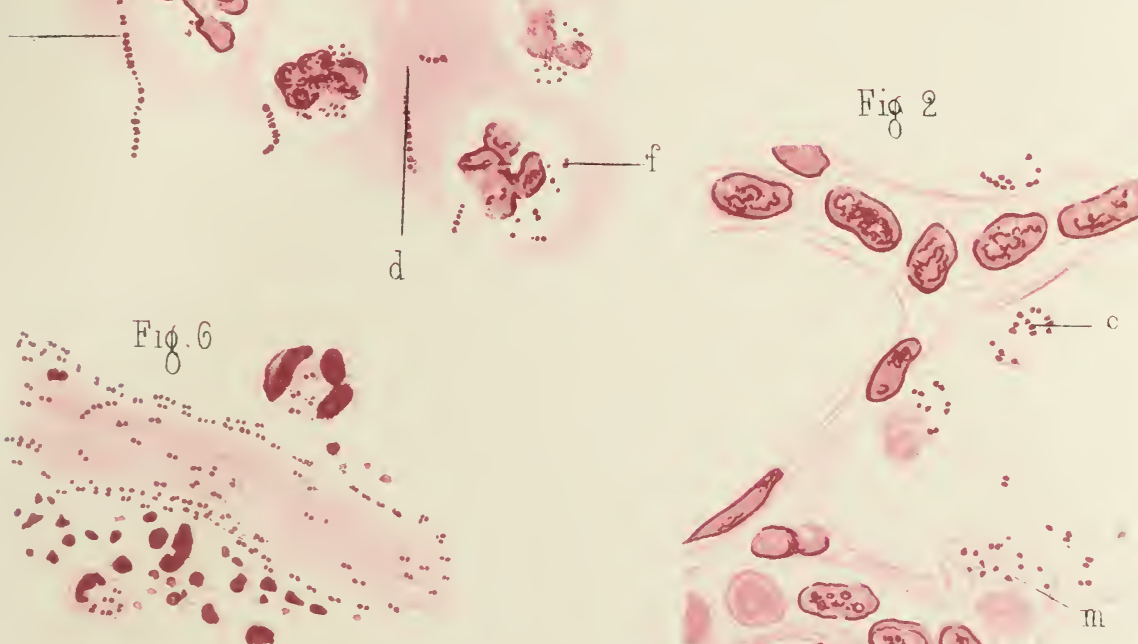

Fig. 4
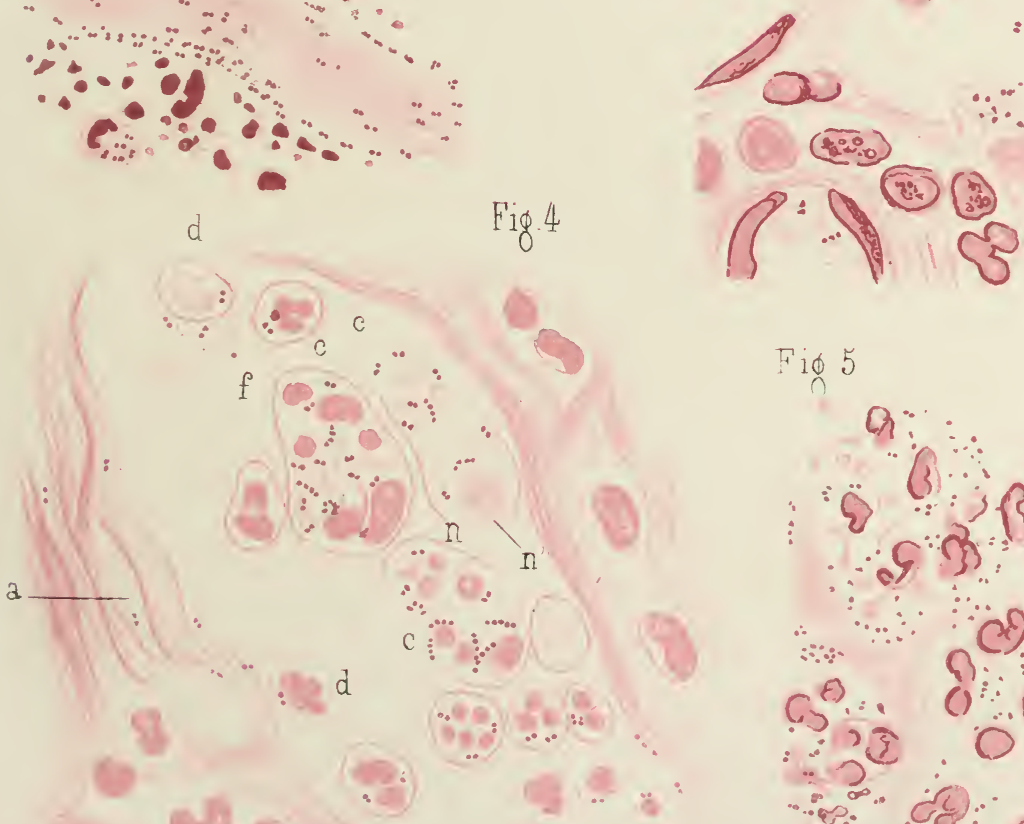

Fio 5

$$
\begin{aligned}
& \text { a: } \\
& \text { (3) } \\
& \begin{array}{ll}
8 \\
\therefore
\end{array} \\
& \int_{0}^{\theta} 0^{0} 0^{3} \\
& 0 \text { o } 0
\end{aligned}
$$

Cosnes do

Imp Lentercier \& cie Paris 

. 
Fiş 1 .
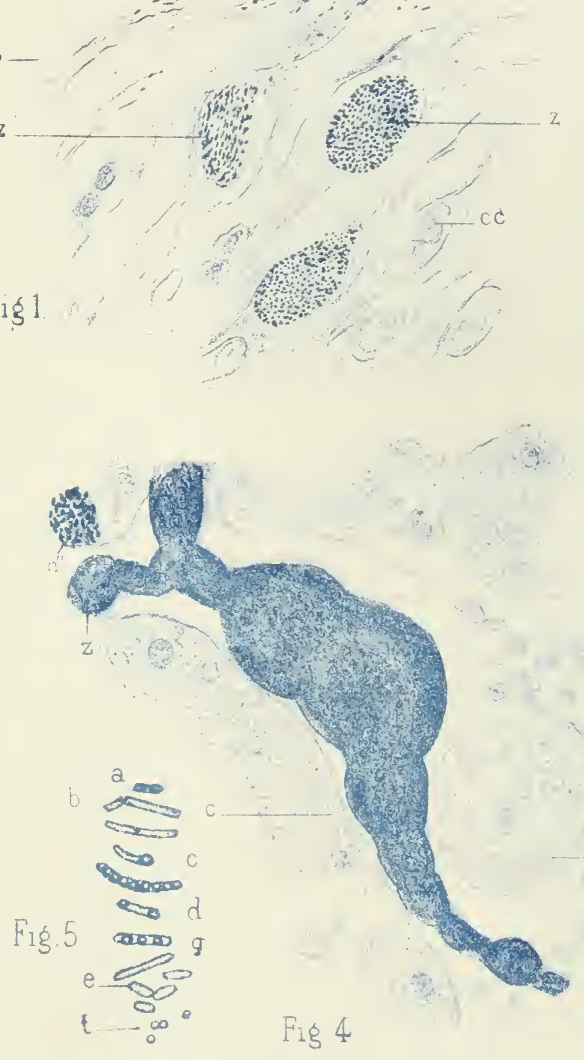

Fing 6

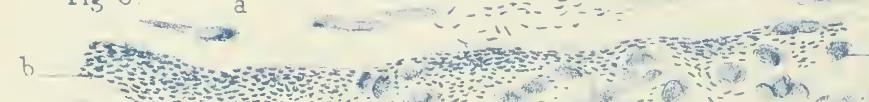

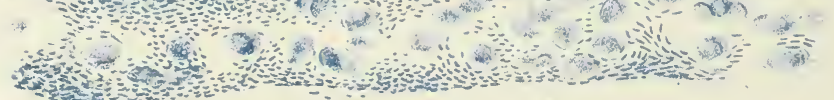
nision

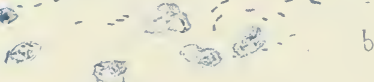

$$
\text { Eका }
$$
Fig 8 d

Fig 9.

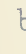

踏,

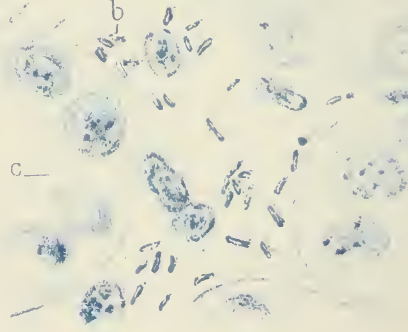

Cornil et Babes del.

hap I.emererer \& ("1e Paris

of 90)

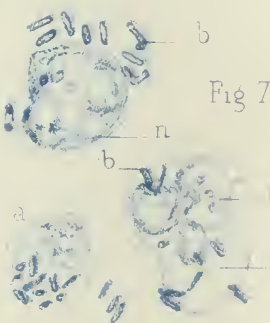




\section{PLANGHE IX}

ARthrite. - CARdite. - Néphrite infectieuse. - Jéquirity

Fıg. 1. - Cartilage altéré dans un cas de polyarthrite rhumatismale (grossissement, $1^{\mathrm{mm}}=5 \mu$.): $s$, surface du cartilage; $c$, cellules endothéliales libres; $b$, bactéries dans le liquide synovial ; $f$, fibres du tissu cartilagineux altéré; $c$, capsules contenant des cellules cartilagineuses; $z$, capsule remplie d'une zooglœe formée de microbes ronds; $z^{\prime}$, capsule remplie d'une zooglœe formée de bactéries allongées.

Fıg. 2. - Myocardite pyémique (grossissement, $\mathbf{1}^{\mathrm{mm}}=5$.) $: m$, fibres musculaires normales; $m^{\prime}$, fibres musculaires pigmentées ; $l$, leucocytes; $m^{\prime \prime}$, fibres musculaires gonflées par la présence d'une zooglœe dans leur sarcolemme; $a$, artère remplie d'une zoogloee; $v$, veine.

Fig. 3. - Rein dans le même cas; substance pyramidale (grossissement, $\left.1^{\mathrm{mm}}=0,09^{\mathrm{mm}}\right): c$, canalicules droits; $i$, foyers inflammatoires suivan $\mathrm{t}$ la direction des canalicules; $m$, vaisssau rempli de bactéries; $a$, abcès rempli de bactéries.

Fig. 4. - Rein dans un fait de méningite cérébro-spinale de Rigal et Chantemesse. $c c^{\prime}$, cellules des tubes urinifères altérées; $z$, zooglœe très dense contenue dans un vaisseau; $c^{\prime \prime}$, cellules d'un tube urinifère contenant des bàctéries.

FIg. 5. - Bactéries isolées provenant de l'infusion du jéquirity : $a$, petil bâtonnet; $b$, bâtonnets plus longs; $g$, bàtonnet rempli de spores; $d$, bâtonnet contenant un spore à chaque extrémité; $c$, bacille en battant de cloche; $t$, spore; $\epsilon$, bâtonnets courts. Grossissement de 1,000 diamètres.

Fıg. 6. - Vaisseau du mésentère d'une grenouille empoisonnée par l'infusion de jéquirity et rempli de bacilles : $a$, noyaux de cellules appartenant à la tunique adventice du vaisseau; $b, b$, bacilles en amas contenus dans le vaisseau; $b^{\prime}$, bacilles dans le tissu conjonctif du péritoine. Grossissement de 3 כ̋0 diamètres environ.

FIG. 7. - Trois cellules lymphatiques provenant du ganglion lymphatique du mésentère de la mème grenouille. $a, a, a$, protoplasma des cellules contenant des bacilles $b, b, b ; n, n, n$, noyaux des cellules. Grossissement de 800 diamètres.

Fig. 8. - Section du rein de la grenouille dans l'empoisonnement par l'infusion de jéquirity. Les vaisseaux capillaires inter-tubulaires sont dilatés et plus ou moins remplis de bactéries $b$; $c$, cellules épithéliales des tubes urinifères; $m$, granulations contenues dans la lumière des tubes. Grossissement de 600 diamètres.

Fig. 9. - Section du même rein au niveau d'un glomérule : $n$, paroi de la capsule de Bowmann; $c$, cellules plates de la capsule; $a$, cellules détachées de la capsule; $n$, cellule migratrice libre dans la capsule; $p$, cellule du revêtement des anses vasculaires du glomérule; $v$, $v$, vaisseaux du glomérule; $g$, globules sanguins; $b$, hactéries contenues dans le sang qui circule dans les anses vasculaires du glomérule. Grossissement de 800 diamètres. 


\title{
PLANGHE $X$
}

\author{
VARIOLE. - ERYSIPÈLE.
}

Fig. 2. - Coupe passant à travers la surface de l'épiderme soulevé au niveau d'une pustule de variole. $c$, cellules épidermiques cornées; $c^{\prime}$, cellules épidermiques aplaties; $c^{\prime \prime}$, cellules épidermiques dont le protoplasma est vésiculeux et qui ressemblent à des cellules végétales; $m, m^{\prime}$, noyaux de cellules du corps muqueux. $l$, cellule migratrice déformée; $a$, lacunes creusées au milieu du corps muqueux et contenant des microbes $b, b^{\prime}$, avec des cellules migratrices $l$. Les microbes sont souvent accolés au bord de ces lacunes. Grossissement de 500 diamètres. 0bj. $\frac{1}{12}$ de Zeiss.

Fig. 3. - Coupe à travers la muqueuse du larynx dans un cas de laryngite varioleuse. $b$, microbes siégeant à la surface de la muqueuse, dans le mucus $m$ et en particulier dans une dépression qui conduit dans le conduit excréteur d'une glande muqueuse. Les cellules épithéliales $c$ ont subi, à la surface, une dégénérescence muqueuse et sont caliciformes; leur protoplasma muqueux contient des microbes, $\mathrm{m}$. rm, revèlement épilhélial dans lequel on voil des cellules migratrices $\mathrm{cm}$. $v$, vaisseaux capillaires; $g$, conduit glandulaire. Même grossissement que dans la figure précédente.

Fig. 4. - Coupe du corps muqueux au niveau d'une pustule de vaccin de la vache. $b, b$, bactéries situées dans une lacune du corps muqueux avec des cellules migratrices déformées $l ; n, n^{\prime}$, noyaux des cellules du corps muqueux. Grossissement de 700 diamètres.

Fig. כ. - Coupe du derme dans l'érysipèle. On voit dans cette figure deux sections de vaisseaux lymphatiques siégeant au milieu d'un tissu fibreux enflammé. $b, b$, chainettes formées par de petits microcoques tous égaux eutre eux; $c$, cellule endothéliale. La majorité des cellules endothéliales est desquamée. Grossissement de 500 diamètres.

Fig. 6. - Section à travers le tissu cellulo-adipeux sous-cutané dans l'érysipèle. $c g$, cavité primitivement occupée par une gouttelette de graisse; $\iota$, bactéries de l'érysipèle qui ont pris la place de la cellule adipeuse dont il reste deux noyaux à la gauche de la cavité; $m g$, tissu conjonctif; $b$, bactéries situées entre les faisceaux de ce tissu. Grossissement de 800 mètres.

Fıg. 7. - Coupe du derme dans l'érysipèle. Les chaînettes $b, b^{\prime}$, de l'érysipèle sont situées dans les voies lymphatiques entre les faisceaux du derme;,$l l$, cellule plasmatique limitant une de ces fentes lymphatiques. Grossissement de 800 diametres. 


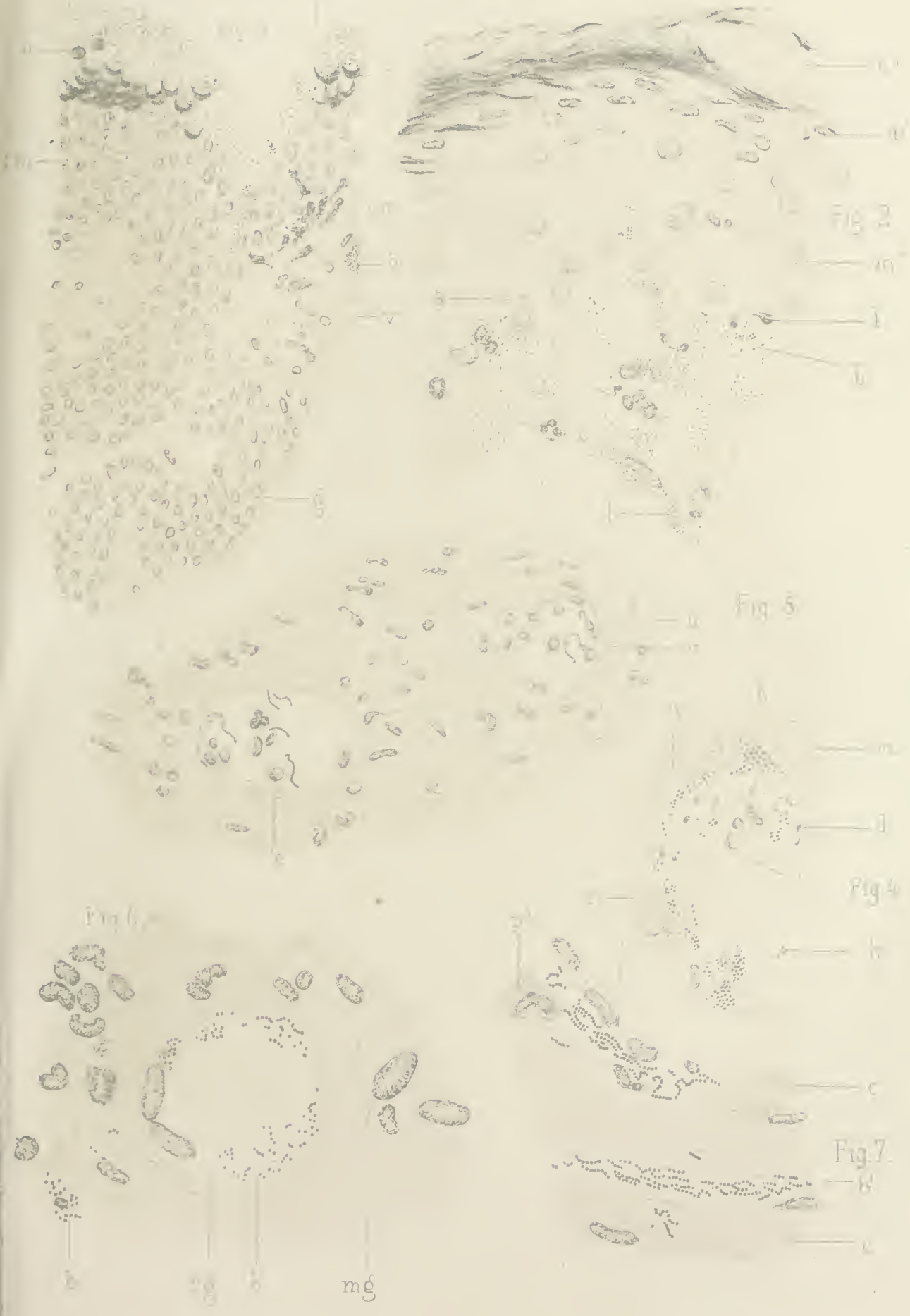







\section{P'LANGHE XI}

VARIOLE.

Fig. 1. - Vue d'ensemble d'une pustule. La figure représente une coupe de la peau perpendiculaire à sa surface. $a$, partie superficielle du corps muqueux de Malpighi qui est devenue homogène, hyaline, et qui s'est creusée de lacunes remplies en $a^{\prime}$ de cellules migratrices. $d$, cellules de la couche granuleuse; $c, c$, l'épiderme corné dont la couche profonde représente le stratum lucidum. Les microbes $b, b$, siègent dans certaines lacunes du corps muqueux assez rapprochées de la couche granuleuse. Dans les cloisons interlacunaires du corps muqueux, on voit en $h$ des cellules hyalines, globuleuses. A la périphérie de la pustule, on voit en $\mathrm{cm}$ des cellules du corps muqueux en voie de division par kariokinèse. Des cellules globuleuses très tuméfiées provenant du corps muqueux se trouvent parfois libres dans les alvéoles, comme en ch. Les cellules du corps muqueux situées à la périphérie de la pustule $c a$ sont très riches en éléidine; elles montrent aussi comme en $c^{\prime \prime \prime}$ l'apparence de cellules végétales. Il en est de même des îlots de cellules au début de la pustulation comme en $e$. Les papilles $p, p$ sont hypertrophiées et infiltrées de cellules migratrices dans toute l'étendue de la pustule, d'autant plus qu'on se rapproche de sa partie centrale; ces cellules migratrices sont surtout abondantes autour des vaisseaux des papilles ou de leur' base comme en vo. Entre les papilles hypertrophiées, le corps muqueux envoie des prolongements $g$ qui pénètrent profondément. A la limite des papilles et des cellules du corps muqueux il existe des fentes qui présentent des bactéries rondes. Grossissement de 200 diamètres. 


\title{
PLANCHE XII
}

\author{
PNEUMONIE RUBÉOLIQUE.
}

Fıg. 1. - Hépatisation gris jaunâtre en partie caséeuse consécutive à la rougeole. Grossissement de 15 diametres environ. $p l$, plèvre couverte et remplie des bactéries $b$; $t i$, tissu interlobulaire œdémateux embryonnaire contenant des vaisseaux sanguins $v$ el des vaisseaux lymphatiques dilatés $l$ souvent remplis de bactéries en zooglœe; $k$, masses hyalines dans le tissu interlobulaire; $c b$, bactéries infiltrées dans la partie centrale du tissu interlobulaire qui est infiltré de fibrine; $v^{\prime}$, petile artère oblitérée par un caillot étoilé ; $t i^{\prime}$, tissu inflammatoire pénétrant entre les alvéoles et produisant un épaississement considérable des cloisons interalvéolaires; $a$, alvéoles; $b^{\prime}$, microbes dans la fibrine qui renıplit la plupart des alvéoles.

Fig. 2. - Contenu des alvéoles d'un îlol gris jaunâtre pulpeux dans cette pneumonie: $e a$, épithélium des alvéoles; $e a^{\prime}$, une cellule épithéliale en voie de destruction par l'invasion des bactéries; $c b$, cellule presque tout à fait détruite par les bactéries ; $c b$, cellules épithéliales des bronches; $b$, bactéries dans leur disposition caractéristique en $8 ; b^{\prime}$, les mêmes formant des chapelets (600 diamètres).

Fig. 3. - Tissu interlobulaire infiltré par de la fibrine coagulée et par des bactéries. Grossissement de 600 diamètres environ. $l$, vaisseau lymphatique avec des cellules endothéliales gonflées; $f$, fibrine coagulée; $f^{\prime}$, fibres du tissu conjonctif; $c$, cellules infiltrées dans ce tissu; $g$, gouttelettes de graisse; $g^{\prime}$, globules rouges du sang; $b$, bactéries; $z$, zooglœe des mêmes bactéries (600 diamètres).

Fig. 4. - Un vaisseau pulmonaire. Grossissement de 600 diamètres. $f$, cellules multipliées de la paroi; $e$, cellules endothéliales; $z$, masses des bactéries en zooglœe, remplissant la lumière du vaisseau.

Fig. 5. - Sang pris dans la peau de la face, affectée par la rougeole, desséché et coloré avec la fuchsine. Grossissement de 1,000 environ ( $\mathrm{n}^{0} 10$ imm. homog. de Vérick, chamb. cl.). $g$, globules rouges; $l$, globules blancs; $b$, bactéries en $8 ; b^{\prime}$, les mêmes formant de courts chapelets.

Fig. 6. - Mucus catarrhal du nez, pris au commencement de l'éruption rubéolique. Grossissement de 700 environ, chamb. claire. $\mathrm{m}$, mucus; $\mathrm{cm}$, cellules muqueuses; $c$, cellule cylindrique; $b$, bactéries caractéristiques surtout en $8 ; b^{\prime}$, bactéries plus grandes et allongées. 


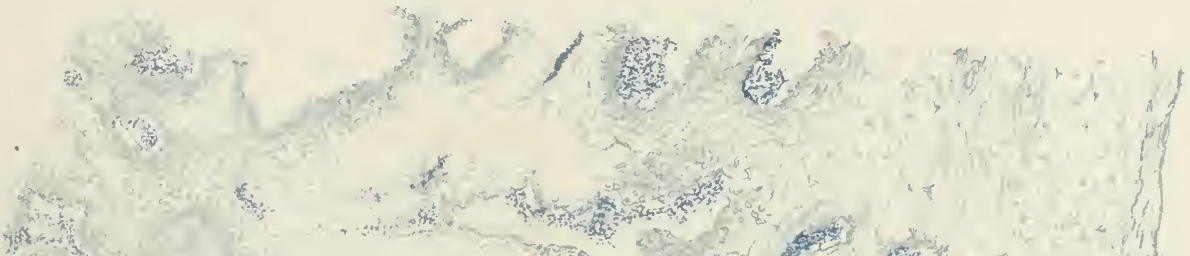

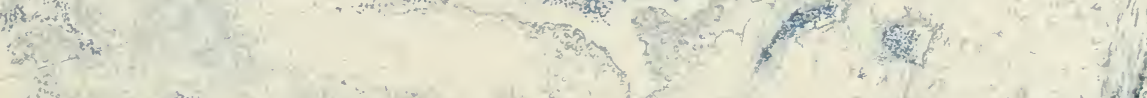
की (4)
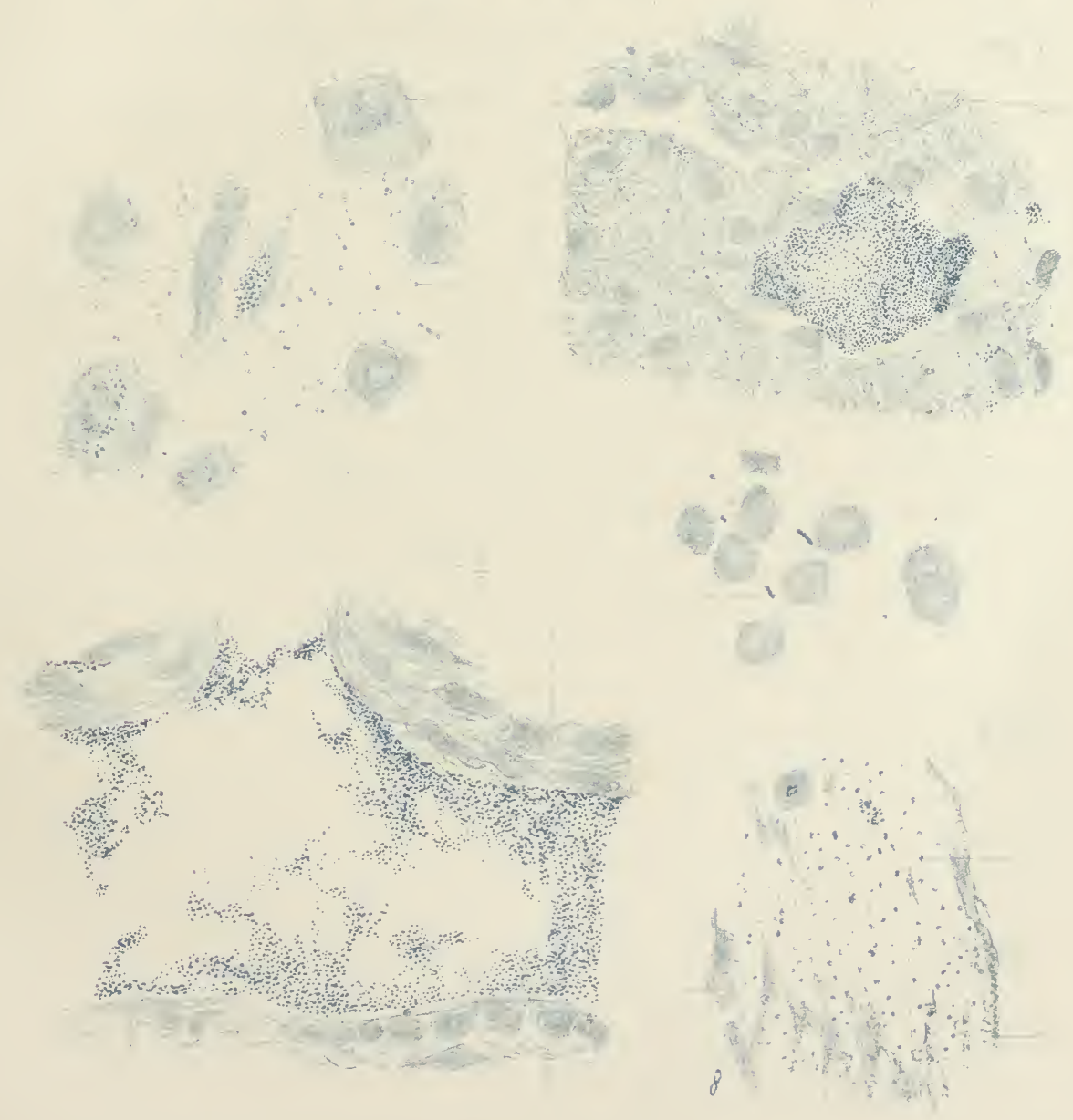


$x_{2} \quad x^{2}$

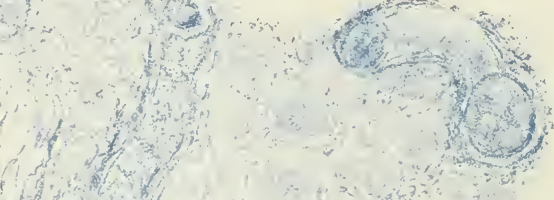

\section{(a) $x)$ \\ 1.}

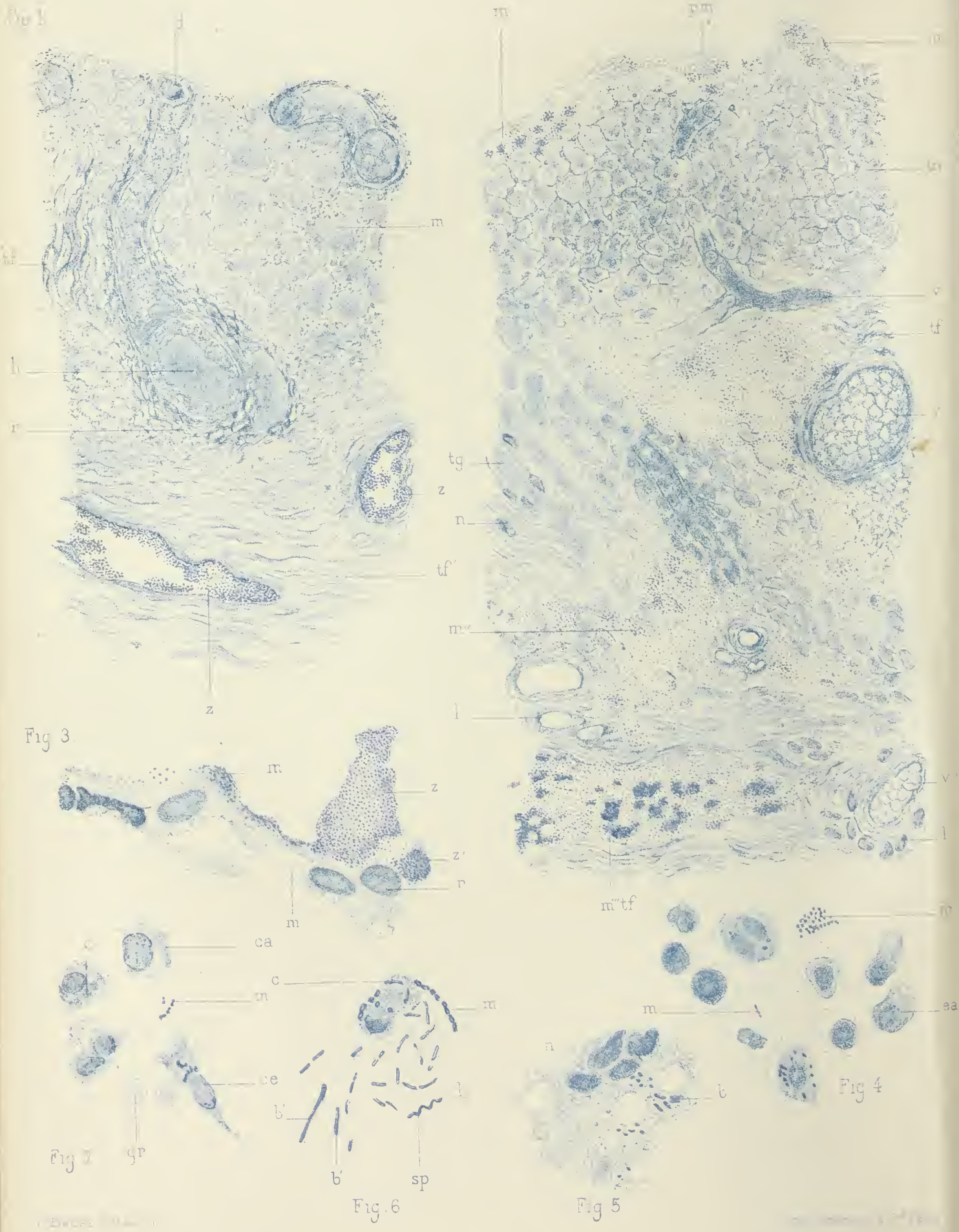

Fig 3
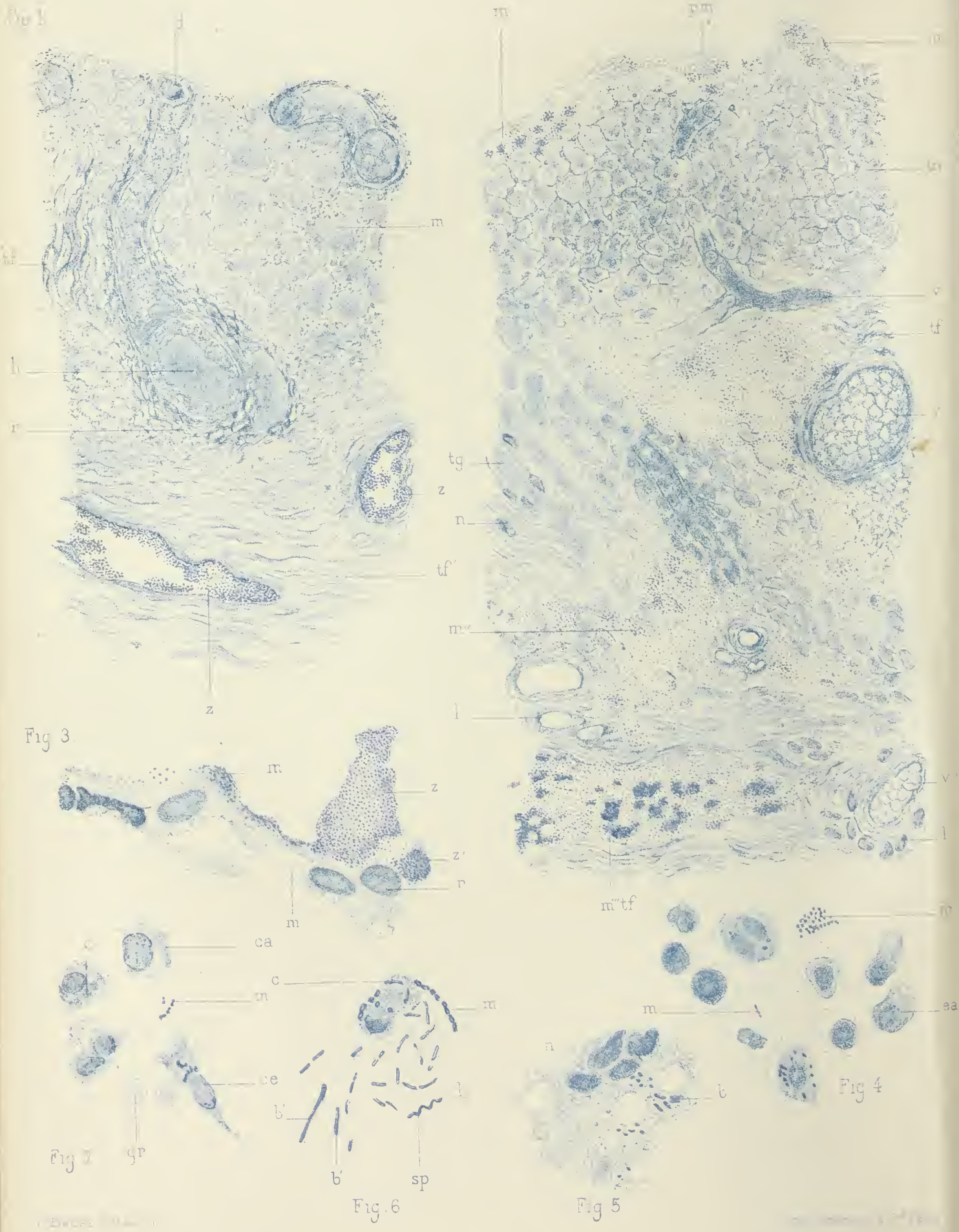

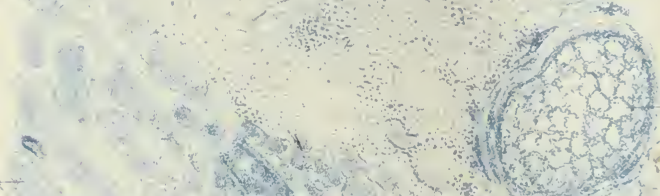
(1)

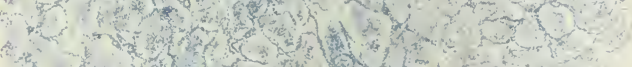

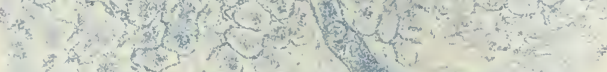
$x_{0} x^{2}$ the al $x^{2}$

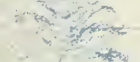

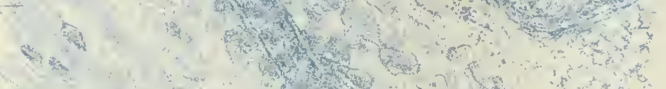
th efond bet and

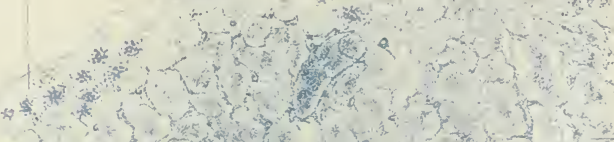

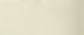




\title{
PLANCHE XIII
}

\author{
DIPITHÉRIE. - DYSENTERIE.
}

Fig. 1. - Partie postérieure du larynx dans la diphthérie. L'épithélium et la couche superficielle sont remplacés par une pseudo-membrane renfermant des masses hyalines $(h)$ et des parties superficielles des glandes muqueuses $(g)$. $-r$, réseau brillant autour de la glande; $f f$, lissu fibreux devenu brillant, rigide. Les vaisseaux, dans la profondeur de la muqueuse, sont remplis de masses zooglœiques $z, z$.

Fig. 2. - Partie du larynx dans la diphthérie consécutive à la rougeole. - $t n$, pseudo-membrane formée par des masses homogènes arrondies et montrant à sa surface des microbes $m, m^{\prime}$; $v$, vaisseau sanguin pénétrant dans la pseudo-membrane et rempli d'une masse hyaline; $v^{\prime}$, vaisseau sanguin dans la profondeur de la muqueuse rempli d'un réticulum grenu; $t \rho$, tissu fibreux sous la pseudo-membrane; $t g$, glande remplie et entourée de grandes cellules homogènes; $m^{\prime \prime}$, microbes disséminés dans le tissu pâle de la muqueuse; $v^{\prime \prime}$, vaisseau sanguin du tissu sous-muqueux; $m^{\prime \prime \prime}$, microbes en grandes masses à la limite du tissu mortifié diphthéritique.

Fıg. 3. - Pseudo-membrane diphthéritique desséchée et colorée par le violet de méthyle 3 B. $-n$, noyaux; $z$, zooglœe à petits microbes; $z^{\prime}$, petite zooglœe formée par des microbes plus gros. Grossissement de 500 diamètres.

Fig. 4. - Raclage desséché du poumon affecté de pneumonie catarrhale du même individu (grossissement : 500 diamètres). - e e cellules épithéliales des alvéoles; $m$, microbes en amas; $m^{\prime}$, microbes en chapelets ou deux à deux; $c$, cellule alvéolaire remplie de bactéries.

Fıg. 5. - Raclage de la diphthérie circonscrite de la langue. - n, noyaux ; $b$, bâtonnets. Grossissement de 500 diamètres.

Fig. 6. - Dysenterie, raclage de la muqueuse du rectum. - cellule grenue contenant différentes espèces de bactéries; $m$, grands microbes en chapelet; $b$, bàtonnets assez longs, foncés, homogènes; $b$, fins bâtonnets pâles ; $s p$, spirilles. Grossissement de 500 diamètres.

Fig. 7. - Raclage du poumon atteint de pneumonie catarrhale chez le même individu. - gr, globules rouges du sang; ea, endothélium des alvéoles; $c e$, cellules à cils vibratils des bronches; $m$, microbes en chapelets ou deux à deux. Grossissement de 500 diamètres. 


\title{
PLANCHE XIV
}

\author{
ennogardite ulgéreuse ou bactérienne. - DipHThÉrie de la peau.
}

Fıg. 1. - Coupe d'une valvule sigmoïde de l'aorte près de son implantation sur l'anneau fibreux $a$. Dans le muscle cardiaque, $m$, on voit des cellules en assez grande quantité autour des vaisseaux. A la surface de la valvule, soit du côté du ventricule, soit du côté de l'aorte, il existe des bourgeons $p$ dans l'intérieur desquels on voit des colonies de bactéries $s v$, qui sont colorées en bleu plus foncé que le reste de la préparation. Quelques colonies se montrent aussi dans le tissu de la valvule près de l'anneau fibreux. En $f$, on voit une fente qui résulte de la chute d'une partie mortifiée, remplie de bactéries et l'on apercoit des bactéries tout le long de cette perte de substance. Grossissement de 40 diamètres.

F1G. 2. - Une portion d'un bourgeon de la même valvule examiné à un fort grossissement (objectif $\frac{1}{20}$ de Reichert). On constate à la surface de ce bourgeon un réseau formé d'une substance homogène creusée de vacuoles $v$, dans lesquelles il y a des bactéries. Les colonies les plus volumineuses existent à une certaine distance du bord du bourgeon, et les vacuoles qui les contiennent sont aussi limitées par une substance homogène.

Flg. 3. - Les mêmes bactéries dessinées à un très furt grossissement. Parmi ces bactéries, les unes sont rondes, les autres sont allongées sous forme de bâtonnets courts, terminés par une extrémité conique ou pointue, les autres sont des diplococci; $g r$, globule rouge du sang modifié.

Fig. 4. - Coupe de la peau dans un cas de diphthérie de la vulve: $d$, surface de la fausse membrane qui occupe la place de l'épiderme. La fausse membrane est soulevée à droite de la figure et laisse à nu les papilles $p$. On voit une première zone superficielle de bactéries $b$, et au-dessous une couche plus épaisse $b^{\prime}$. Les papilles $p$ montrent aussi des bactéries. Il en existe à l'orifice et dans la profondeur du follicule pileux; $v$, vaisseau et $g$, tissu adipeux du derme. Grossissement de 40 diamètres.

Fig. 5. - Coupe de la partie superficielle de la pseudo-membrane $e$, montrant de petits bacilles $b$ situés à sa surface et dans une fente placée entre les fibres de fibrine. En $b$, à gauche et en bas de la planche, on voit les bacilles précédents et des microcoques dessinés à un grossissement considérable, à 2000 diamètres environ. 




$$
\therefore
$$
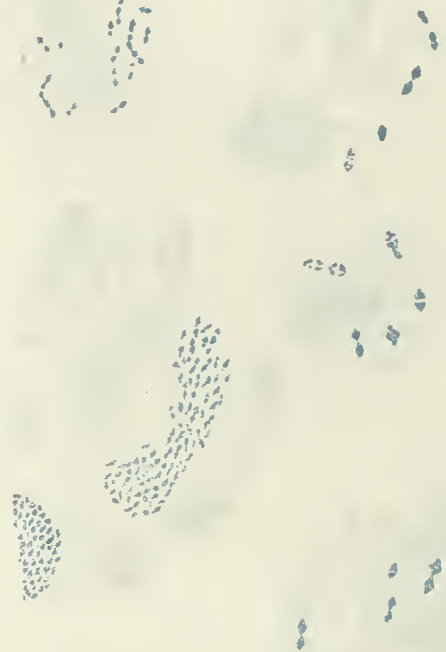

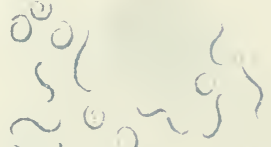

$e^{1} e^{-3} e^{2} e^{2}$

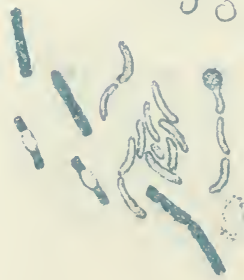

$$
\text { की }
$$

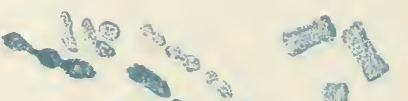

- 11 . - 15
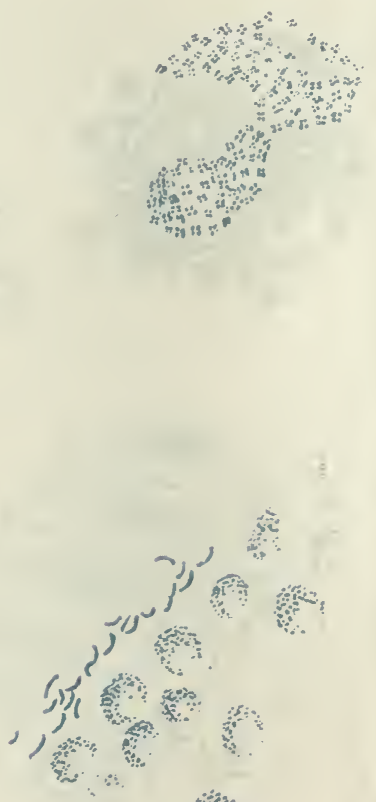

: 


\section{PLANCHE XV}

\section{PNEUMONIE AIGUE. - CHOLÉRA.}

Fig. 1. - Exsudat oblenu par le raclage du poumon atteint de pneumonie aiguë : $f$, fibrine; $n$, une cellule granuleuse; be, bactéries de la pneumonie avec leurs capsules. Grossissement de 600 diamètres.

Fig. 2. - Coupe d'une travée interlobulaire dans un cas de péripneurnonie aiguë chez l'homme : $t i$, tissu interlobulaire enflammé, phlegmoneux; $v$, vaisseaux sanguins remplis de sang; $v^{\prime \prime}$, vaisseaux lymphatiques remplis de cellules lymphatiques; $v^{\prime}$ vaisseau du poumon entouré de tissu embryonnaire; $a$, tissu pulmonaire dont les alvéoles contiennent de la fibrine. Grossissement de 60 diamètres.

- Fig. 3. - Cocci en chaînettes dans un cas de méningite accompagnée de pneumonie aiguë (400 diamètres).

FIG. 4. - Diplococci provenant d'une pleurésie aiguë concomitante d'une pneumonie (600 diamètres).

FIG. כ. - Pseudo-membrane attenant au péricarde viscéral dans un fait de péricardite compliquant une pneumonie aiguë. $b v$, bourgeon vasculaire pénétrant dans la masse fibrineuse; $n$, noyau d'une cellule embryonnaire; $a$, zooglœe ronde formée de bactéries; il existe une autre zooglœe allongée, formée de cocci et de diplococci allongés et lancéolés au milieu de cette figure. Grossissement de 400 diamètres.

Fig. 6. - Une partie dı tissu conjonctif interlobılaire enflammé dans la pneumonie. Au centre de ce dessin se tronve une cellule d'où part un réseau de fibrilles de fibrine, qui renferme dans ses mailles des diplocoques lancéolés et capsulés caractéristiques.

Fig. 7. - Micrococius tetragenus de Koch, provenant d'une culture du contenu d'une caverne tuberculeuse. La culture a été injectée à une souris. La figure 7 représente une coupe de la rate de cette souris. On y voit des masses de microbes en tétraèdres; $v$, vaisseau sanguin; $c$, cellules de la rate; $r$, réseau du tissı splénique épaissi.

Fig. 8 - Coupe d'une partie de l'appendice cœeal dans un cas de choléra: $b$, surface de l’intestin montrant diverses espèces de bactéries; $s$, tissu hyalin superficiel avec des espaces contenant de grandes quantités de petits bacilles, ge, glande avec ses cellules épithéliales confluentes et vitreuses. Les bacléries pénètrent dans une fente entre les cellules épithéliales et la membrane basale de la glande; $t r$ tissu réticulé situé dans la profondeur de la muqueuse. Grossissement de 300 diamètres.

Fig. 9. - Coupe de la partie inférieure de l'intestin, au niveau d'une glande, daus le choléra aigu : $c v$, cellules épithéliales tuméfiées et hyalines d'une glande de Lieberkühn. Entre les cellules et le tissu reticulé de la muqueuse, on voit une quantité de bacilles en virgule. La muqueuse renferme beaucoup de cellules granuleuses de Ehrlich, $\mathrm{cr}$.

Fig. 10. - Bacilles en virgule dans une culture pure avec un grossissement de 13000 diamètres.

FIG. 11. - Liquide intestinal de cobaye renfermant une grande quantité de vibrions ou monades $v$.

FIG. 12. - Bactéries trouvées dans les selles dans un fait de choléra nostras (1 200 diamètres); $b$, bàtonnets droits normaux; $v$, vibrions en forme de virgule, formant quelquefois des chaînettes ondulées et montrant de grosses spores $s$.

Fig. 13. - Diverses formes de bactéries trouvées dans la pneumonie, l'endocardite et la pleurésie, dessinées à un très fort grossissement $(2000$ diamètres environ). $a, b, c, d, e, k, i, k$, diverses formes de cocci, diplococci et chainettes, capsulés ou non, provenant de la pneumonie aiguë et des maladies qui la compliquent; $e$, bactéries pathogènes trouvées dans le pus d'une pleurésie purulente septique; $r$, bacilles courts provenant d'un cas de gangrène spontanée des poumons où ils étaient à l'état de culture pure; $0, p, q$, diverses formes de bactéries prises dans une autopsie d'endocardite ulcéreuse de la valvule mitrale quelques heures après la mort. 


\title{
PLANCHE XVI
}

\author{
hÉpatite de la fièvre JaUne. - Néphrites infectieuses.
}

Fig. 1. - Coupe transversale du foie d'un individu mort de la fièvre jaune (Zeiss, ocul. 3, obj. 1/12 imm. hom.) : cb, canalicule biliaire contenant des noyaux proliférés; $t c$, tissu conjonctif épaissi, embryonnaire; $c p$, cellules plasmatiques situées à la limite des lobules; $h c$, cellules hépatiques contenant des gouttes de graisse; $p$, pigment jaune à la limite des cellules ; $s$, globules du sang dans des capillaires intralobulaires; $g$, grains hyalins dans ces vaisseaux.

Fig. 2. - Une autre partie de ce foie avec un plus fort grossissement (ocul. 4) : le noyau de certaines cellules hépatiques est atrophié, irrégulier; $g$, grains hyalins situés dans les vaisseaux.

Fig. 3. Une partie du foie à la périphérie des foyers inflammatoires : $p$, pigment dans les cellules $\mathrm{ch} ; \mathrm{cm}$, capillaire intralobulaire dilaté, rempli de filaments de microbes.

Fig. 4. - Lésion de la substance médullaire du rein, dans la fièvre jaune : $t c$, tissu conjonctif épaissi ; $v$, petite veine; $s$, capillaire rempli de sang; $g$, goutles faiblement colorées dans le tissu conjonctif; $t$, tubuli avec des cellules gonflées et granuleuses; $t^{\prime}$, tubuli avec des cellules détachées et contenant des cylindres hyalins ; $t^{\prime \prime}$, canalicules droits dont le protoplasma contient de petits grains colorés; $t^{\prime \prime \prime}$, canalicules contenant du pigment et des gouttes hyalines.

Fig. 5. - Partie de la limite d'un petit foyer inflammatoire de la substance corticale (grossissement, Vérick, ocul. 1,obj.8) : c, état embryonnaire du tissu conjonctif; $s$, globules du sang dans les capillaires. Entre les globules rouges, on remarque quelques grains très petits, fortement colorés ; $t$, tubuli contorti remplis de masses granuleuses, provenant d'une dégénérescence moléculaire des épithéliums; $t^{\prime}$, tubule droit contenant un cylindre hyalin; $t^{\prime \prime}$, tube contenant un cylindre formé en partie de petits grains hyalins; $t^{\prime \prime \prime}$, tube contenant un cylindre formé seulement de petits grains; $t^{\prime \prime \prime}$, tube contenant des masses fortement colorées et confluentes; $t \mathrm{v}$, tube contenant du pigment et de petites masses allongées et colorées.

Fig. 6. - Cylindre fortement coloré, framboisé, dans un tube contourné.

Fig. 7. - Affection rénale parenchymateuse et hémorrhagique d'origine bactérienne : $c$, capillaire rempli de sang et de diplococci formant par place de petites chaînettes entre les globules rouges; $c^{\prime}$, accumulation des microbes tapissant la paroi d'un petit vaisseau, $a$, coupe d'un tube en anse de Henle; $t$, tubule contourné, dilaté, montrant une multiplication, un état granuleux et un détachement des cellules épithéliales el renfermant un cylindre jaune $c p$, formé de masses rondes de dimensions différentes. 


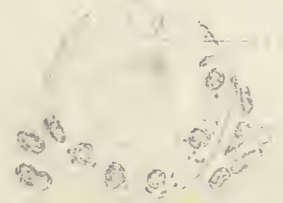

$$
\text { 17. }
$$

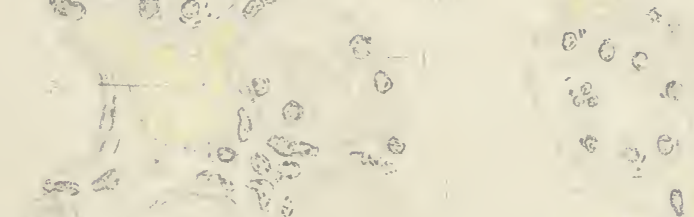

$\theta$

की

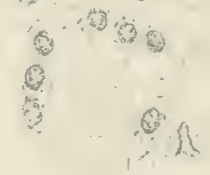

is

s

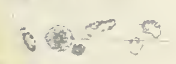

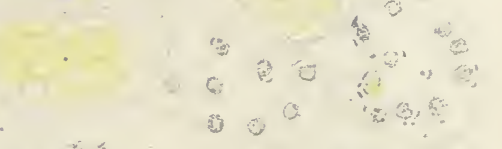

(1) $\Leftrightarrow$ 0.000
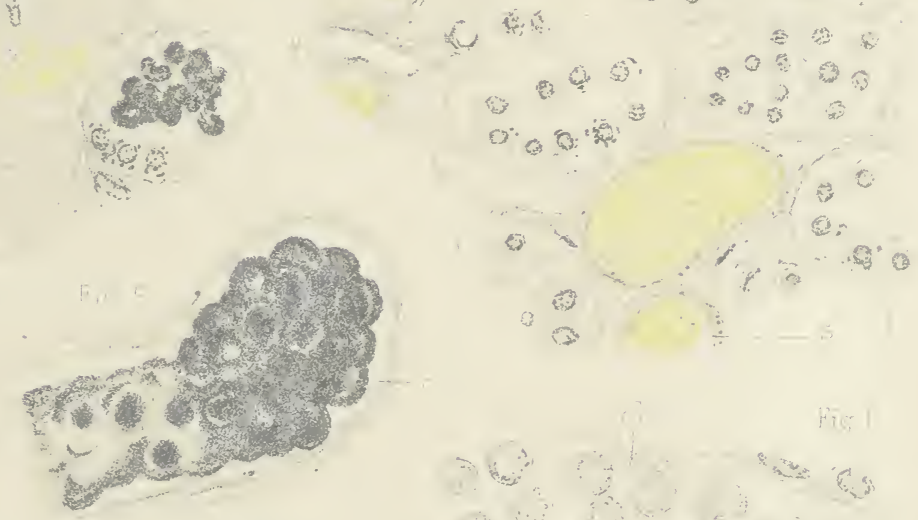

3

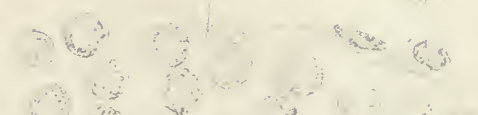
(6.) $3 \times$
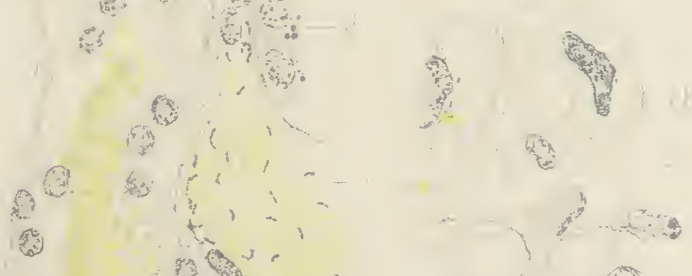

繁

*6
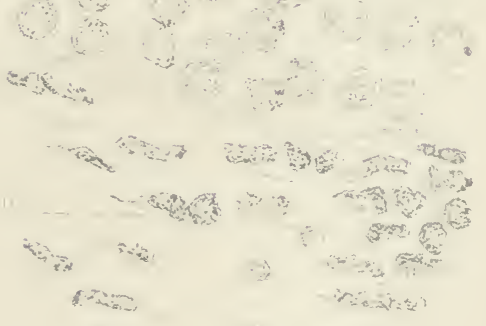

恼

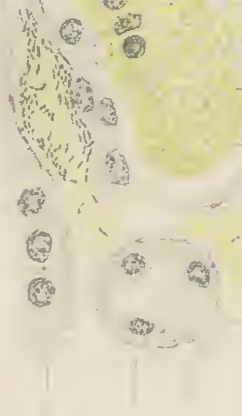





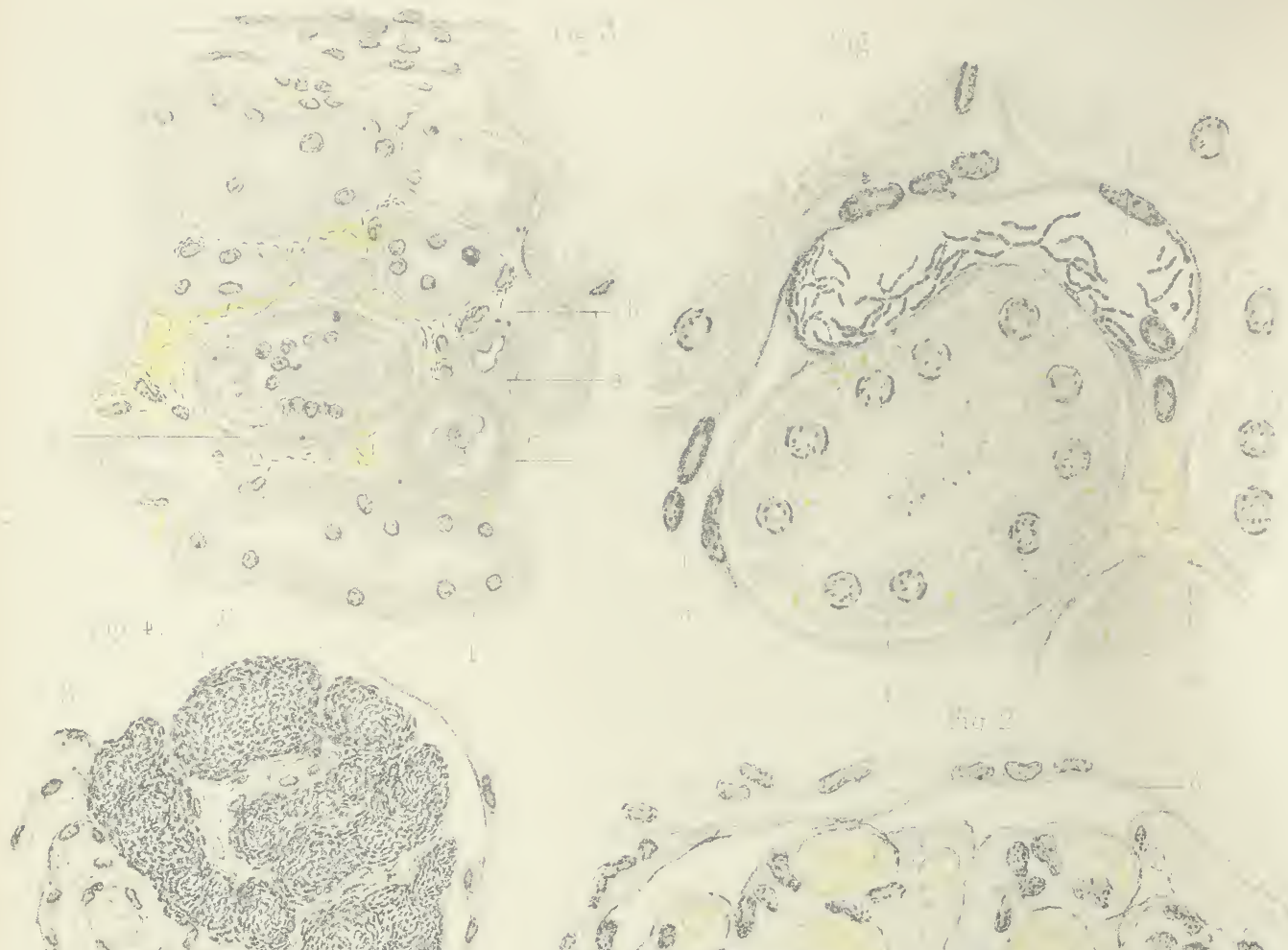

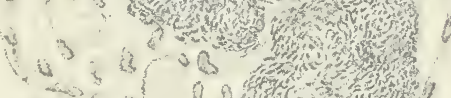

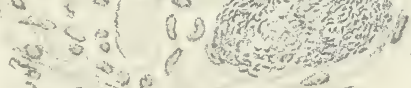

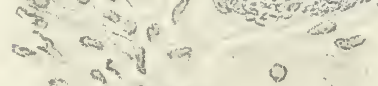
$\therefore$ की 0 व

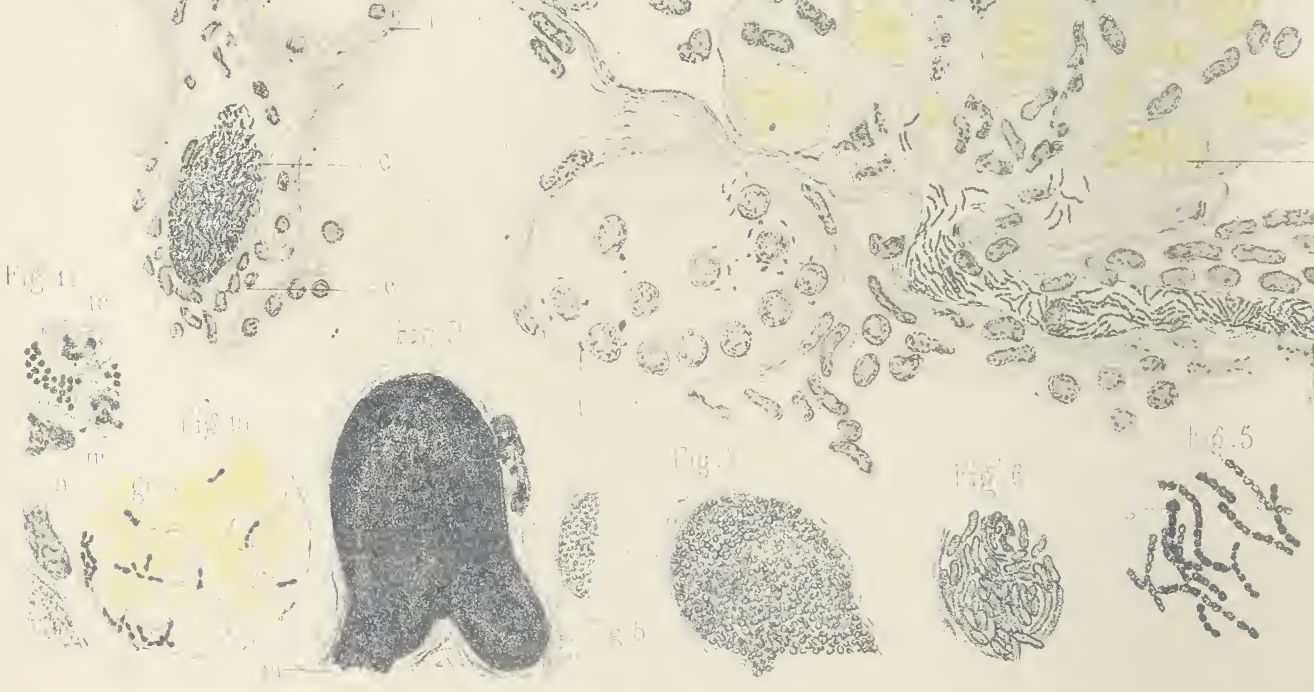

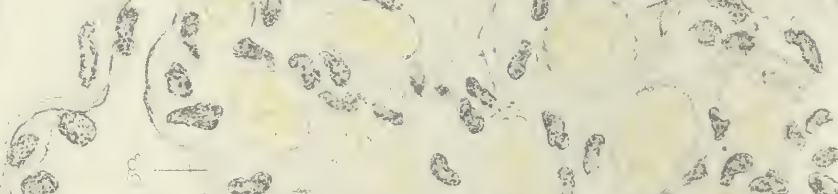
6

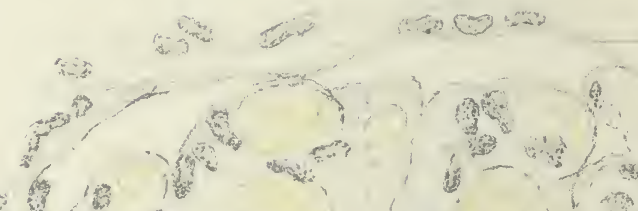
i)

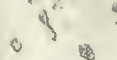
at और 95 की 


\title{
PLANCHE XVII
}

\author{
NÉPURITES INFEC'TIEUSES. - FIÈvRE JAUNe.
}

Fig. 1. - Coupe transversale du rein, dans la fièvre jaune, à la limite d'un petit foyer inflammatoire (grossissement, Vérick, oc. 3, obj. 1 im. hom.). Autour des capillaires, $c$, les cellules du tissu conjonclif sont multipliées; les capillaires contiennent ordinairement du sang, $s$; ils sont parfois extrêmement dilatés $c^{\prime}$, et renferment des filaments bactériens composés de diplococci; $t$, tubule contourné dont les cellules tuméfiées, granuleuses, montrent à leur partie centrale des vacuoles. Dans leur intérieur, il y a des masses granuleuses qui sont séparées par des vacuoles.

Fig. 2. - Glomérule dans la fièvre jaune (grossissement, Zeiss. ocul. 3, ob. imm. hom. 1/12) : c, capsule du glomérule; les éléments de la paroi et les cellules qui la tapissent sont gonflés; $g$, anses du glomérule pleines de sang, montrant une prolifération de leurs noyaux; $m$, arlère afférente, remplie de filaments bactériens serrés et fortement colorés ; le tissu conjonctif est proliféré autour de ce vaisseau; $t$, tubule rempli de cellules épithéliales.

Fig. 3. - Rein dans la septicémie de la souris de Koch (grossissement, Verick, ocul. 2, obj. 8): c, capsule fibreuse du rein; $t$, tubule dont l'épithélium est granuleux; t', tube avec une dégénérescence vitreuse de l'épithélium; on trouve des gouttes hyalines dans son intérieur; $g$, glomérule; $b$, bacilles circulant dans le sang des capillaires; $a$, artère.

FIg. 4. - Néphrite diffuse parenchymateuse, bactérienne : e, état inflammatoire du tissu interstitiel; $t$, tubuli dont les cellules sont confluentes et manquent souvent de noyaux; $g$, glomérule; $g^{\prime}$, la plus grande partie du glomérule dont les anses sont extrêmement dilatées et remplies d'une zooglœe de bacilles; c, vaisseau capillaire rempli des mêmes bactéries.

Fig. 5 et suivantes. - Ces figures sont dessinées avec un grossissement de plus de 1,000 diamètres (Verik, ocul. 3 obj. 10 à imm. homog., tube tiré.) Figure 5, bactéries trouvées dans ỉa fièvre jaune. Figure 6, les mêmes bacilles que dans la figure 4. Figure 7, les microbes de la figure 3. Figure 8, ceux d'une néphrite complexe contenant aussi des bacilles. Figure 9, masses zooglœiques dans les capillaires du rein dans un cas de méningite. Figure 10, les mêmes microbes situés dans le sang que ceux de la figure 7 (PL.XIV): gr, globules rouges; $n$, noyaux du tissu conjonctif. La figure 11 représente de grands microbes ronds trouvés dans le tissu inflammatoire du rein dans un fait d'arthrite foudroyante. 


\title{
PLANCHE XVIII
}

\author{
JÉQUIHITY. - NÉPHRITES INFEGTIEUSES.
}

F'ı. 1. - Microbes tels qu'on les voit dans la décoction du jéquirity : $a$, microbes en battant de cloche; $b$, bàtonnet avec une spore; $c$, deux petits bàtonnets articulés; $d$, long bâtonnet; $c$, deux longs bàtonnets soudés; $s$, bâtonnets contenant des spores. Grossissement de 600 diamètres.

Fig. 2. - $-v$, section d'une branche interlobulaire de la veine porte chez un lapin, empoisonné par la décoction de jéquirity; $f$, filaments de fibrine; $b$, bactéries comprises dans le réticulum de fibrine; $c$, cellules endothéliales; $a$, cellules du foie; $t$, tissu conjonctif périvasculaire; $n$, noyaux de cellules endothéliales.

Fig. 3. - v, vaisseau capillaire intralobulaire contenant des bacilles $b$ dans le même empoisonnement; $a, a$, cellules du foie.

Fig. 4. - Deux vaisseaux capillaires intralobulaires $v$ contenant des bacilles $b ; a$, cellules hépatiques.

FIG. 5. - Coupe du foie normal : $v$, $v$, vaisseaux; $a$, cellules hépatiques ; $n$, noyaux.

Fig. 6. - Empoisonnement par la décoction de jéquirity. $v$, $v$, vaisseaux capillaires intralobulaires remplis de cellules lymphatiques atrophiées $d$, et de granulations $e$; les cellules hépatiques $a$ présentent des vacuoles $m$ creusées dans leur protoplasma.

Fig. 7. -- Petit foyer inflammatoire conique de la périphérie du rein, dans la fièvre jaune (grossissement $1^{\mathrm{mm}}, 0,01^{\mathrm{mm}}$ ); $c$, capsule du rein; $t i$, tissu inflammatoire avec des vaisseaux dilatés $v$, et des tubes remplis de cylindres hyalins ou framboisés $t, t^{\prime \prime} ; g$, glomérule situé au sommet du foyer inflammatoire; $b$, petits vaisseaux dilatés remplis de filaments bactériens; les tubuli voisins sont très altérés.

Fig. 8. - $g$, glomérule dans un cas d'ostéomyélite (gross. $1^{\mathrm{mm}}=5$ $u$ ). L'artère afférente a et une grande partie des anses dilatées sont remplies par une zooglœe de grands microbes ronds $z ; g$, grains fortement colorés dans la partie centrale des épithéliums des tubuli $t$. 


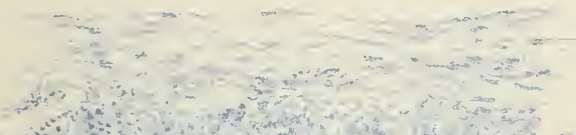

$x_{2} x^{2}$ is

*

.

(4)

3. +20

Hat

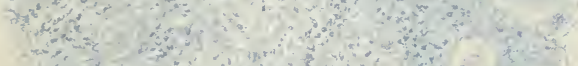

$\int_{1}^{4}$ os

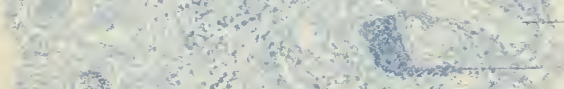

a 3 of

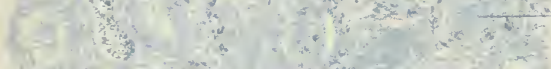

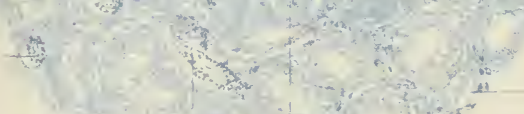
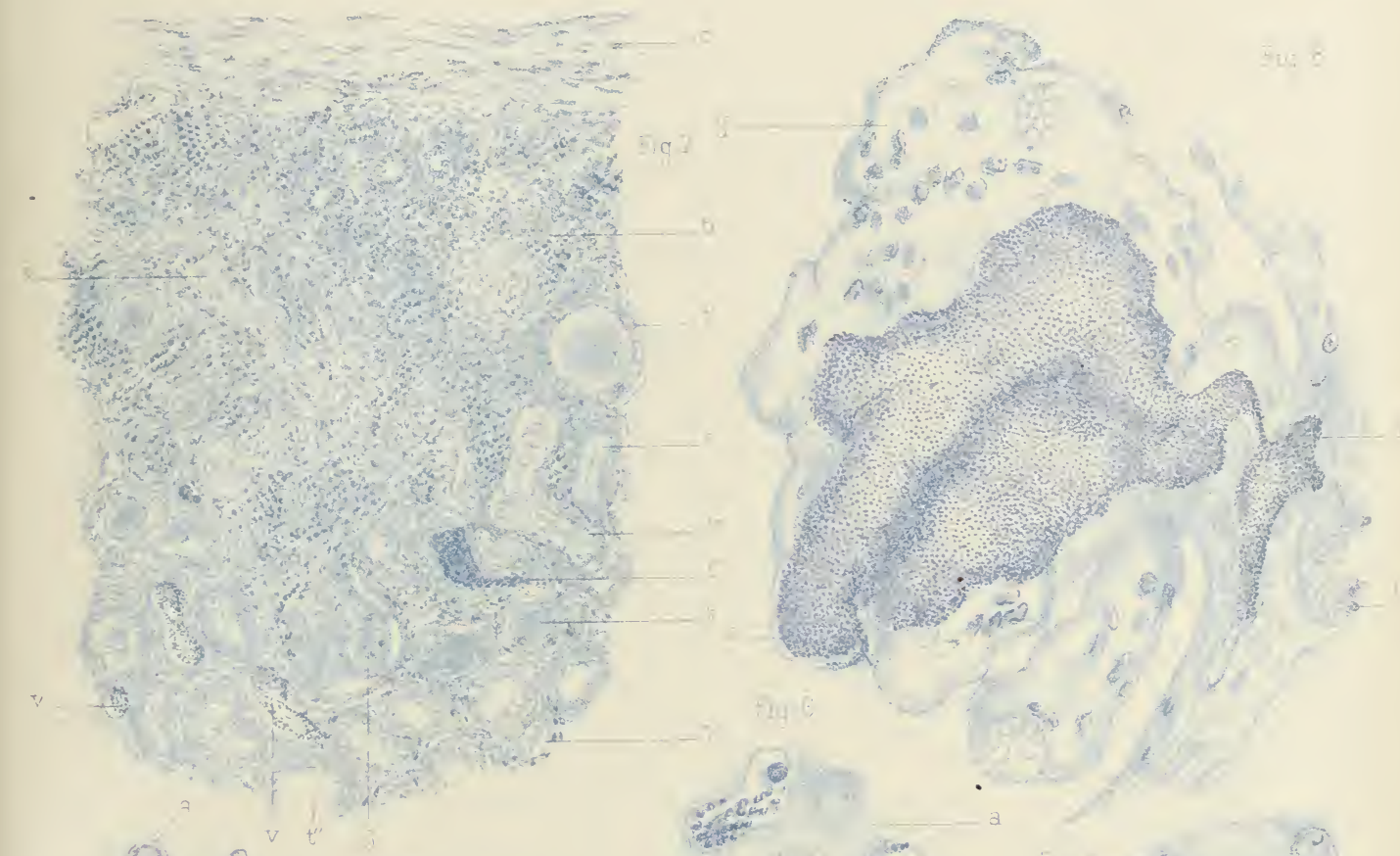

(2)

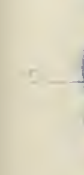

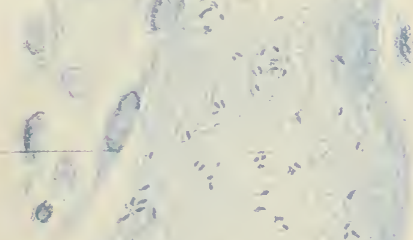

)

$6 \quad \div$

f.

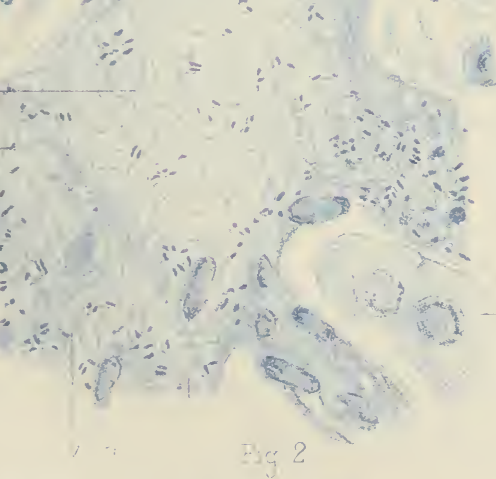

$F_{g}$
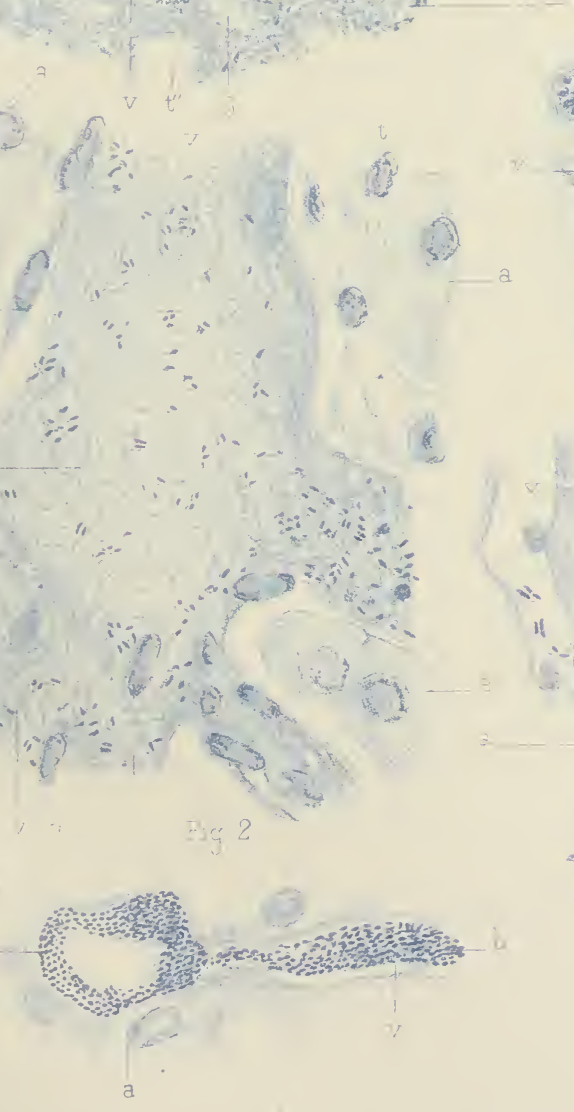

i.

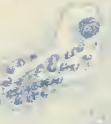

F

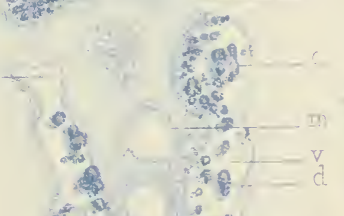

-

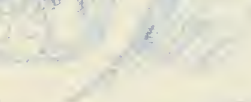



PIXIX

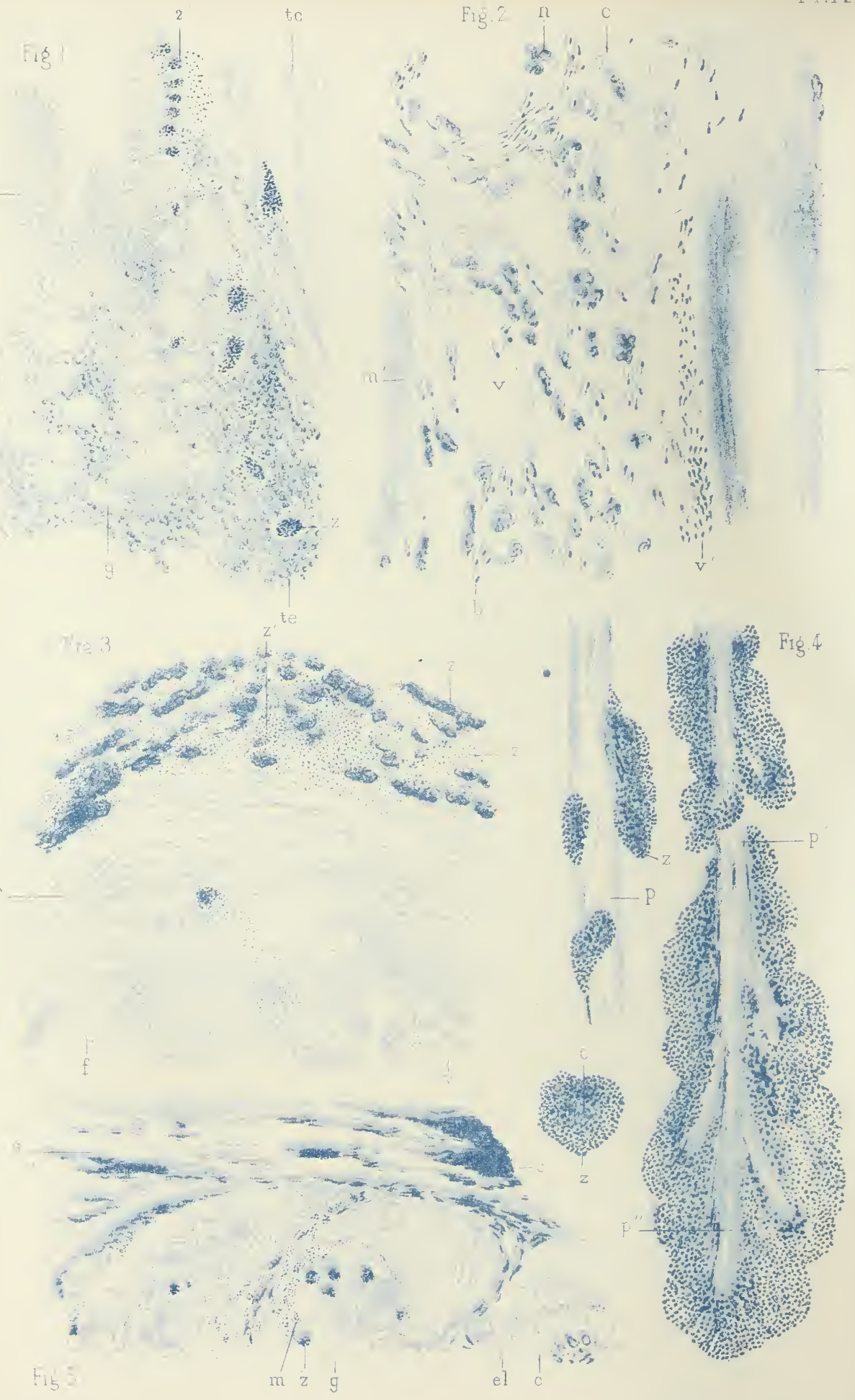

Imp Lemercier \& C C Fark

CHARBON SYMPTOMATIQUE_.CANGRENE_VERRUE SUEUR ROUGE. 


\title{
PLANCHE XIX
}

\author{
charbon symptomatique. - gangrène. - verrues. - sueurs rouges.
}

Fig. 1. - Mortification d'une partie du tissu de la peau dans la fièvrc typhoïde (grossissement : 100 diamètres environ). - $s$, tissu mortifié, $g$, cellules graisseuses. A la limite du tissu mortifié, il existe une série de vacuoles allongées au dessous desquelles il existe des amas de microbes. Entre la partie mortifiée et le tissu vivant, il s'est formé un tissu embryonnaire contenant beaucoup de microbes, surtout dans les vacuoles qui correspondent aux cellules graisseuses $z_{\text {. }}-t c$, tissu conjonctif.

Fig. 2. - OEdème inter-musculaire du charbon symptomatique. - $m$, fibre musculaire dissociée dans sa partie supérieure; $m$, fibre musculaire devenue pâle et homogène; $v$, espaces lymphatiques dilatés dans le tissu inter-musculaire; $c$, noyaux des cellules fixes; $n$, noyaux des cellules migratrices; $v$ ', petit vaisseau rempli de bàtonnets en battant de cloche.

Fig. 3. - Coupe de la partie mortifiée superficielle d'une plaque de Peyer de l'intestin dans la fièvre typhoïde (grossissement : 200 diamètres environ), - z, couche superficielle du tissu mortifié formée par des masses énormes de microbes disséminés ou en zooglœe plus fortement colorée du côté de la profondeur qu'à la surface; $z$, une autre espèce de microbes en zooglœe avec beaucoup de substance gélatineuse intermédiaire; $t r$, travées de tissu fibreux pâle parallèles à la surface; $f$, follicules mortifiés. On peut suivre la pénétration des microbes dans les vaisseaux dilatés $(v)$.

Fig. 4. - Les microbes de la sueur rouge en zooglœes sur les poils et libres dans la sueur. - $z$, zooglœe adhérente au poil; $p$, poil entouré des masses zooglœiques; $p$ ", dissociation du poil sous l'influence des microbes.

FIG. 5. - Verrue. - $s$, substance cornée à la surface de la verrue peu colorée ou fortement colorée par les couleurs d'aniline en $c ; g$, papille; on peut distinguer les cellules cylindriques à la surface du réseau de Malpighi, en $c$. Au lieu des cellules polygonales, on y trouve des cellules remplies d'éléidine. Sur les coupes d'autres papilles, on ne peut plus distinguer ni le tissu conjonctif ni la stratification de l'épithélium. La place de la papille est remplie par une masse homogène colloïde ou hyaline, tandis que les couches épithéliales sont remplacées par des cellules aplaties et souvent infiltrées de grains d'éléidine ou kératinisées. Dans les masses hyalines siègent des bactéries en petits amas deux à deux ou quatre à uıuatre, très serrées ou bien en petits chapelets $(z)$. 


\section{PLANCHE XX}

BaCilles de la tuberculose. - MÉNiNgite et Pleurésie tuberCúleuses.

Fig. 1. - Tuberculose des méninges. - $s$, surface de l'arachnoïde; $a$, coupe d'une pelite veine de la pie-mère contenant un coagulum fibrineux. Dans ce coagulum et dans la paroi vasculaire, il existe un très grand nombre de bacilles. - v, artériole dont la paroi et le caillot contiennent aussi des bacilles; $c$, veinule également remplie; $r$, tissu réticulé de la pie-mère; $b$, limite de la substance corticale; $d$, tissu de la substance grise, $t$, tubercule cérébral dans lequel les granulations siègent surtout autour des capillaires $m$; $s$, lacunes du tissu nerveux autour du tubercule; $n$, vaisseau capillaire normal du cerveau. Grossissement de 100 diamiètres.

Fig. 2. - Section de la pie-mère dans une méningite tuberculeuse. - $b$, arachnoïde ; $e$, tissu fibreux; $a$, paroi d'une artériole contenant des bacilles, $b$, et des grains ronds $d$, qui se colorent par le même procédé que les bâtonnets ; $c$, caillot fibrineux intra-artériel, hyalin à son bord inférieur, renfermant aussi des bacilles et des grains ronds; $m$, fente située dans le tissu de la pie-mère; $e, e$, faisceaux byalins. Grossissement de 500 diamètres; obj. à immersion homogène $n^{\circ} 10$ de Vérick, oc. 2.

Fıg. 3. - Tuberculose primitive aiguë de la plèvre. - $a$, couche de fibrine à la surface de la plèvre; $f$, cellules rondes infiltrées dans le tissu conjonctif de cette membrane; $b$, bacille contenu dans une cellule géante $c$; $d$, nombreux bacilles situés dans la paroi d'un petit vaisseau de la plèvre. Grossissement de 500 diamètres; obj. à immersion homogène n 10 de Vérick, oc. 2.

FIs. 4. - Pleurésie chronique de nature tuberculeuse. - La figure représente la coupe de pseudo-membranes fibreuses $m, m$, appartenant à la plèvre, membranes entre lesquelles il existait du pus caséeux; $b$, fente lymphatique qui s'ouvre en $b$ ' et qui présente là beaucoup de bacilles. La surface des membranes est tapissée de bacilles en $b^{\prime \prime}$. On en trouve aussi des amas dans un vaisseau lymphatique en $n$. $-v$, vaisseaux ; $p$, pigment noir situé à la limite du poumon; $d$, surface de la fausse membrane $m$. Grossissement de 1300 diamètres. 
Fig. 2
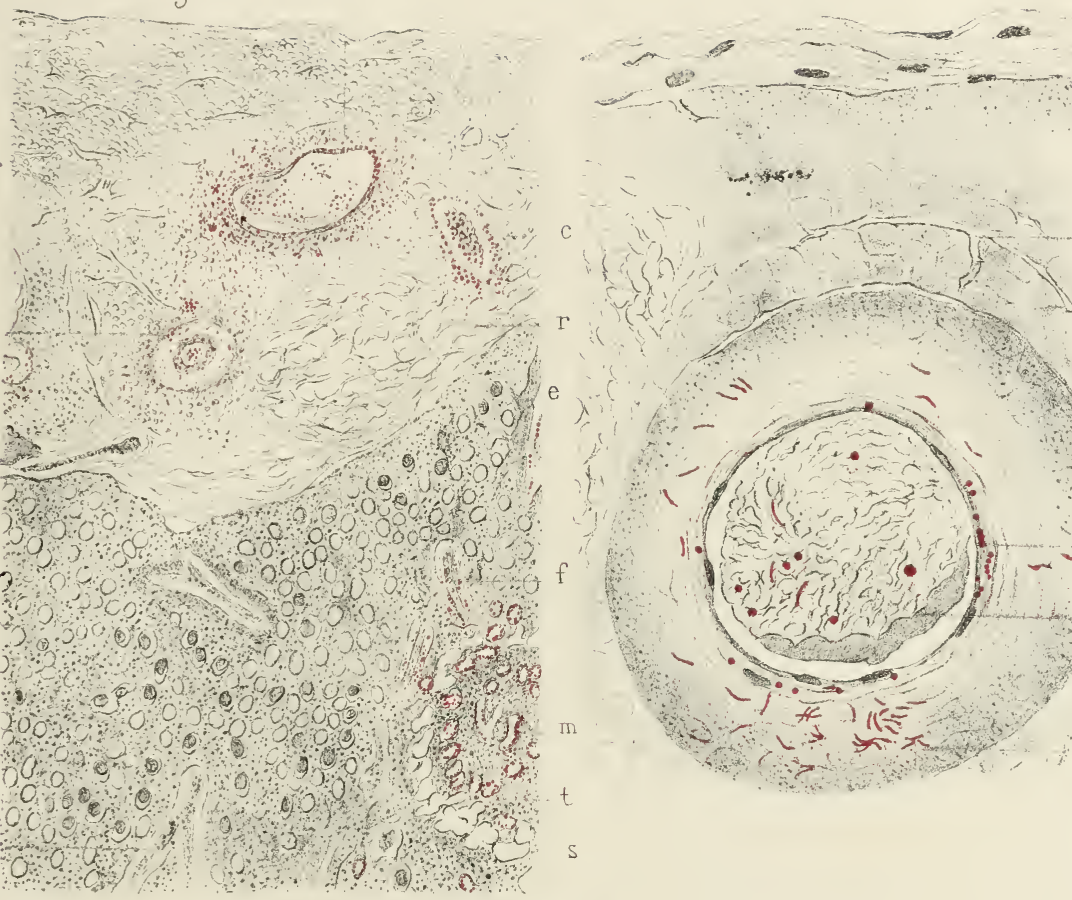

$$
\text { Fig. } 3 .
$$

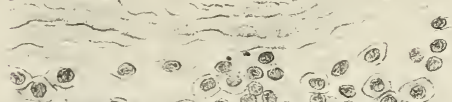

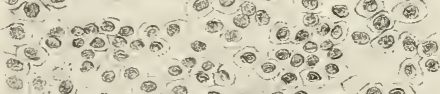
स (ब) 6 (1)

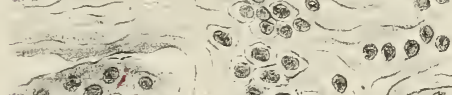

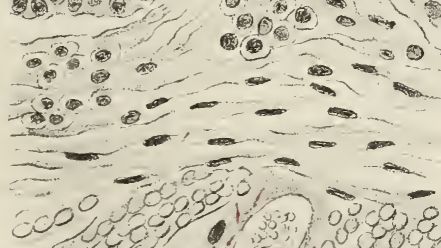

n

d

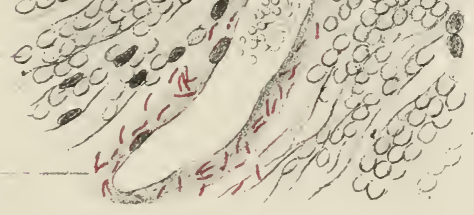

3.
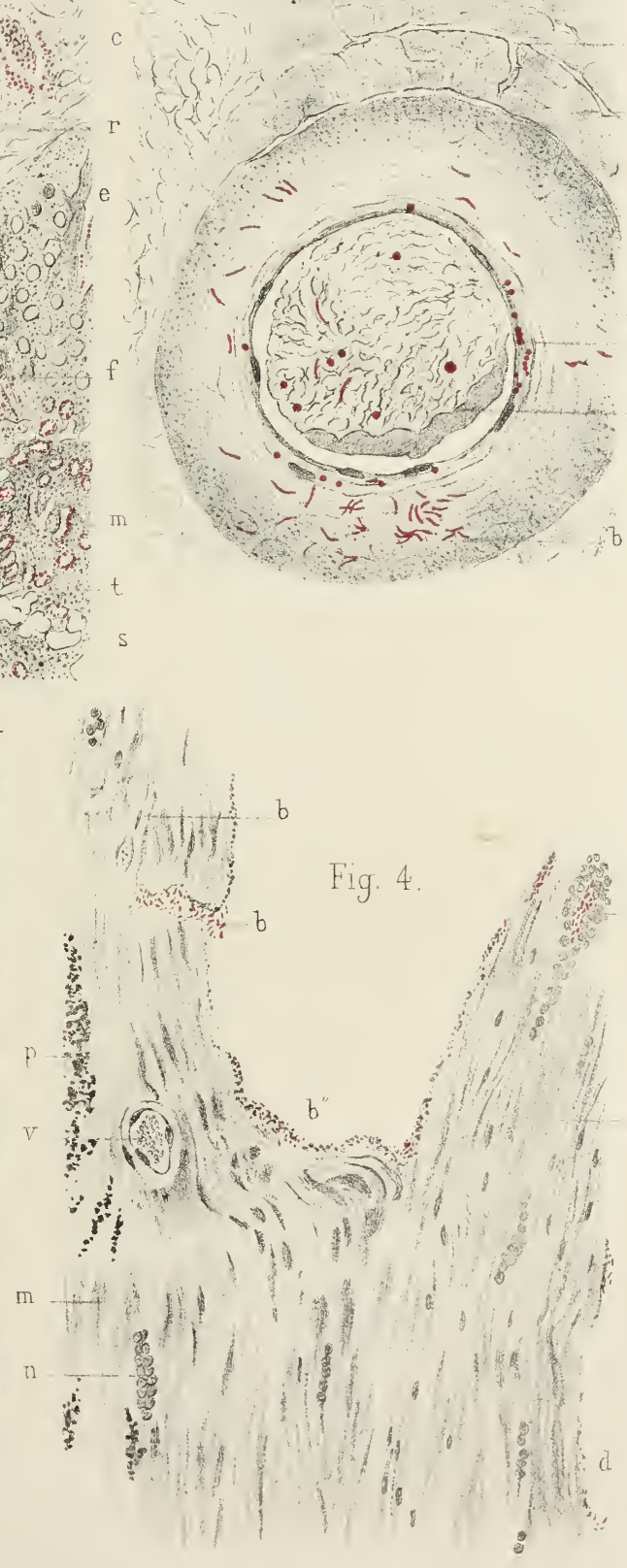

Babies del. 

Fig. 5 .

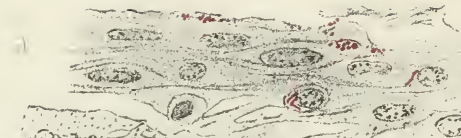

सro 30

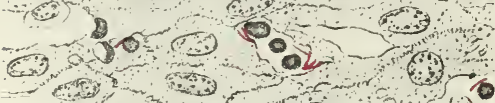

$20 \quad 6 y 00$

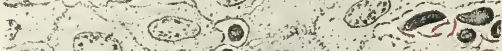
(1) $\rightarrow$ OPAO 2. 30 co

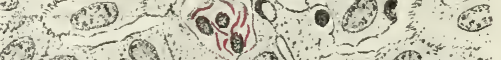

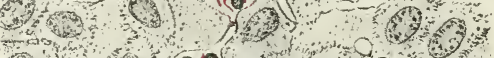

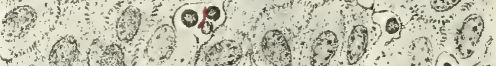

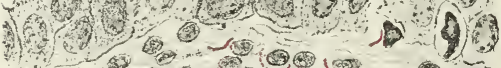
28 (2) - 3 a

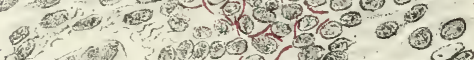
(10) (5) की 36 , ก०1 100000 (2) 0.000

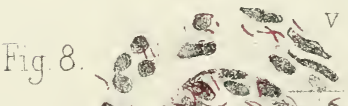

- का ए (2) (2) 2 (1) ".

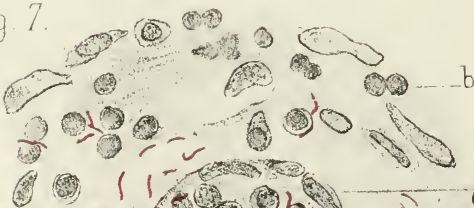

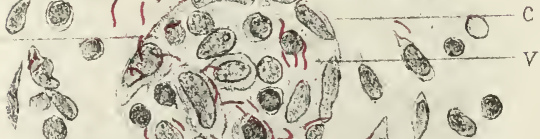
(3) (2)
III

Fig. 9

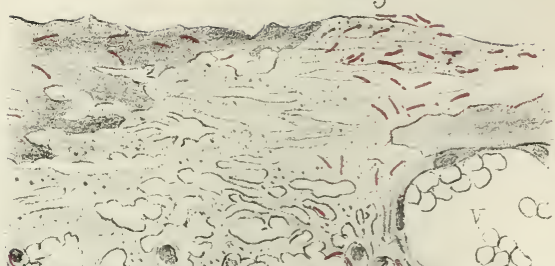

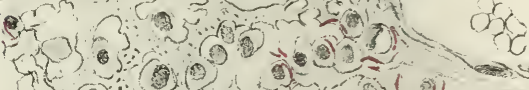

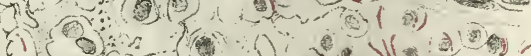

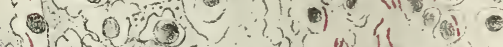
0100 (6) (I) (1)

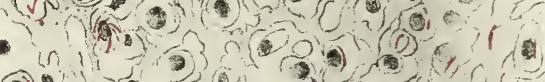

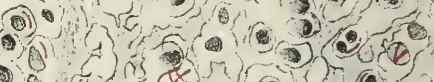

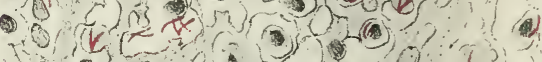
-340(1) \%(c)

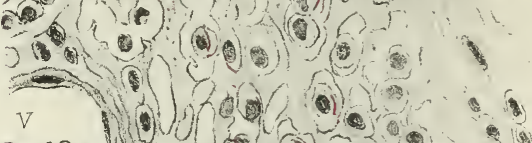

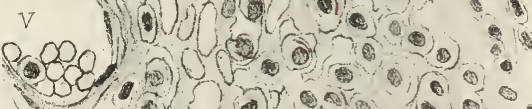

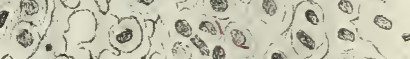
(2) 0101000

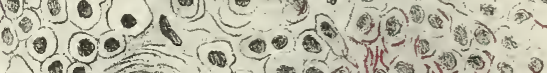

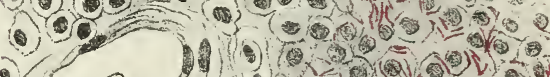

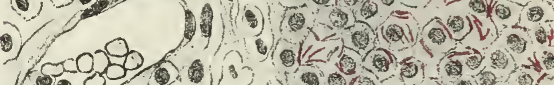

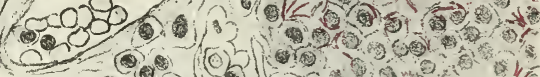
6) 0 (0)

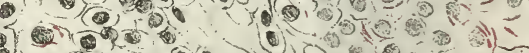

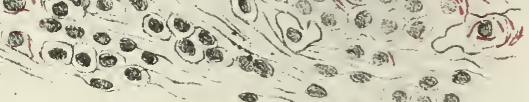
Fig. 6

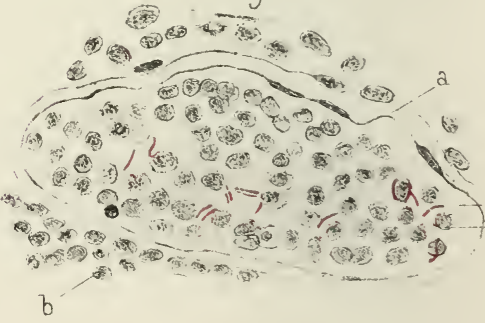

Bacilles de la tuberculose 


\section{PLANCHE XXI}

Bacilles de la tuberGulose. - poumon, foie, rein, Rate.

Fig. ว̆. - Section de la muqueuse pharyngienne envahie par la tuberculose. - $a$, surface de la couche épithéliale de la muqueuse. Les cellules d'épithélium sont séparées par des cellules migratrices $m$ qui pénètrent entre elles dans les voies lymphatiques de l'épithélium. Ces cellules migratrices entraînent avec elles des bacilles, ainsi que cela se voit en $c_{\text {. }}$ $h$, amas tuberculeux formé par des cellules rondes et des bacilles dans la couche la plus superficielle du chorion de la muqueuse; $g$, cellule géante remplie de bacilles; $v$, petit vaisseau qui présente des bacilles dans son endothélium. Grossissement de 500 diamelres; obj. im. homogène de Vérick n 10. oc. 2.

FIg. 6. - Section d'une veinule dans la tuberculose du pharynx. - a, paroi du vaisseau ; $c$, corpuscules blancs du sang contenus dans ce vaisseau avec des bacilles; $b$, tissu périphérique infiltré de leucocytes. Grossissement de 250 diamètres.

Fig. 7. - Vaisseau capillaire agrandi et oblitéré dans la tuberculose du pharynx. La cavité, $v$, du vaisseau est remplie de cellules rondes ou globules blancs du sang, de cellules endothéliales et de bacilles $h$. - c , paroi du vaisseau devenue hyaline; $b$, tissu conjonctif périphérique. Grossissement de 800 diamètres.

FIG. 8. - Cellule géante $g$ toute remplie de bacilles dans un cas de tuberculose de l'amygdale. Le tissu tuberculeux périphérique $a$ en contient également. Grossissement de 400 diamètres.

Fig. 9. - Tuberculose de la muqueuse intestinale. $-s$, surface de la muqueuse ulcérée. En $m$, cette surface présente une dégénérescence hyaline et des bacilles; le vaisseau $v$ montre aussi dans sa paroi, en $p$, une dégénérescence de même nature. Le tissu conjonctif, $t$, est réticulé et offre des lacunes arrondies ou longitudinales qui contiennent des cellules rondes et des bacilles. En $n$, on voit une granulation tuberculeuse. Dans cette granulation, de même que dans tout le tissu conjontif de la muqueuse depuis la surface de l'ulcération, il existe un grand nombre de bacilles disséminés. 


\section{PLANGHE XXII}

Bacilles de la tuberculose. - poumons. - crachats.

Fig. 10. - Tuberculose miliaire du poumon chez l'homme. Au centre se trouve la section transversale d'une veine $v$ dont la lumière est remplie d'un caillot fibrineux contenant des bacilles $a$ en très grande quantité. Une portion $p$ de la paroi vasculaire est normale, tandis que la partie de la paroi qui se trouve en $p$ ' est dissociée, réticulée, infiltrée de petites cellules., La paroi confine là en effet au tissu conjonctif et aux alvéoles pulmonaires qui sont le siège d'une néoformation tuberculeuse. $-b, b, b$, alvéoles pulmonaires remplis de fibrine et de cellules en dégénérescence caséeuse appartenant à ce nodule tuberculeux; $m$, alvéoles normaux. Grossissement de 150 diamètres.

Fig. 11. - Tubercule fibreux du poumon. - $a$, tissu pulmonaire atteint de pneumonie interstitielle et infiltré de charbon; $b$, bacilles en forme de touffes, en quantité assez considérable, situés surtout entre les faisceaux du tissu conjonctif constituant le tubercule fibreux; $m$, petit séquestre situé au milieu d'une perte de substance dont les bords sont couverts de bacilles; $n$, fente située entre le tubercule et le tissu voisin. Grossissement de 500 diamètres.

Fig. 12. - Bacilles des crachats dans un cas de luberculose chronique. $b$, bacilles en bàtonnets formés de petits grains bout à bout; $a$, agglomération de spores et bàtonnets présentant la même disposition que les sarcines de l'estomac; $c$, mucus et cellules des crachats pàlis par le mode de préparation. La préparation a été faite avec un crachat conservé pendant 10 jours dans un tube de verre après l'expectoration. Grossissement de 1,000 diamètres; obj. $n^{\circ} 10$ à immersion homogène de Vérick, oc. 3, tube élevé.

Fıg. 13. - Bacilles des crachats dans un cas de tuberculose aiguë. - $a$, grande cellule conterrant des bacilles; $p$, cellule pigmentée contenant aussi des bacilles; $b$, bacilles libres. Les cellules représentées ici proviennent de l'épithélium du poumon. Grossissement de 1,000 diamètres.

Fig. 14. - Bacilles de l'urine dans la tuberculose des organes génitourinaires. - $e$, cellule de la vessie ne contenant pas de bacilles; $l, l$, cellules rondes contenant des bacilles plus ou moins nombreux; $m$, petite cellule ronde contenant un bacille. Grossissement de 1,000 diamètres. 
Fig. 12

Fig. 11

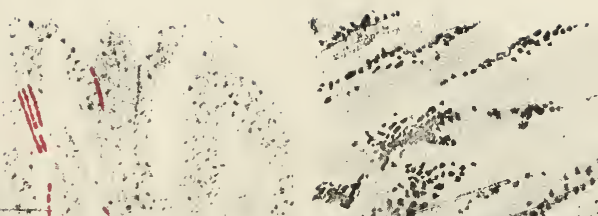

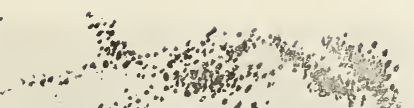

b

$21 \div 1$

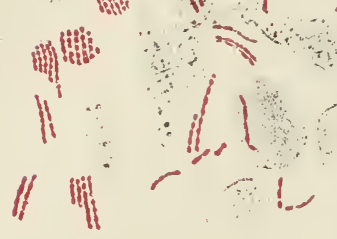

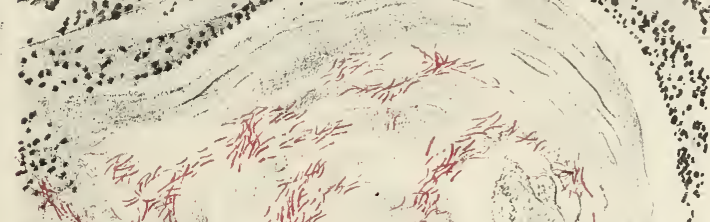

An

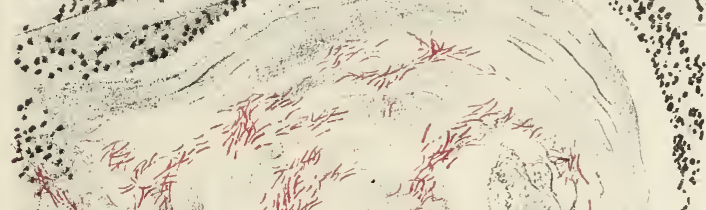
$\because \quad n$ d m

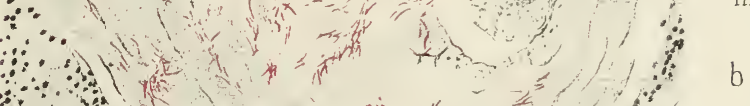

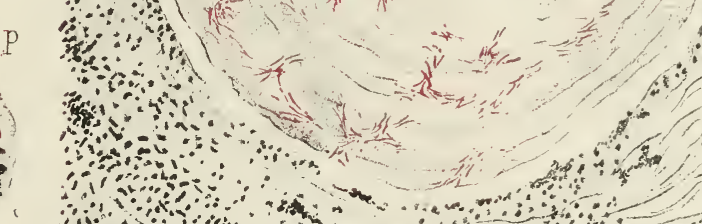

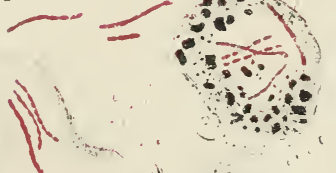

a arda

Fig. 14

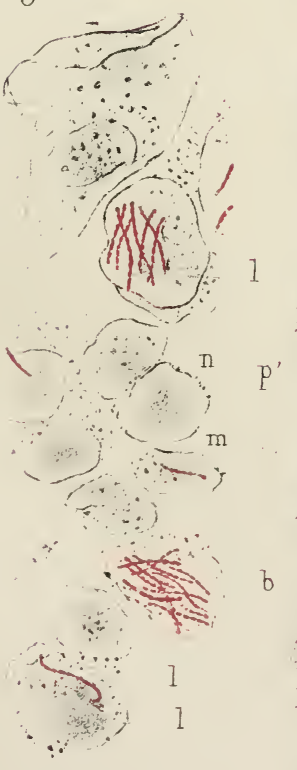

Bazes del

त)

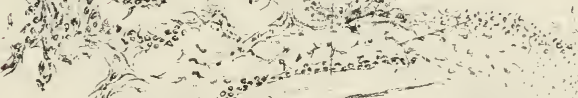

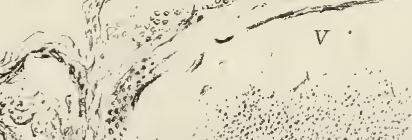
to Ti, 1

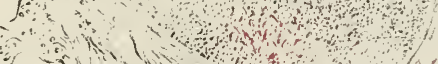
$\therefore$ at

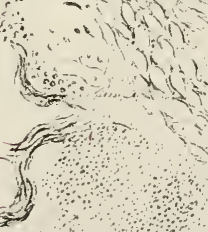

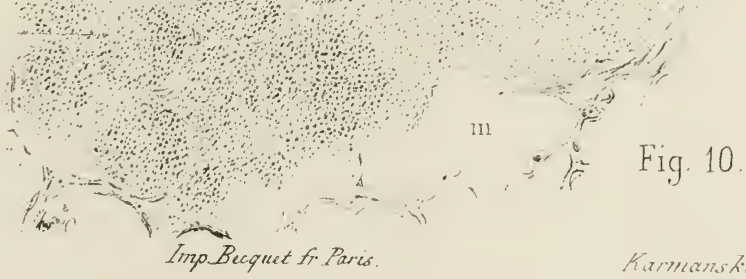

Bacilles de la tuberculose 



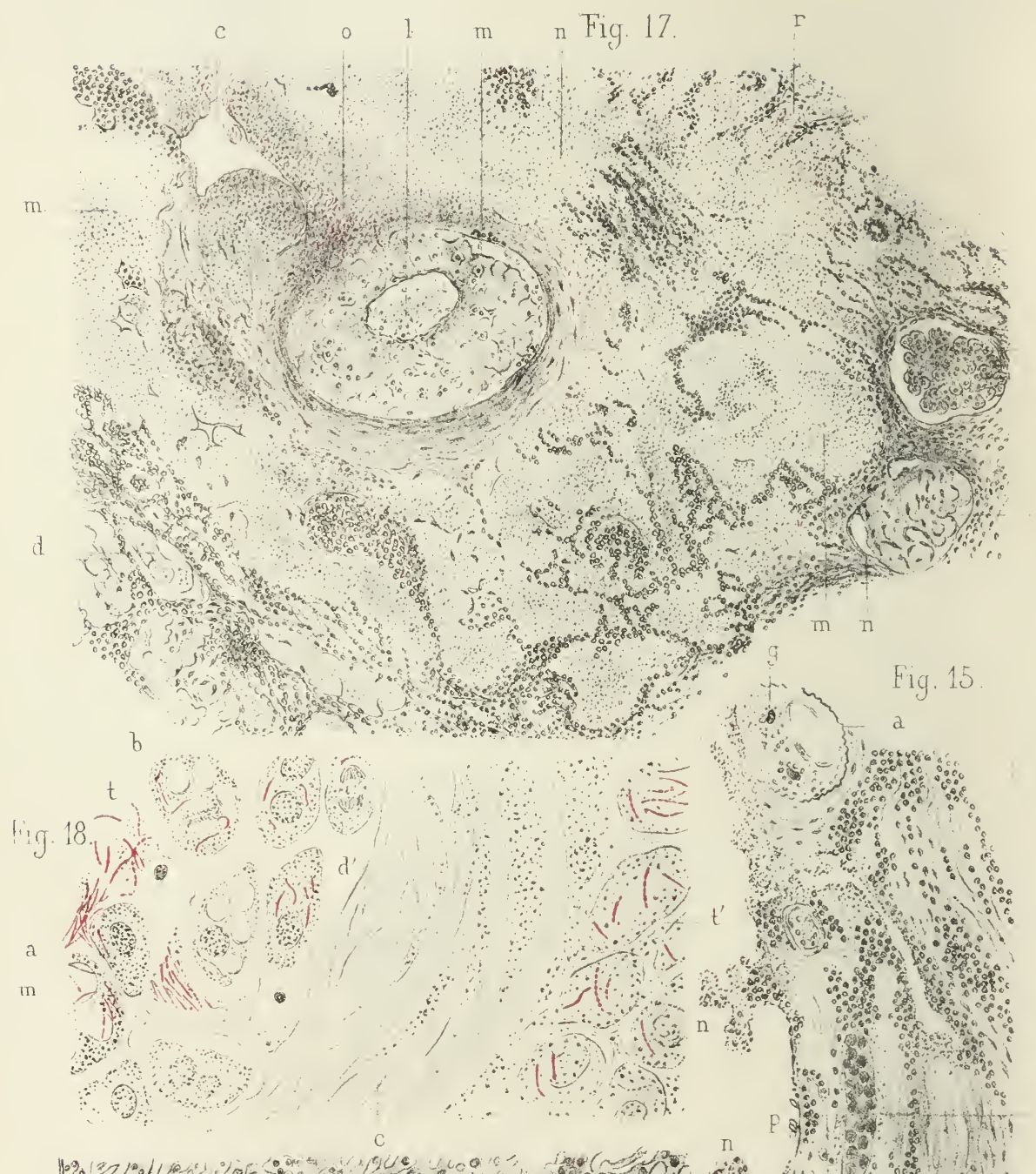

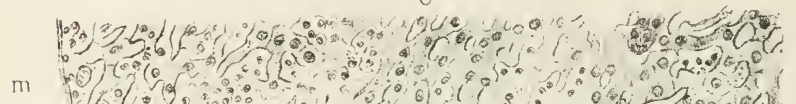
F. oc

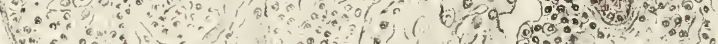
Pon B.

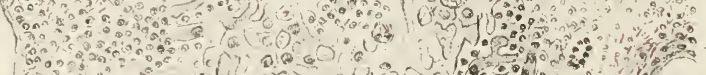
(5) Cho

Fig. 16. vino 00 o Ig. 10. Pirteis del. a b v

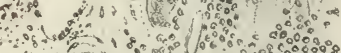

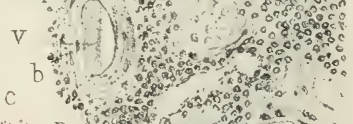
n $n$, the

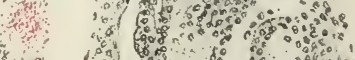

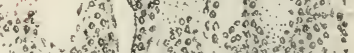
of

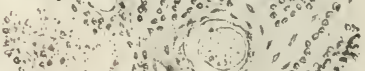
a d o

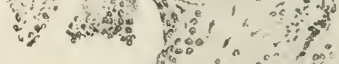
A. Koumarske lith 


\section{PLANCHE XXIII}

Bacilles de la tuberculose. - poumon, foie, rein, rate.

FıG. 15. - Surface interne d'une caverne tuberculeuse du poumon. A la surface de la caverne, on voit en $b$ des bacilles qui siègent aussi sur les parties saillantes $n, n$, qui représentent des fragments de parois alvéolaires libres dans la caverne sous forme de petits bourgeons. Le tissu conjonctif de ces parois alvéolaires montre aussi des bacilles. - $p$, bronche en partie détruite à la surface de la caverne; $c$, cartilage de la bronche; $a$, artériole dans la paroi de laquelle il y a des bacilles et deux cellules géantes $g$; $t$, granulation tuberculeuse. Grossissement de 100 diamètres.

Fig. 16. - Tubercules du foie développés à la suite de l'inoculation chez le cobaye. - $t$, granulation tuberculeuse développée à la surface du foie, composée de petites cellules rondes et parsemée de bacilles; $n$, infiltration tuberculeuse dans l'ilot hépatique; $a$, granulation tuberculeuse siégeant autour d'une branche de la veine porte $v ; b$, canalicule biliaire; $c$, cellule géante. Cette granulation présente aussi beaucoup de bacilles. $m$, travées de cellules hépatiques. Grossissement de 150 diamètres.

Fig. 17. - Tuberculose du rein chez l'homme; masse tuberculeuse développée autour d'un vaisseau. - $l$, lumière d'un vaisseau dont les parois sont fortement épaissies et qui montre de très nombreux bacilles dans la paroi et autour d'elle; sa tunique interne est épaissie et devenue hyaline; $m$, espace libre rempli de bacilles situé entre la tunique interne et la tunique moyenne; 0 , tissu périphérique à l'artériole rempli de bacilles; c, lacune causée par la désintégration du tissu tuberculeux el dont le pourtour contient beaucoup de bacilles; $m, m$, tissu caséeux dans lequel les cellules sont atrophiées; $n$, tissu conjonctif contenant des cellules vivantes à la périphérie du tissu caséeux; $g, g$, glomérules du rein; $d$, tubes uriniféres de la substance des pyramides; $r$, lacunes de la substance corticale remplies de bacilles et qui sont vraisemblablement des tubes contournés. Grossissement de 150 diamètres.

Fig. 18. - Tuberculose de la rate du cobaye consécutive à l'inoculation dans le péritoine. - $t$, tubercule dans lequel il existe de grandes cellules épithélioïdes $b$ à noyaux multiples et remplies, de bacilles ou de grandes cellules à un seul noyau a, également remplies de bacilles. En $d$, on voit une de ces cellules en voie de division. - $c$, tissu conjonctif. En $t$, il existe une autre masse tuberculeuse dont on voit quelques cellules mortifiées contenant des bacilles. Grossissement de 800 diamètres. 


\section{PLANCHE XXIV}

LÈPRE.

Fig. 1. - Coupe de la peau au niveau d'un tubercule cutané de la lèpre. Grossissement de 100 diamètres. $a$, couche cornée de l'épiderme; $b$, couche granuleuse; $c$, corps muqueux; $d$, cellules cylindriques du corps muqueux. Ces diverses couches sont moins épaisses qu'à l'état normal. Audessous d'elles, la surface du chorion muqueux, $f$, ne présente pas de papilles, parce que la coupe passe au niveau de la partie la plus saillante du tubercule; tout le chorion muqueux de $f$ en $e$ est infiltré de grosses cellules; $v$, vaisseau sanguin.

Fig. 2. - Cette figure représente une portion du derme après la teinture au violet de méthylaniline o $\mathbf{B}$. (Grossissement de 300 diamètres; oc. 2 obj. 8 de Vérick.) $v$, lumière d'un vaisseau sanguin; $a$,cellule plate de la membrane interne contenant des bâtonnets; $b$, cellule de la paroi du vaisseau contenant aussi des bàtonnets; $e, f, d$, cellules de nouvelle formation qui infiltrent tout le derme et qui contiennent un nombre plus ou moins considérable de bàtonnets.

Fig. 3. - Dessin des cellules qui infiltrent le derme et qui sont remplies de bactéries examinées à un fort grossissement sur des coupes. (Grossissement de 7 à 800 diamètres. obj. 7 à immersion de Nachet.) B. Cellules arrondies, sphériques, ou ovoïdes, remplies de bàtonnets droits ou un peu arqués; $C$, les bàtonnets vus isolés; $D$, les mèmes grandes cellules; $F$, bâtonnets disposés en faisceaux et non isolés.

Fig. 4. - Un vaisseau du chorion muqueux vu en long sur une coupe. (Grossissement de 200 diamètres.) $a$, cellules du derme; 0 , lumière du vaisseau contenant des globules sanguins; $m$, paroi du vaisseau.

Fig. 5. - Un vaisseau coupé en travers; $m$, les cellules qui infiltrent le derme; $p$, paroi épaissie du vaisseau.

Fig. 6. - Coupe du foie à un grossissement de 230 diamètres. $a, a$, cellules hépatiques ne contenant pas deux bactéries; $c, c$, de cellules hépatiques contenant des bactéries; $b, b$, cellules lymphatiques migratrices contenant des bactéries. En $A$, nous avons représenté à un fort grossissement une cellule lymphatique migratrice du foie contenant des grains et des bâtonnets. 


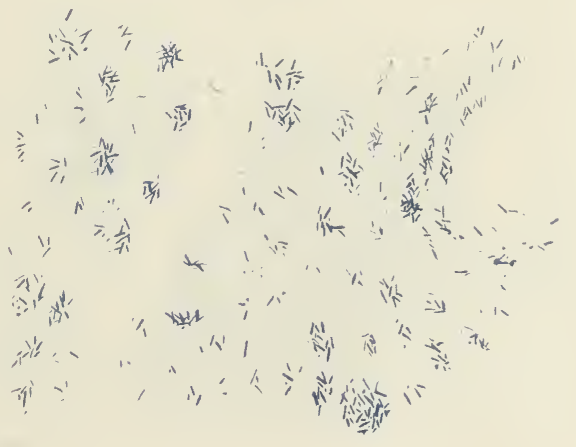

a

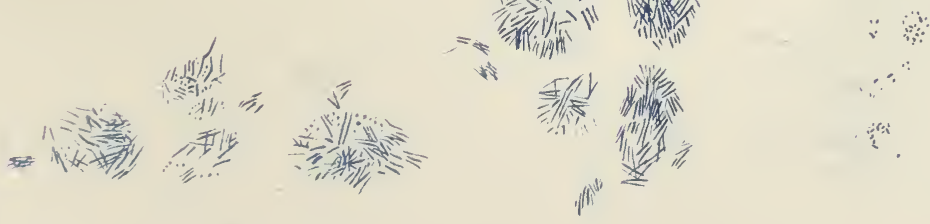





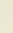


Fig 4.

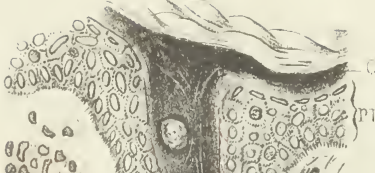

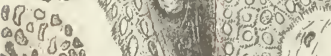

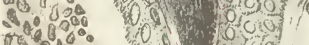

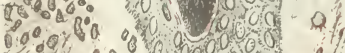

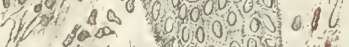

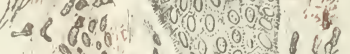
$800 \%$. 1.

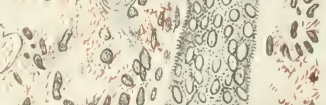

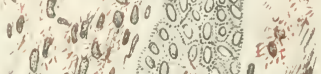

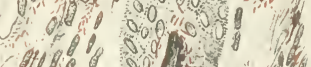

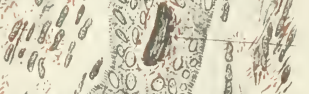

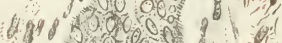
(o.

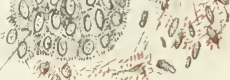
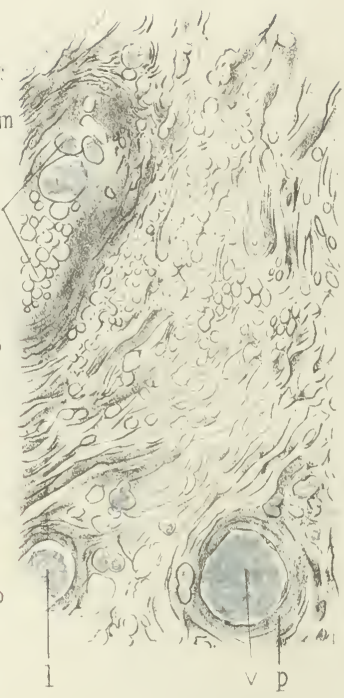

Hig 3
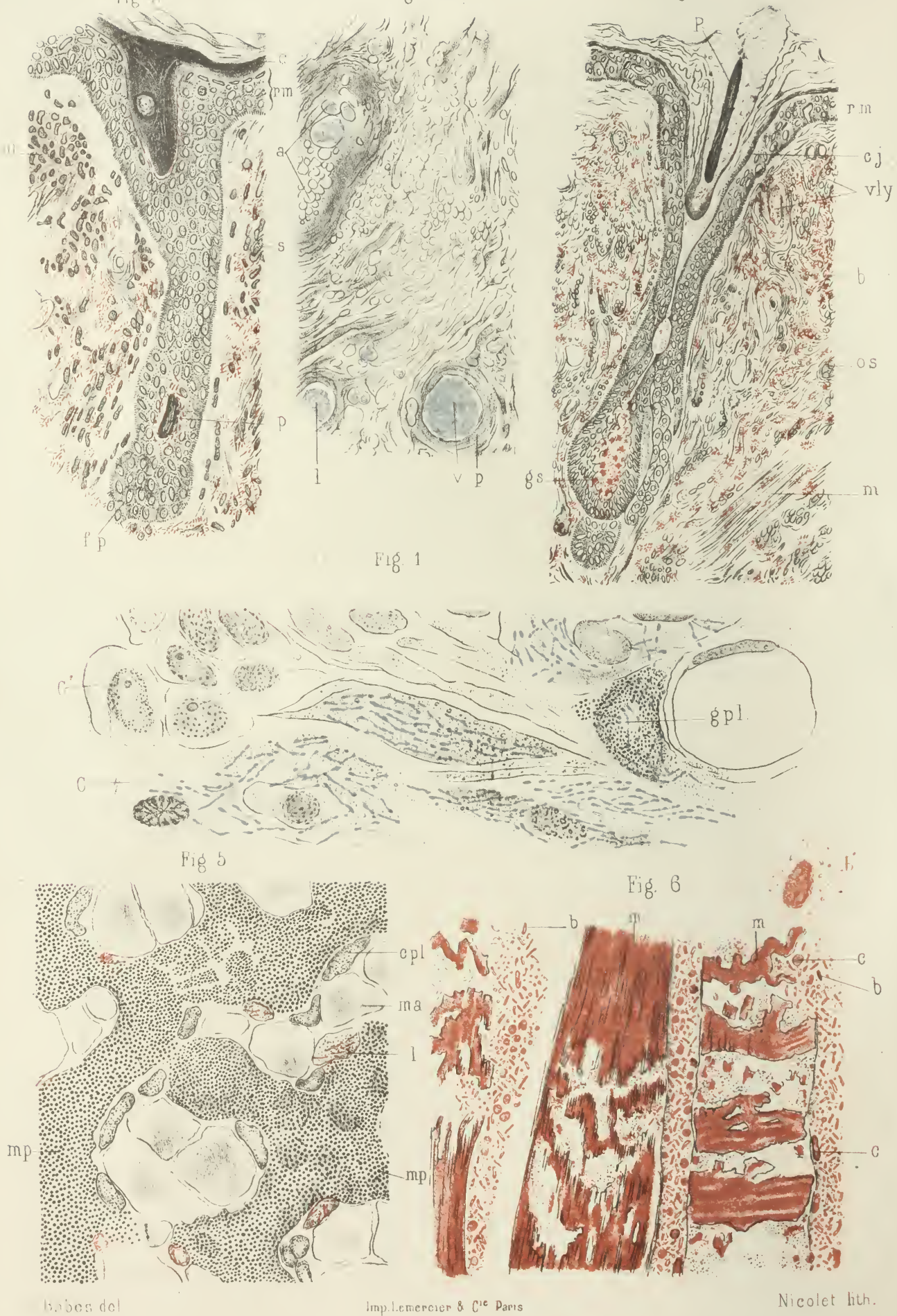

LEPRE._CHOLERA DES POULES 


\section{PLANCHE XXV}

LÈPRE. - CHOLÉRA DES POULES.

Fig. 1. - Lèpre tubéreuse de la peau enlevée sur le vivant. Les bacilles, colorés en bleu, siègent dans les grandes cellules lépreuses. Ces cellules peuvent être : des cellules endothéliales, de grandes cellules fixes, parfois en voie de division indirecte, des cellules fixes fusiformes ou des cellules plasmatiques granuleuses $g p l$. Grossissement de 1,000 diamètres environ.

Fig. 2. - Tubercule lépreux de la peau d'un enfant, enlevé sur le vivant, montrant des bacilles dans la gaine interne d'un poil. c, Stratum corneum. $r m$, réseau de Malpighi. $f \beta$, follicule du poil. $p$. racine du poil entouré par les bacilles de la lèpre. $n l$, nodule lépreux superficiel. Grossissement de 200 diamètres.

Fig. 3. - Préparation de la même pièce que la figure 2, montrant des bacilles dans une glande sébacée. $p$, poil; $c j$, couche granuleuse de la gaine interne. $\mathrm{rm}$, réseau de Malpighi. gs, glande sébacée. vlg, voies lymphatiques superficielles dilatées avec des cellules endothéliales tuméfiées renfermant des bacilles $b$. os, vaisseaux oblitérés ou à paroi épaissie. $m$, muscle lisse du derme. Grossissement de 150 diamètres.

Fig. 4. - Ganglion lymphatique lépreux sclérosé. v, vaisseau oblitéré par une masse hyaline et par des bacilles. La paroi du vaisseau est sclérosé et montre un revêtement endothélial. $a$, amas scléreux avec de petites vacuoles renfermant des bacilles.

FIg. 5̌. - Foie d'un lépreux, mort de pyémie. $m, a$, masses amyloïdes correspondant aux cellules hépatiques. $c p l$, cellules plasmatiques, limitant les vaisseaux intralobulaires; plusieurs d'entre elles renferment des bacilles de la lèpre, $l . m p$, microbes de la pyémie oblitérant et dilatant les vaisseaux intralobulaires. Grossissement de 600 diamètres.

Fig. 6. - Section en long du muscle enflammé et infiltré par les microorganismes du choléra des poules (coloré par le séjour de 24 heures dans la safranine). $m, m$ ' faisceaux musculaires primitifs et en partie divisés en disques); c, noyaux des cellules lymphatiques; $c$, noyaux des cellules fixes. $b$, bâtonnets. Grossissement de 800 diamètres.

$b^{\prime}$ bàtonnets de la même pièce que la figure 6 figurés à un plus fort grossissement. 


\section{PLANCHE XXVI}

DIVEHSES CULTURES DE BaCtÉRIES SUR DES MILIEUX GÉlatiNiStS.

Fig. 1. - Culture des bacilles de la tuberculose sur le sérum du bœuf un mois après l'ensemencement. Le liquide qui se trouvait à la partie inférieure du tube s'est évaporé. On voit au milieu de la culture blanchâtre un petit fragment du tissu tuberculeux ensemencé.

Fig. 2. - Culture du bacille du charbon dans la gélatine à 6 p. 100, 25 heures après l'inoculation. La liquéfaction de la gélatine commence à la surface, en même temps qu'il se développe, le long de la piqûre, de fins rayons parallèles à la surface de la gelatine. (Voir aussi la figure $\mathbf{2 3}$ de la planche XXVII.)

Fig. 3. - Culture de couleur jaune du pus sur de l'agar-agar, cinq jours après linoculation en strie.

Fig. 4. - Culture des cocci de la pneumonie sur la gélatine trois jours après une inoculation superficielle.

FIG. 5. - Culture du bacille en virgule de Koch sur la gélatine, 24 heures après une inoculation par piqûre. Comme ce dessin n'est pas bien venu, on verra aussi la figure 2a de la planche XXVII.

(Les figures qui représentent les tubes à gélatine ne sont pas bien réussies.)

Fig. 6. - Plaque de culture montrant différentes espèces de cultures; $a$ et $b$ colonies de bactéries de l'air développés à la surface de la gélatine. $c$, forme de la culture du microbe de l'érysipèle sur l'agar-agar. $d$, forme du microbe jaune du pus sur l'agar-agar, huit jours après l'inoculation par une strie. $e$, colonie en partie blanche, en partie jaune des bactéries pathogènes d'un phlegmon. $f$, forme de la culture du charbon sur une plaque d'agar-agar. $g$, commencement du développement sur la gélatine des colonies du choléra mêlées avec des colonies plus grandes qui liquéfient rapidement la gélatine. $h$, colonies provenant de l'ozène, offrent une odeur caracléristique et liquéfiant, après 24 heures, la gélatine d'un tube, ou d'une plaque 12 heures après l'ensemencement. $i$, diverses colonies développées dans la gélatine mêlée avec une goutte d'eau du conduit de l'eau du laboratoire.

Fig. 8. - Une culture des bacilles de la tuberculose dans un cristallisoir (d'après Koch).

Fig. 9. - Colonie de la tuberculose avec un faible grossissement.

Fig. 10. - Une partie de la même culture dans laquelle les bacilles sont disposés en arabesques, vue avec un grossissement de 500 diamètres environ. 

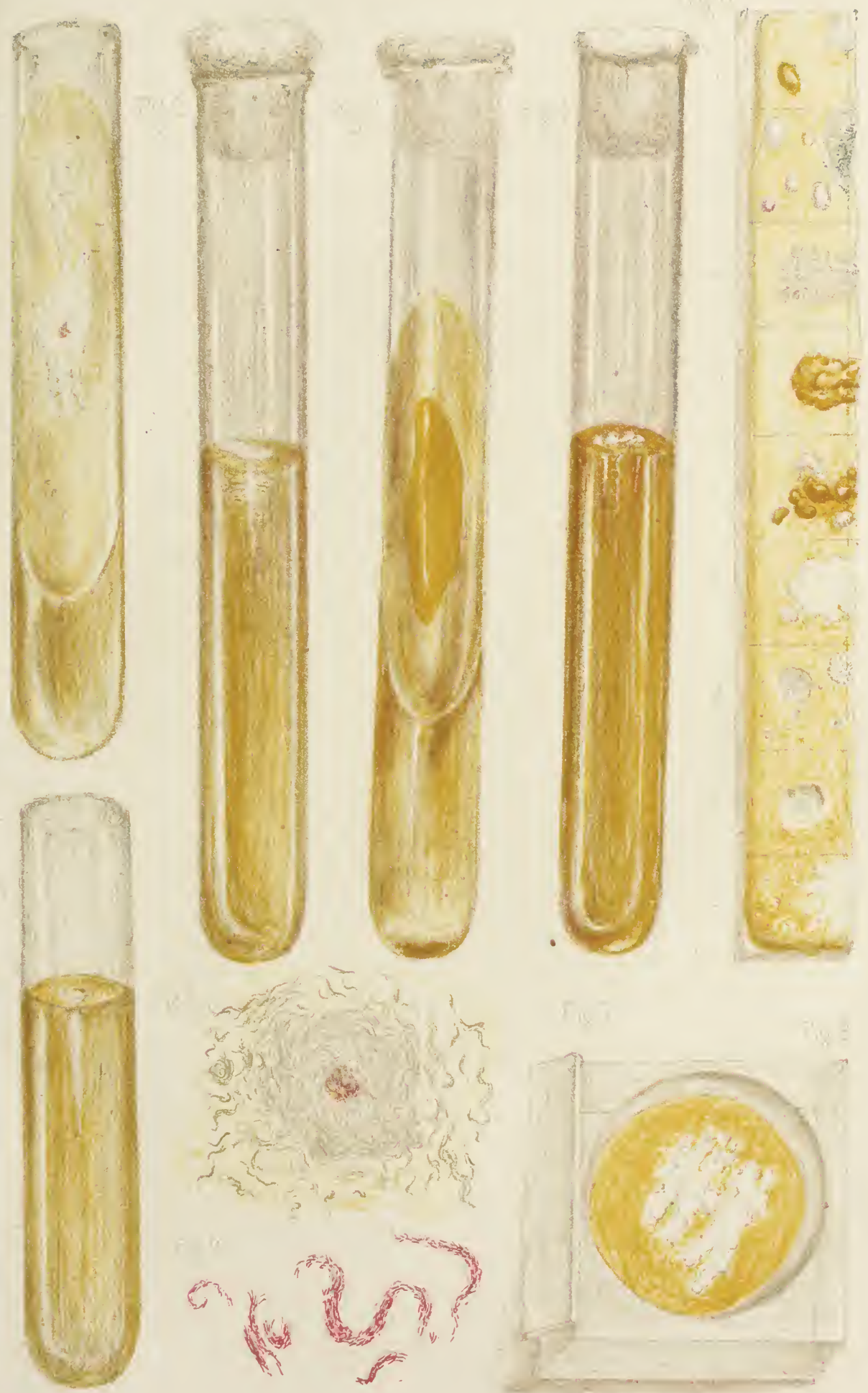

(d)
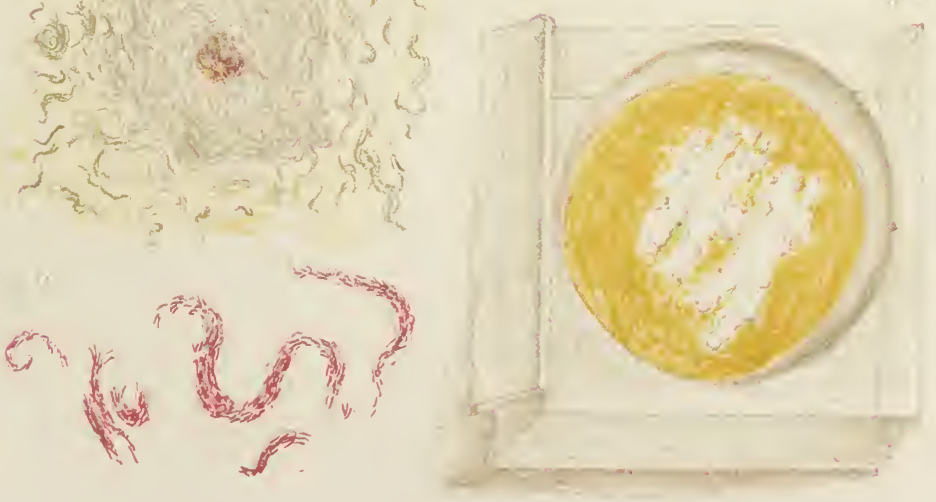




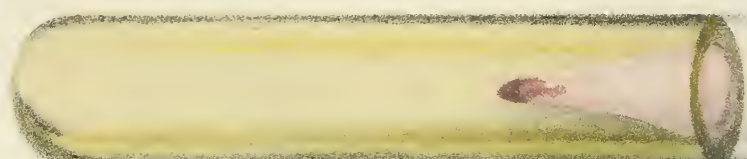

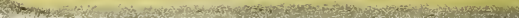
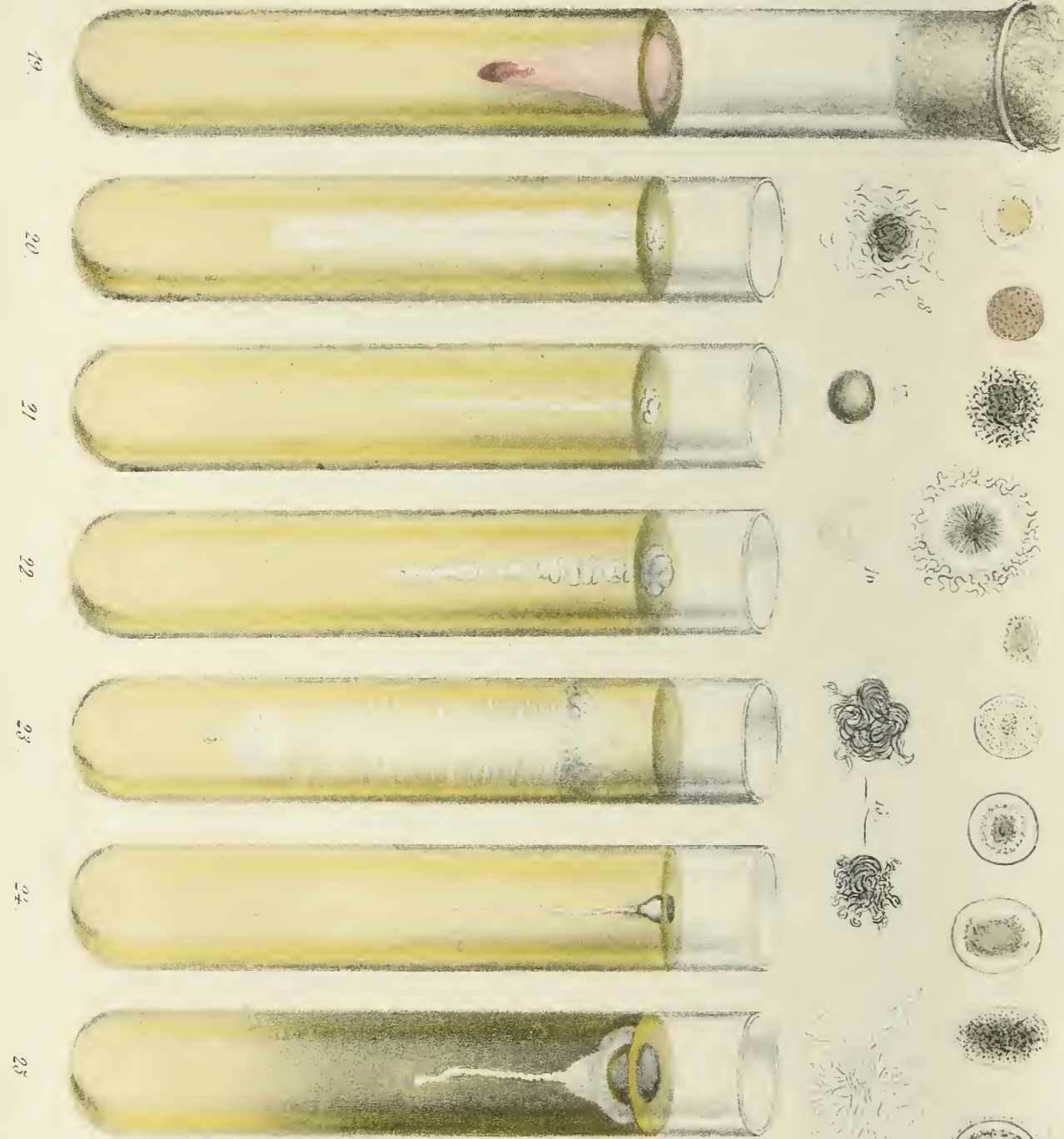


\section{PLANCIHE XXVII.}

Fıg. 1-18. - Colonies de diverses espèces des bactéries développées dans la gélatine neutre à 10 p. 100 étalée sur des plaques de verre à la tempéralure de $18^{\circ}$, et examinées avec un grossissement de 50 diamètres euviron.

Fig. 1. - Culture jaune proveriant de l'eau et liquéfiant la gélatine; elle se développe dans les 24 heures, et elle est formée de petits bacilles un peu courbés.

Fig. 2. - Culture du bacille courbé de Finkler trouvé dans le choléra nostras, développé dans les 24 heures.

Fig. 3. - Cuiture d'un bacille courbé trouvé par Flugge dans le fromage putréfié, développé dans le même laps de temps.

FIg. 4. - Culture du bacille en virgule de Koch développée en 2i heures.

Fig. 5. - Culture d'un bacille liquéfiant la gélatine, developpée en 48 heures.

Fig. 6 et 7. - Culture du bacille en virgule du choléra développée en 48 heures.

Fig. 8-11. - Colonies du bacille en virgule du choléra après trois jours.

Fig. 12. - Une colonie brune compacte de bactéries provenant de l'air.

FIG. 13. - Bacille formant des racines, provenant de l'air et développé en 48 heures.

Fig. 14. - Colonie du bacille de la septicémie de la souris, développée en 3 jours.

Fıg. 10̈. - Colonies du bacille du charbon après $2 \dot{t}$ heures.

Fig. 16. - Colonie du bacille du choléra des poules.

Fig. 17. - Colonie des microbes de la pneumonie développée en trois jours.

FIg. 18. - Colonie du bacille de la tuberculose développée sur le sérum du bœuf au bout de quinze jours.

Fig. 19-27. - Cultures par piqûre dans la gélatine peptonisée neutre à 10 pour 100 .

Fig. 19. - Culture du micrococcus prodigiosus développée 48 heures après l'ensemencement.

Fig. 20. - Culture de la septicémie des souris après 3 jours.

Fig. 21. - Culture du choléra des poules après 3 jours.

Fig. 22. - Micrococcus tetragenus après 8 jours.

Fig. 23. - Charbon développé au bout de 5 jours dans la gélatine à 8 p. 100 ; la partie superficielle de la gélatine est liquefiée et claire; au-dessous de cette première zone elle est liquéfiée et troublée comme par des filament d'ouate; dans sa partie médiane elle présente de fins rayons blancs.

Fig. 24. - Choléra au bout de 48 heures : on voit, à la surface de la gélatine, une dépression sous la forme d'une petite bulle d'air. La culture s'enfonce dans la gélatine en présentant la forme d'un filament blanc.

FIg. 22o. - Choléra après 3 jours : la culture montre une zone liquéfiée, une bulle et elle se continue avec un filament blanc.

Fig. 26. - Culture du bacille de Finkler prétendu analogue à celui de Kocb, après 24 heures. La gélatine est liquéfiée sous la forme d'un sac tout le long de la piqûre.

Fıg. 27. - Pneumonie après 3 jours. 







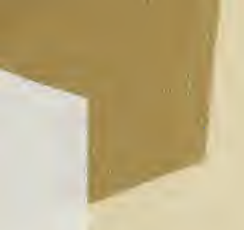

I. 


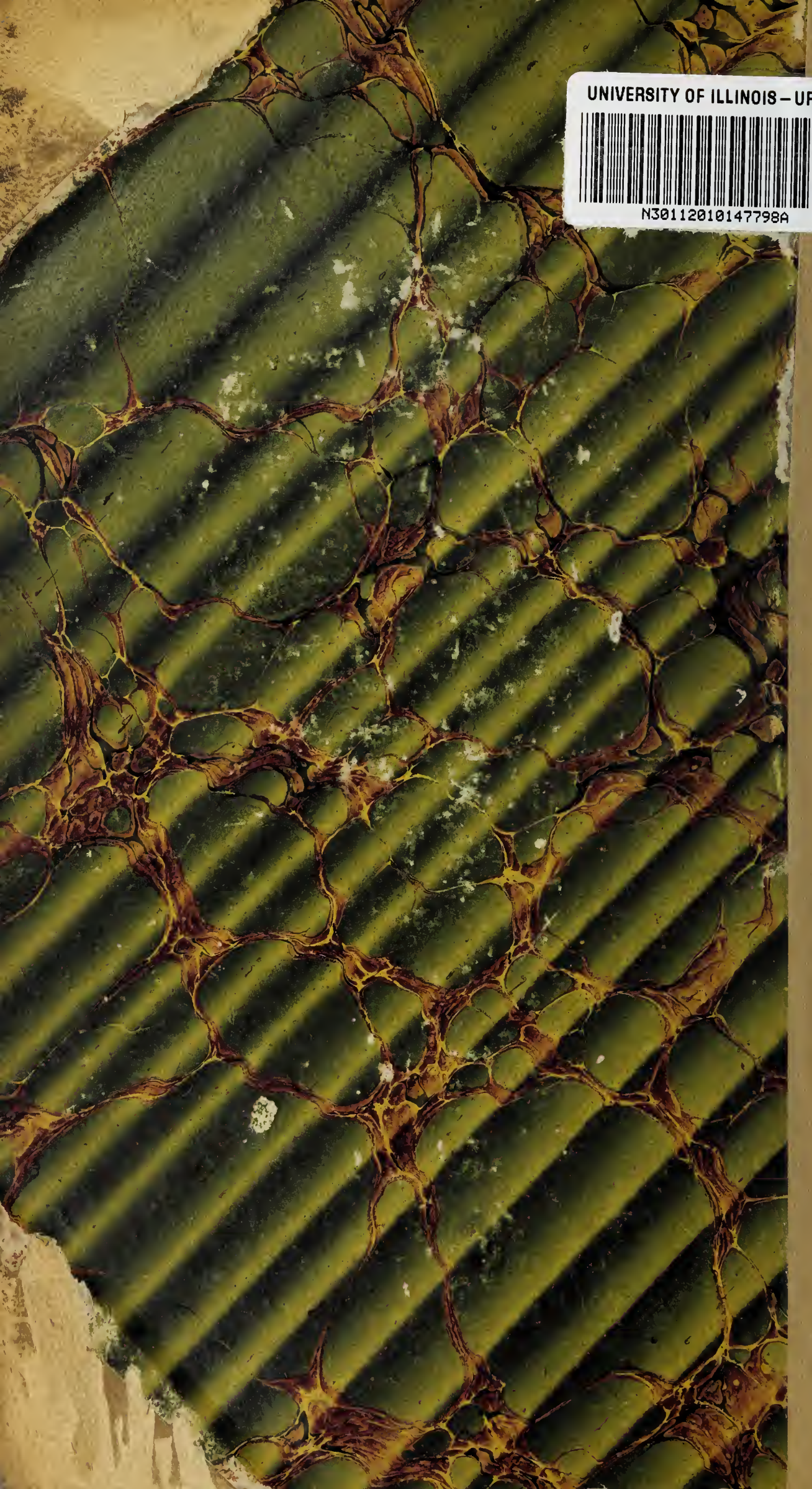

